\title{
Use of a zeolite slurry to increase the charge retention of a low-cost \\ aqueous supercapacitor
}

\author{
Written by Sam Devese \\ Supervised by Thomas Nann
}

A thesis submitted to the Victoria University of Wellington in fulfilment of the requirements for the degree of Master of Science

TE WHARE WĀNANGA O TE ÜPOKO O TE IKA A MĀUI
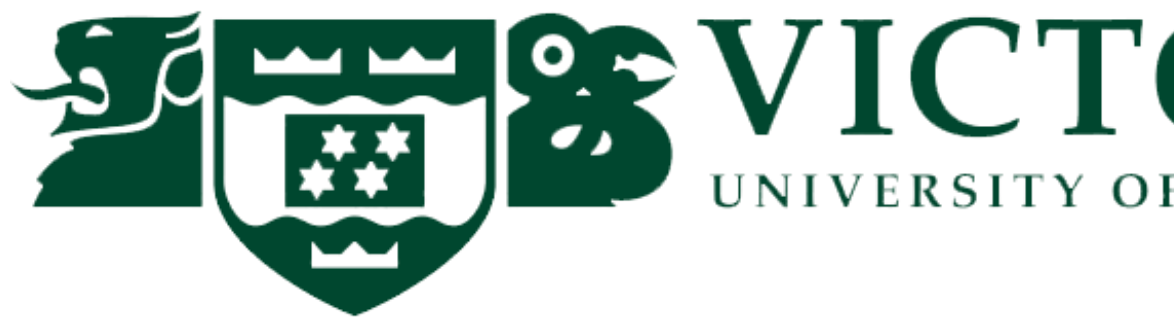

UNIVERSITY OF WELLINGTON 


\begin{abstract}
To increase the viability of renewable energy technology, improvements must be made to existing energy storage devices. One such device is the supercapacitor, which is able to store energy like a battery, but with faster charge-discharge times and increased cyclability. The two main factors limiting the widespread use of supercapacitor technology are the high component cost and high rate of self-discharge. In this project, both of these aspects were addressed, and a supercapacitor was successfully constructed using a carbon black slurry containing zeolitic structures with a pore size of $4 \AA$ to accommodate the electrolyte ions of potassium and chloride.

Low-cost materials and production methods were used to create a supercapacitor with a measured capacitance of $17.25 \mathrm{~F} \mathrm{~g}^{-1}$ and a coulombic efficiency of $100 \%$ determined by galvanostatic charge-discharge curve measurements.
\end{abstract}




\section{Acknowledgements}

There are many people who were fundamental in different aspects of this project and provided valuable help and assistance along the way.

Firstly, to Professor Thomas Nann, my excellent supervisor who was a huge believer in me and a wealth of knowledge in absolutely every area I had a problem, as well as those that I did not. Thank you very much, I deeply value the time I have spent with you and wish you all the best in your future.

To Dr Renee Goreham, who also provided support throughout the year and took the time to proof-read my work, offering much needed formatting and structural help.

To David Flynn, for his help and time in setting up the microscopes for SEM and EDS imaging.

To Chris Lepper, for assisting with BET measurements on the rarely-used gas adsorption machine.

To the entire Nann research group for providing an incredibly comfortable and driving environment in which to achieve my work. It has been wonderful being in your company over the past few years. Especially to:

Fraser Hughson, for answering my constant electrochemical questions and the use of his equipment and materials in the lab,

And Shalini Divya, for her background knowledge of supercapacitors.

To my family for always being there, making me smile.

And lastly to my girlfriend, Madison Charles, who has been a massive support throughout the year, reading through my work and listening to my excited outbursts about battery technology.

Thank you all so much for your individual contributions to this work, I am very grateful. 


\begin{tabular}{|c|c|}
\hline Anode & Positive electrode \\
\hline BET & Brunauer-Emmett-Teller \\
\hline Cathode & Negative electrode \\
\hline CDC & Charge-discharge curve \\
\hline CE & Counter electrode \\
\hline CV & Cyclic voltammogram \\
\hline DMF & $\mathrm{N}, \mathrm{N}$-dimethylformamide \\
\hline EDLC & Electrochemical double-layer capacitor \\
\hline EDS & Energy-dispersive X-ray spectroscopy \\
\hline EPD & Electrophoretic deposition \\
\hline IM & Imidazolium \\
\hline IPA & Isopropyl alcohol \\
\hline Li-ion & Lithium ion \\
\hline NMP & N-methyl-2-pyrrolidone \\
\hline OCV & Open cell voltage \\
\hline PAN & Polyacrylonitrile \\
\hline PANI & Polyaniline \\
\hline PEEK & Polyether ether ketone \\
\hline PPO & Poly(p-phenylene oxide) \\
\hline PPy & Polypyyrole \\
\hline PVDF & Polyvinylidene fluoride \\
\hline RE & Reference electrode \\
\hline SEI & Surface-electrolyte interface \\
\hline SEM & Scanning electron microscopy \\
\hline SSA & Specific surface area \\
\hline WE & Working electrode \\
\hline Z-CNF & Zeolite-embedded carbon nanofibres \\
\hline
\end{tabular}




\section{List of figures}

Figure 1: Mismatch between energy supply and energy demand Page 10

$\begin{array}{lll}\text { Figure 2: } & \text { Ragone plot } & \text { Page } 11\end{array}$

$\begin{array}{lll}\text { Figure 3: } \quad \text { Capacitor schematic } & \text { Page } 14\end{array}$

Figure 4: $\quad$ Electrochemical double-layer capacitor schematic Page 16

$\begin{array}{ll}\text { Figure 5: Electrospinning apparatus schematic Page } 20 & 0\end{array}$

Figure 6: $\quad$ lonic liquid example structures $\quad$ Page 22

$\begin{array}{lll}\text { Figure 7: } \quad \text { Novel supercapacitor design schematic } & \text { Page } 27\end{array}$

Figure 8: $\quad$ Zeolite example structures $\quad$ Page 29

Figure 9: Cyclic voltammogram example plot Page 30

Figure 10: Two- and three-electrode cell schematic Page 31

$\begin{array}{ll}\text { Figure 11: Gas adsorption machine Page } 35 & \end{array}$

Figure 12: Carbon nanofibre heat treatment process Page 36

Figure 13: Supercapacitor PEEK cell body Page 38

$\begin{array}{ll}\text { Figure 14: } & \text { Electrode fabrication process }\end{array}$

Figure 15: Pristine carbon nanofibre SEM Page 39

Figure 16: Zeolite attachment SEM Page 40

Figure 17: Zeolite-embedded carbon nanofibre EDS Page 41

Figure 18: $\quad$ Electrophoretic deposition EDS Page 41

Figure 19: $\quad$ Slurry EDS Page 42

Figure 20: $\quad$ Slurry weight loading SEM Page 43

Figure 21: Slurry weight loading cyclic voltammogram Page 44

Figure 22: $\quad 70$ wt\% slurry electrode charge-discharge curve Page 46

$\begin{array}{lll}\text { Figure 23: } \quad 70 \mathrm{wt} \% \text { slurry electrode coulombic efficiency } & \text { Page } 47\end{array}$

Figure 24: $\quad 70$ wt\% slurry electrode charge discharge at varying current rates Page 47

Figure 25: $\quad 70 \mathrm{wt} \%$ slurry electrode compared to uncoated electrode Page 48

Figure 26: Uncoated electrode charge-discharge curve Page 49

Figure 27: $\quad 70$ wt\% slurry electrode compared to uncoated electrode 
charge retention

Page 50

Figure 28: $\quad$ Logarithmic $70 \mathrm{wt} \%$ slurry electrode compared to uncoated electrode charge retention

Page 51

Figure 29: Logarithmic $70 \mathrm{wt} \%$ slurry electrode charge retention charged up to $1.8 \mathrm{~V}$

Page 53

List of tables

Table 1: $\quad$ Ionic conductivity

Page 24

Table 2: $\quad$ Properties of electrolytes

Page 25

Table 3: $\quad$ Measured charge retention enhancement

Page 52 


\section{Table of Contents}

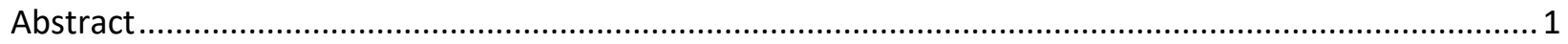

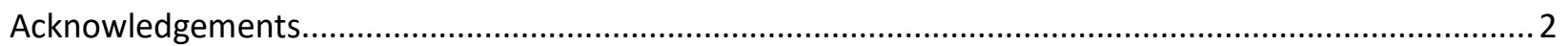

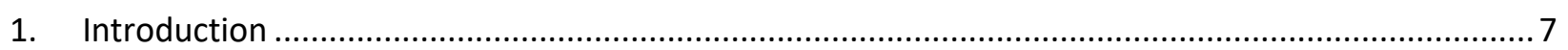

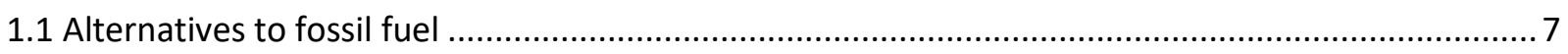

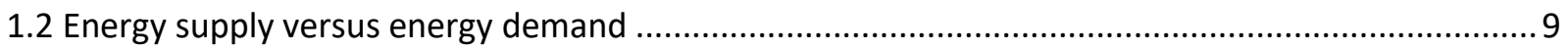

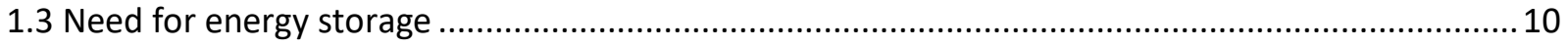

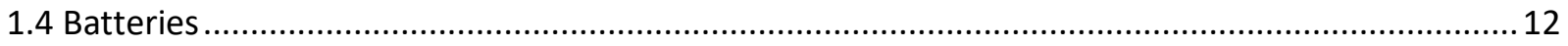

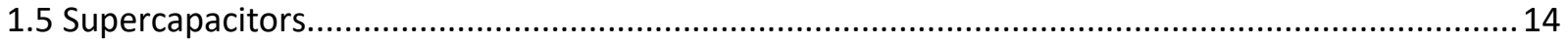

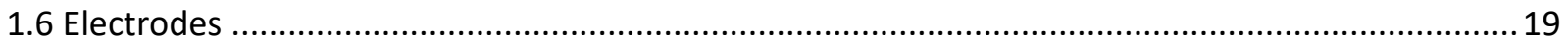

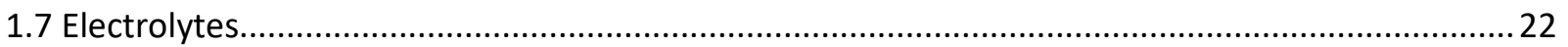

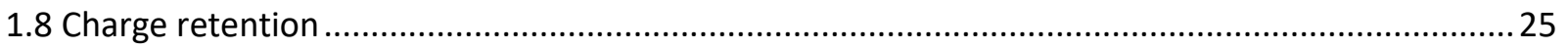

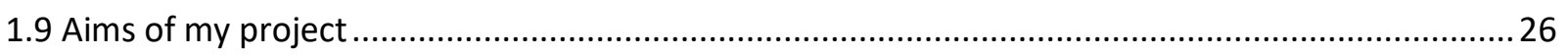

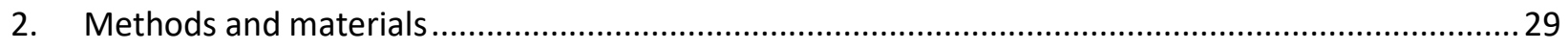

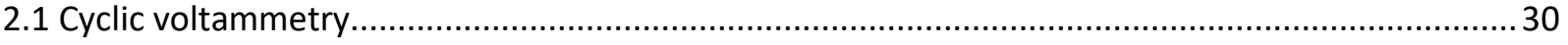

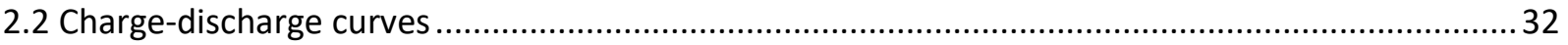

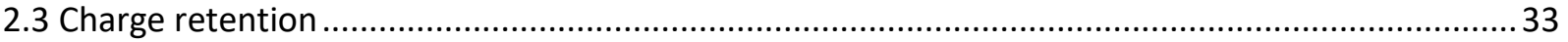

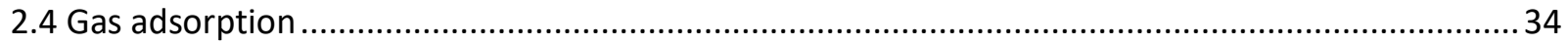

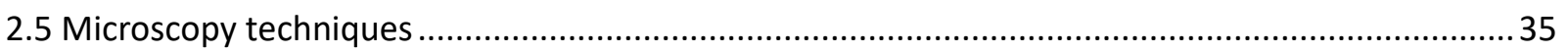

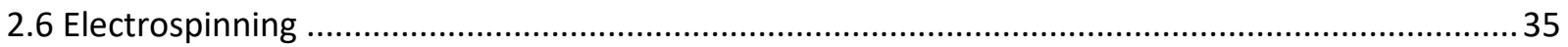

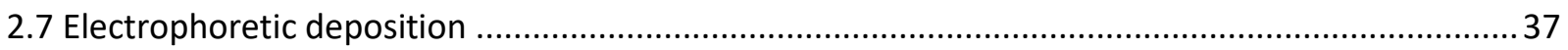

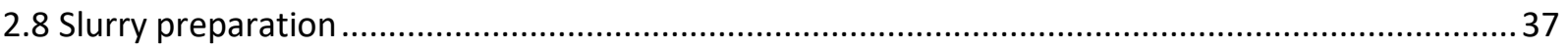

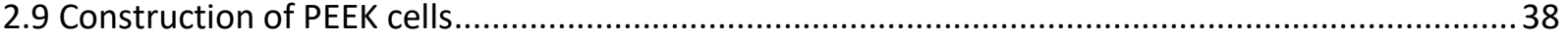

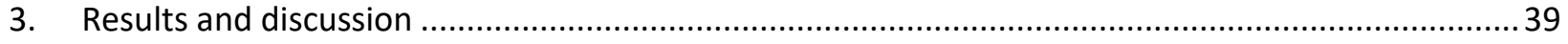

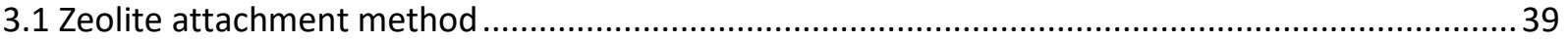

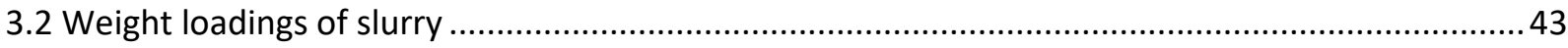

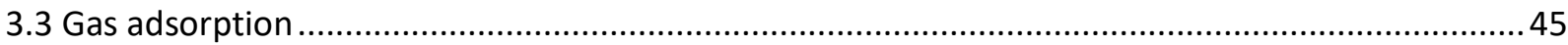

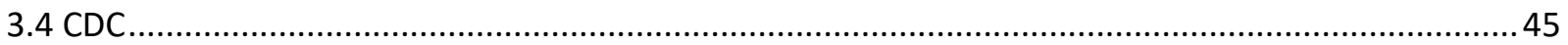

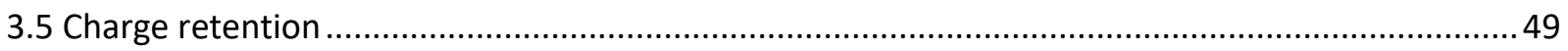

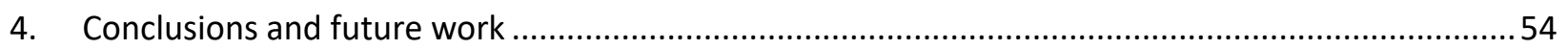

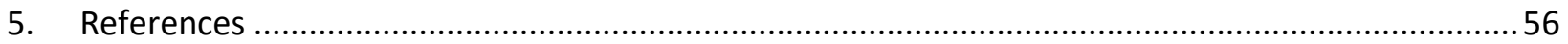

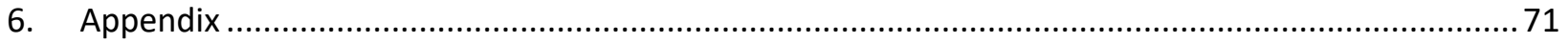




\section{Introduction}

Humanity's incredible progress as a species has been largely due to our ability to harness and manipulate energy. Where fire once let us cook meat and mould metals, electricity now powers our homes and, increasingly, our lives. We have learnt to transform energy into numerous sources for use in transport, entertainment, hygiene, and scientific development, as well as many others, to improve our overall quality of life. But along with extensive benefits, one of the largest sources of energy in constant use, fossil fuels, negatively impacts our planet and our health.

Fossil fuel is a broad label used in everyday life and refers to any hydrocarbon-based product formed from decayed organic matter through geological processes. While this technically makes fossil fuels a renewable resource, the organic matter is transformed into usable hydrocarbons on the order of millions of years, which means that the rate of fossil fuel formation is negligible in comparison with our rate of use. ${ }^{[1]}$ Along with the fact that fossil fuel deposits will one day run out, their use today results in the production of carbon dioxide as a byproduct. This carbon dioxide is free to enter the atmosphere where it works as a greenhouse gas; trapping heat by absorbing and then reemitting infrared wavelengths of light back towards Earth. ${ }^{[2]}$ Due to our global scale of fossil fuel use, carbon dioxide levels have been increasing drastically, now measuring over 400 ppm despite consistently being below 290 ppm for the past 1000 years (prior to 1880) and are a significant contribution towards global warming and the changing of our climate. ${ }^{[3][4]}$ This has led to a movement to find a replacement energy source for fossil fuels; one with a much-reduced carbon dioxide output, and from a source that will not be exhausted during human existence, which can be termed 'renewable'.

\subsection{Alternatives to fossil fuel}

\section{Solar}

The greatest source of nearby energy is the sun. Almost all life on Earth relies on its energy to survive, especially the lowest food chain organisms, plants. Plants convert light energy into chemical energy via photosynthesis, and we have used this natural idea to develop synthetic solar cells of our own, reaching conversion efficiencies of over $40 \%{ }^{[5]}$ compared to a maximum of about $8 \%$ photosynthetic efficiency, found in sugarcane. ${ }^{[6][7]}$ 
Solar panels are a collection of solar cells and can be positioned anywhere to transform sunlight into electricity. This has allowed them to be placed on rooftops to power the house below, without the need to transport energy. However, geographic areas with higher sunlight intensity will have a higher power output for the same area covered by solar panels, and so solar panels are often grouped in solar farms, far from housing locations, for greater power production at the expense of needing to transport the energy to cities where it will be used. This transportation can be through overhead cables or shipped in bulk energy storage forms such as hydrocarbons, however both options permit losses in efficiency. ${ }^{\left[{ }^{8]}\right.}$ Regardless of site location, any earthbound position will inevitably go through some amount of time where sunlight does not reach the panels and will result in a power output of zero during this time. This is unacceptable for a reliable source of energy, and so further systems must be implemented alongside this technology for a complete solution, namely energy storage devices, as will be discussed later.

\section{Nuclear}

Replication of solar processes would bring the immense energy output of a star to Earth. The process involved is nuclear fusion, but this has not been synthetically sustained for much more than a minute on Earth, ${ }^{[9]}$ and so current nuclear power plants generate electricity using fission instead. Fusion reactions involve the combination of light atoms, while fission relies on the splitting of heavy atoms. Both processes release energy, depending on the atoms used; that is, fusion releases energy for atoms lighter than nickel-62, while fission releases energy for atoms heavier than nickel-62. ${ }^{[10]}{ }^{[11]}$ Since we have yet to attain fusion capabilities, we are restricted to the use of heavy atoms for fission, such as uranium and plutonium, both of which decay into radioactive waste products which must be carefully disposed of to avoid cellular damage to living creatures. Nuclear materials have also been used to intentionally harm and kill humans, through the creation of atomic weapons, and this has left a mark on public perception regarding its safety and use - despite it being a continuous and efficient source of energy - leading to some resistance in widespread nuclear power plant facilities.

\section{Hydro}

One of the oldest sources of renewable energy, hydropower, has also faced public negativity due to the installation of its facilities. In fact, 35 times as many people have died per kilowatt hour of 
hydroelectricity production than from nuclear production. ${ }^{[12]}$ This is mostly a result of structural failure in the dam, which releases large volumes of water with high gravitational potential energy downstream and, potentially, through inhabited areas. Due to the large volume of elevated water needed for power generation, hydroelectric stations also require specific geographical features, which restricts the locations available for building such a station. However, once they have been built, hydroelectric stations have notably low running costs and require low maintenance, as well as producing minimal amounts of carbon dioxide while in operation. [13]

\section{Wind}

Humans have harnessed the power of the wind for thousands of years, with sails to propel boats and mills to grind grains. These mills have been refined into turbines and convert the kinetic energy of the wind into electricity through induction, by rotating magnets inside a generator. Faster wind speeds generate more power, and so optimal locations are those where wind speeds are generally higher. This is often around coastal areas, or very flat plains, and means that the produced electricity must be transported into cities for use, which, like solar farms, requires energy storage devices. Even if wind turbines were situated beside a city, wind supply is noncontinuous, with potentially large daily variations in speed and only a rough seasonal cycle of intensity. ${ }^{[14]}$ However, wind has minimal carbon dioxide output and is a cost-effective means of producing electricity, making it an interesting and leading choice for power production.

\subsection{Energy supply versus energy demand}

Wind as a renewable energy source suffers from the same problems as solar: intermittence and accessibility. This means that a complete energy grid would be unable to rely on either technology to supply constant power to a population when they demand it, despite both being clear options for a replacement of fossil fuels. Sunlight intensity is greatest during the middle of the day, while human energy consumption peaks at dusk. ${ }^{[15][16]}$ This is somewhat balanced out by wind which typically peaks in the afternoon, as shown in fig. 1, but even with a tandem supply of solar and wind technology, the risk of zero power output is unreasonable for a functioning grid and a reliant population. 


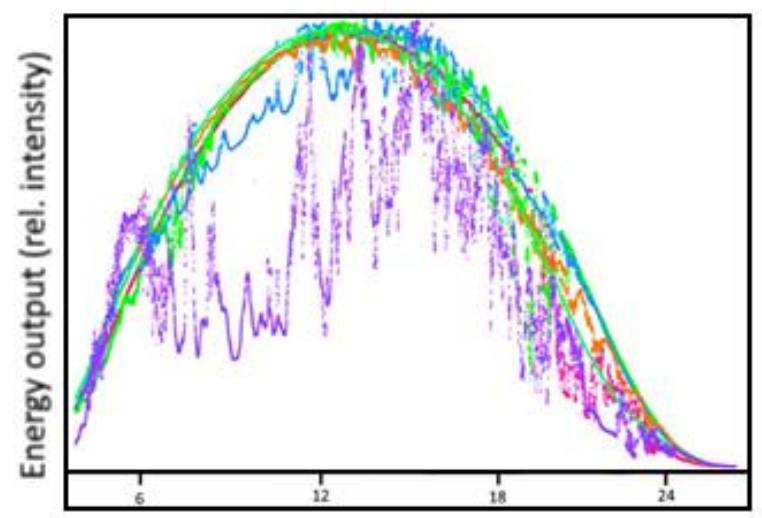

Time (Hours)

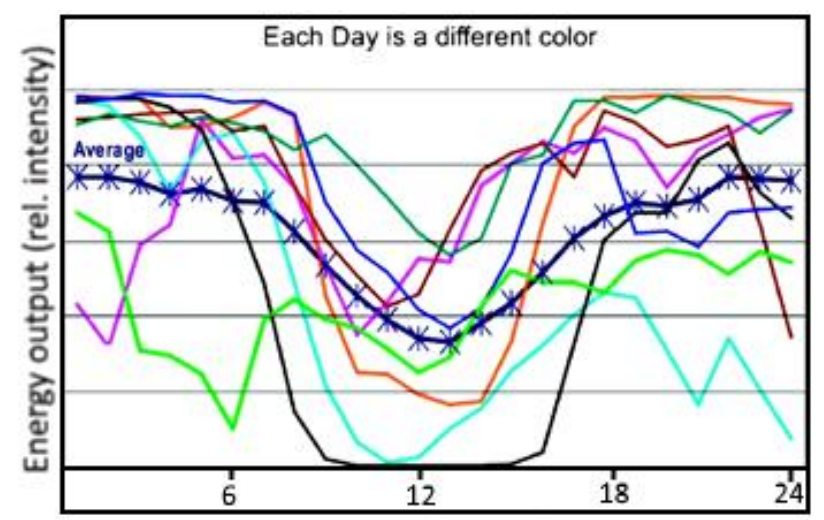

Time (Hours)

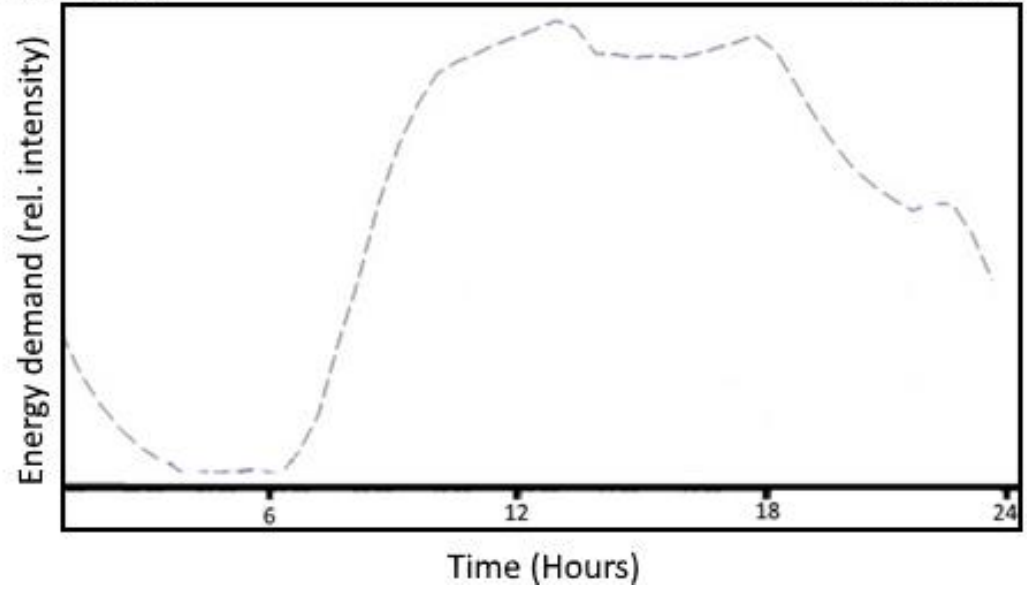

Figure 1: Plots showing relative energy production by a solar farm (top left) and a wind turbine (top right) ${ }^{[15]}$ compared to energy demand (bottom) over a 24-hour period. ${ }^{[16]}$

During times where power production is greater than power consumption, any excess energy will be unused and lost. This seems doubly wasteful when it is clear that there will be other times when power consumption is greater than power production, because it is not that the system is incapable of producing enough energy to meet demands throughout the day, but that there is a timing mismatch between energy supply and demand. This mismatch can be compensated for via the implementation of energy storage devices.

\subsection{Need for energy storage}

If electricity is being produced through the harnessing of solar or wind energy while there is no demand for its use, it is much more efficient to store this electricity until it is needed. To do this, we need a technology capable of transforming this energy into a retainable form for extended amounts of time, while also being able to reversibly release this energy when needed. 
Hydroelectric dams can actually be considered energy storage devices, with energy being stored in the elevated water as gravitational potential energy. Other mechanical means of energy storage include flywheels ${ }^{[17]}$ and compressed air storage, ${ }^{[18]}$ but this thesis will focus on electrochemical means of storage, namely supercapacitors, ${ }^{[19]}$ with a mention of batteries. ${ }^{[20]}$

Several battery types, along with supercapacitors and combustion engines are shown in fig. 2 as a Ragone plot. This demonstrates how efficient a device can provide power and energy per weight of the device. Any device that has a high power density can supply a large amount of energy for a short amount of time, while a high energy density means that energy can be supplied for a greater duration of time. There is a general linear trend of decreasing power density with increasing energy density, with the exception of the internal combustion engine (this is because the engine weight is not considered, only that of the fuel). ${ }^{[21]}$ The choice of which energy storage device to use is largely influenced on the intended application and so this has been a driving force in the research of particular technologies. With the miniaturisation of personal electronics, less room is available for the onboard energy storage devices, but due to the relatively high energy density of batteries, lithium-ion batteries have emerged as a leading technology for this application [22] [23] and allowed for the uninterrupted use of cell phones and laptops throughout the day because of the low power usage of these devices. Larger scale applications often require more power at any one time than can be provided by general battery technology.

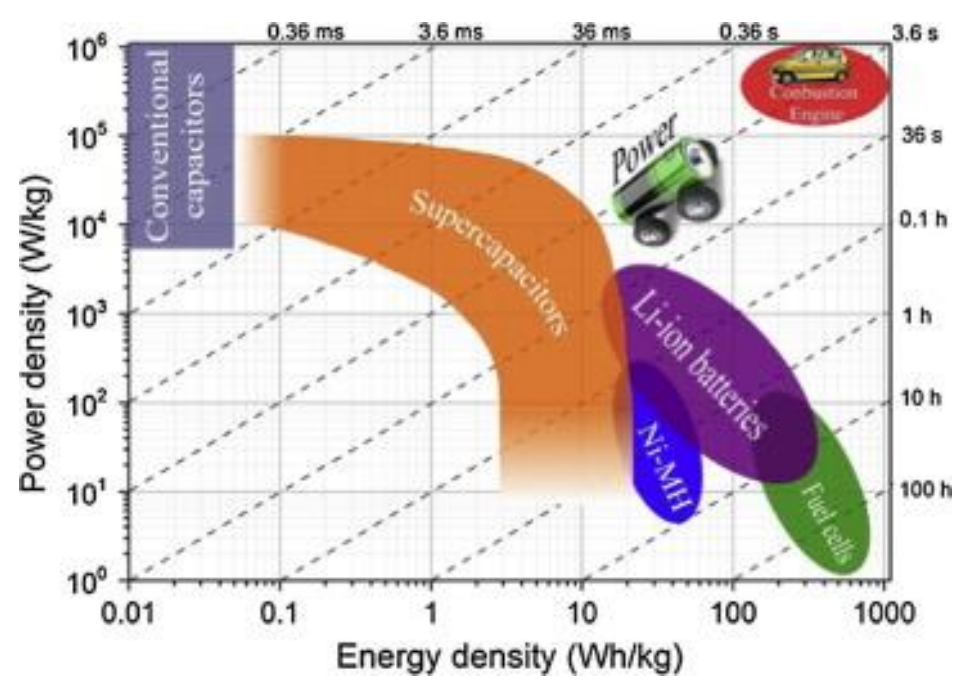

Figure 2. Ragone plot displaying a number of energy storage technologies. Typical discharge values are given on the dotted diagonal line. ${ }^{[21]}$ 
This lack of available high-power devices is most noticeable in the transport sector. Vehicles require constant energy to move around, meaning an intermittent energy source like wind would not be able to provide the necessary energy supply continuously. As a result, vehicles are one of the last aspects of our lives to become electrified and, until recently, have completely relied on fossil fuels to meet the large energy demand in the form of a portable fuel. Electric vehicles are becoming more common, however, as public awareness of climate change increases and lifestyles shift towards greener options. In New Zealand, the number of electric vehicles has increased over 200\% every year since 2014, with the exception of 2016 (188.18\%), and is estimated to be as high as $1,014,641$ in 2030 , compared with 5,919 in 2018. [24] To help facilitate this transition from a fossil-fuelled fleet to an electric fleet of vehicles, energy storage devices must exhibit comparable metrics with current fossil fuels and as such, batteries have been investigated as the primary potential replacement so far for personal vehicles.

For public transportation, overhead wires can provide electricity and remove the need for an onboard fuel, as implemented in tramlines, but in the public space they can be seen as unsightly and potentially disruptive to historic locations. Since inner-city public transport makes frequent stops for passengers, an energy system that could be charged up in a short time at these stop points and provide enough energy to get to the next stop point would completely eliminate the need for overhead wires and fossil fuels. This short charge time would be a perfect application of supercapacitor technology, as opposed to battery technology, as highlighted from fig. 2, which shows the bulk of supercapacitors having a charge/discharge time between 0.36 and 36 seconds. Specific aspects of both batteries and supercapacitors will be discussed to explore each technology, with a focus on supercapacitors.

\subsection{Batteries}

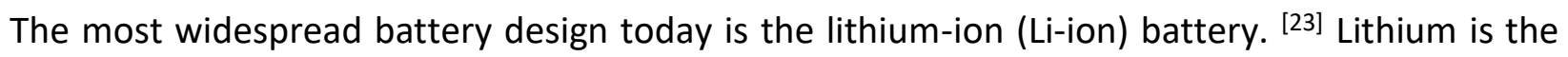
third lightest element and has an ionic state with a charge of +1 . This makes it an excellent candidate for an ion battery, as the reaction from lithium metal ( $\mathrm{Li})$ to lithium ion $\left(\mathrm{Li}^{+}\right)$yields one electron and vice versa, meaning that an energy supply can be used to convert $\mathrm{Li}^{+}$to $\mathrm{Li}$, storing one electron per atom of lithium. When energy is needed, the reverse reaction releases an electron which can be used as electric current to power electrical devices. 
Li-ion batteries have seen implementation alongside portable electronic devices due to their high energy density, allowing for a battery that can provide moderate amounts of power throughout the entire day without adding excessive weight to the device.

Lithium-ion batteries have a high energy density due to the use of lithium metal as the positive electrode (anode), which is the most space-efficient way to pack lithium atoms. Unfortunately, many common lithium salts have a higher reduction potential than the anode, so other species are formed on the electrode surface during charging which forms a film known as the surfaceelectrolyte interface (SEI). ${ }^{[25]}{ }^{[26]}$ This layer is insulating to electrons and so it's formation is detrimental to battery capacity and lifetime. Other anode materials have been considered [27] such as silicon- and carbon-based materials, but these store lithium via an intercalation mechanism (For example, $\mathrm{C}_{6}+\mathrm{LiCoO}_{2} \underset{\text { Discharging }}{\stackrel{\text { charging }}{\longrightarrow}} \mathrm{Li}_{x} \mathrm{C}_{6}+\mathrm{Li}_{1-x} \mathrm{CoO}_{2}$ ) rather than metallic packing, and therefore lower the maximum energy density. ${ }^{[28]}[29]$

A number of materials have also been investigated for use as the negative electrode (cathode) in Li-ion batteries. ${ }^{[30]}$ These are mostly lithium compounds, with the most common material being $\mathrm{LiCoO}_{2}{ }^{[31]}{ }^{[32]}$ which is made up of cobalt, an expensive metal that adds significantly to the total cost of a Li-ion battery. As well as in the electrolyte, lithium is extensively used in cathode materials and similarly has a high price due to it's low abundance. ${ }^{[33]}{ }^{[34]}$ The use of expensive metals in the construction of Li-ion batteries slows their commercialisation and use, but they have become the standard battery of choice despite this, due to their high-performance metrics and lack of viable competition.

Other ion battery designs have been developed. Some of these include sodium, ${ }^{[35]}$ magnesium, ${ }^{[36]}$ and aluminium, [37] [38] all elements located around lithium on the periodic table. These technologies address some of the issues mentioned above, but researchers are still working towards energy density values competitive with those of lithium-ion batteries. In contrast to this, other technology devices, such as supercapacitors, have a different design to batteries and so function and perform in different ways.

It is worth noting here that batteries and supercapacitors are two distinct and useful designs for energy storage devices; the difference is namely in the charge/discharge duration. That is, for 
applications longer than an hour, batteries are favourable, while supercapacitors perform best in short bursts, typically less than a few minutes. There is some crossover for charge/discharge times in between these values, which can be seen from the diagonal discharge lines in fig. 2 , but in general, supercapacitors are not a battery replacement, and vice versa.

\subsection{Supercapacitors}

The main difference between supercapacitors and batteries is the way in which they store energy. The energy storage mechanism in supercapacitors is purely physical, as opposed to the chemical reactions in batteries, which means that there is almost no degradation of the electrode surface, giving rise to extended lifetimes. ${ }^{[39]}$ Supercapacitors were developed from capacitors, a schematic of which is shown in fig. 3. Capacitors consist of two conductive sheets that are separated by some distance filled with an insulating dielectric material, such as paper or air. During charging, electrons accumulate on one plate, leaving a positive charge on the other. This separation of positive and negative charges creates a potential difference, and the energy is stored in the created electric field. When discharged, capacitors discharge entirely on the order of micro- or milliseconds. ${ }^{[40]}$

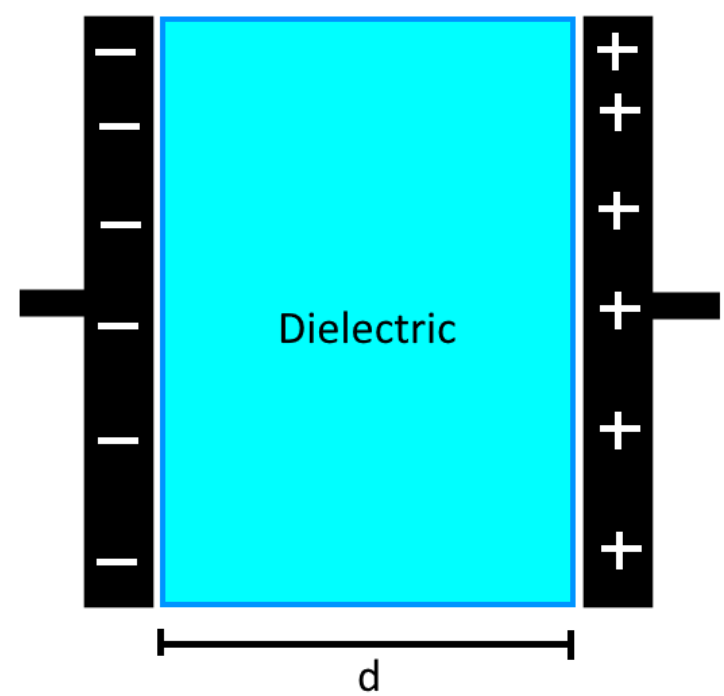

Figure 3: Schematic of a standard electrostatic capacitor. Plates are drawn as negative and positive to demonstrate the charge separation that occurs when fully charged. Distance between the plates is noted as ' $d$ '. 
The capacitance of a capacitor is determined by the area of the plates and the separation distance of the charges, as shown in equation 1 , which shows that capacitance (C) is directly proportional to the area of the plates (A), and inversely proportional to the distance between them (d). ${ }^{[19]}$ The permittivity of free space $\left(\varepsilon_{r}\right)$ and the dielectric constant $\left(\varepsilon_{0}\right)$ are both constants, and so the way to increase capacitance is by increasing area or decreasing distance. Application of this relationship led to the creation of the supercapacitor.

$$
C=\frac{\varepsilon_{r} \varepsilon_{0} A}{d}
$$

Howard Becker held the patent for the first supercapacitor-like device, ${ }^{[41]}$ and used porous carbon electrodes as capacitor plates to obtain "unusually high capacitance values at low voltages", through the use of these high surface area electrodes. He correctly theorised that the energy was stored on the surface of the electrodes but incorrectly thought this was done in the form of atomic hydrogen.

The energy is actually stored in the electric field established between the electrode and a layer of ions adsorbed to the electrode surface, shown in fig. 4 as the Helmholtz layer. The ions are supplied by the electrolyte, which replaced the dielectric from standard capacitors. During charging, positive ions are attracted and adsorb to the negative electrode, while negative ions adsorb to the positive electrode. This was recognised by Robert Rightmire who, several years after Becker's patent, developed the supercapacitor design upon which modern supercapacitors would be based ${ }^{[42]}$ and referred to the charge separation as a 'double-layer'.

This double-layer phenomenon meant that the distance between charge separation was on the order of angstroms as it occurred between the electrode surface and the ion layer, ${ }^{[40]}$ rather than between the two electrodes, drastically increasing the capacitance and energy density of the device, contributing towards this design being referred to as an electrochemical double-layer capacitor (EDLC). 


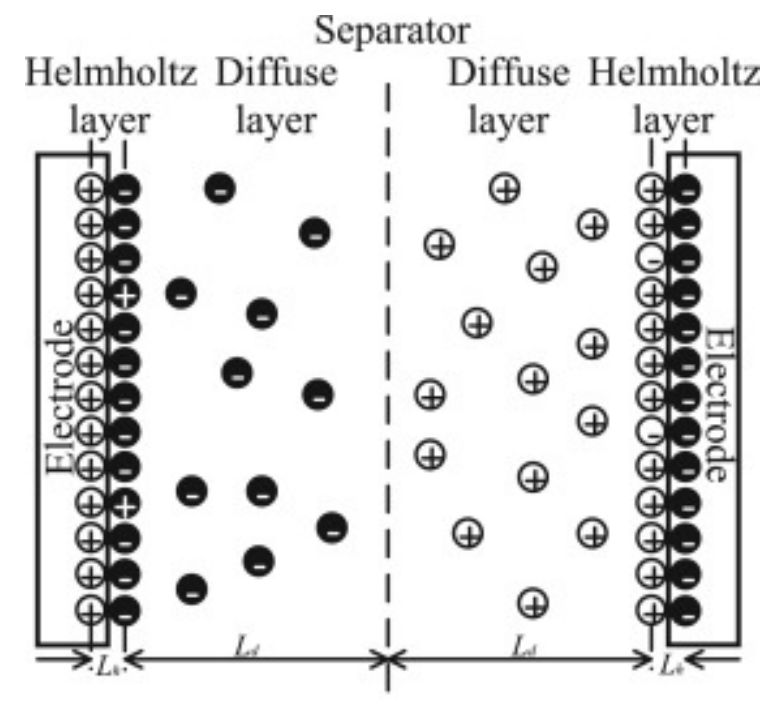

Figure 4: Schematic demonstrating the ion distribution in an EDLC after some amount of charging. The double layer formation can be seen on each electrode, with an electric field established between the ionic layer (Helmholtz layer) and electrode. ${ }^{[43]}$

Since no chemical reactions occur during the charging or discharging processes, there are no degrading surface modifications to damage the electrodes. This allows EDLCs to be cycled (one charge and one discharge process) many times more than batteries before their performance becomes impaired. ${ }^{[39]}$ The rate of charging also has no detrimental effects on the supercapacitor components, as opposed to battery technology, where high charging rates damage electrodes and irreversibly reduce battery capacity. ${ }^{[44][45][46]}$

The ability for supercapacitors to be quickly charged and discharged has seen them applied in situations with fluctuating or infrequent load currents. ${ }^{[47][48]}$ Since charge rate is not proportional to electrode degradation, it does not matter if the current used to charge the supercapacitor is high or low, meaning they can be used as an energy storage device for intermittent sources of energy, such as solar or wind without damage. Another use is to act as a power buffer between sensitive equipment and the energy grid. ${ }^{[49]}\left[{ }^{[50]}\right.$ For an appliance that requires constant uptime, such as hospital machines, power outages could leave crucial instruments without a supply of power and result in catastrophic consequences. Supercapacitors have a quick response time, in that they are capable of providing their maximum voltage supply in a relatively short amount of time, compared to backup batteries for example. 
Even the batteries in smartphones suffer from a variable current load. ${ }^{[51]}$ Turning on the screen requires a sudden pulse of current from the battery, as does calling or data usage, and this startstop behaviour during the discharge is detrimental to the battery's lifetime and subsequent capacity. Using a supercapacitor as a buffer for these current spikes in conjunction with a battery would reduce the damage done to the battery. Smith et al. found that, with a supercapacitorbattery combination, in a system charged to $4.2 \mathrm{~V}$ with a shutdown threshold at $3.0 \mathrm{~V}$, there was a $14 \%$ extension of battery usage time. If the threshold was instead set to $3.5 \mathrm{~V}$, the extension was considerably greater with the system lasting $305 \%$ as long. ${ }^{[52]}$

Another start-stop application is the energy source for public transport, specifically in the innercity where traffic lights and other vehicles necessitate frequent stopping and starting. As previously mentioned, tram systems would be greatly improved by switching their energy source to supercapacitors, as shown through computational simulation where energy savings of over $25 \%$ could be achieved through the integration of a supercapacitor for a $30 \mathrm{~m}$ tram, but this still relied on overhead wires and simply used the supercapacitor bank for as a buffer. ${ }^{[53]}$ The world's first tram completely powered by supercapacitors was put on the rails in $2013^{[54]}$ and could transport 368 passengers up to $4 \mathrm{~km}$ from a single 30 second charge. It was even able to regenerate $85 \%$ of the energy used in braking, which is important, as around $14 \%$ of all available energy can be lost as heat during braking. [55]

Regenerative braking is an application of supercapacitors that can be applied to any vehicle, not just trams, as a way to minimise energy losses during operation. Excess heat from braking can be captured and then stored in a supercapacitor where it can be used to help power the acceleration process when the vehicle next starts moving, reducing the amount of energy needed from the main energy system. ${ }^{[56]}$

Due to the mechanism by which they store energy, supercapacitors will always have an inferior energy density compared to batteries. For applications with extended runtimes, batteries are the preferred option, but it has been shown that supercapacitors can complement such a system through hybridisation, as well as excelling in specific high-power, short-time applications. 
A large barrier to the commercialisation of supercapacitors is their high construction cost. Many of the high-performance supercapacitors use expensive metal oxides, such as $\mathrm{RuO}_{2}$ and $\mathrm{IrO}_{2}$, as their electrodes ${ }^{[57] ~[58]}$ for good conductivity and high surface area properties, along with ionic liquid electrolytes [59] [60] for a larger voltage range. Many ionic liquids are flammable and airsensitive, while also reacting with common electrode materials to form an SEI, making them difficult to work with and result in potentially dangerous devices. [60] [61]

A problem specific to supercapacitors is their tendency to self-discharge. ${ }^{[62]}$ Charging an EDLC causes ions to adsorb to the electrode surface, and when no more ions are able to be adsorbed, the device is fully charged. The fully charged state is a state of higher energy, relative to the uncharged state, and so the ions will have some affinity to return to solution and restore the lowenergy state. This redistribution of charge means that, once fully charged, a supercapacitor would slowly lose its charge while not in use and therefore be at a lower initial voltage when it was required for use. Short storage times would obviously minimise this problem but understanding the processes involved would allow for development of devices with lowered self-discharge rates.

There are a few proposed mechanisms by which charge redistribution occurs. Conway et al. have identified three kinds of mechanisms through which self-discharge can occur. ${ }^{[63]}$ Firstly, for the case of an overcharged electrode, Faradaic charge transfer can occur across the established double-layer to the electrode surface until the overpotential is zero. A second mechanism is where charge is lost to any redox reactions occurring on the surface of the electrode, such as oxygen reduction or carbon oxidation. ${ }^{[64]}$ The other stated mechanism is where electrons are shuttled from one electrode to the other, either via direct contact of the electrodes or, for the case where each of the electrodes is a different composition, as a galvanic couple.

Ricketts et al. describes another mechanism that involves diffusion. ${ }^{[65]}$ Diffusion is the process where species from a region of high concentration move to a region of lower concentration, which, in the case of supercapacitors, means that the high concentration of ionic species on the electrode after charging will slowly transfer back to the lower concentration of ionic species in the main electrolyte solution. 
For a supercapacitor cell that is charged between an appropriate voltage window, both of the first two mechanisms of self-discharge can be minimised. No overpotential will result, and redox reactions will not have enough potential available to be a significant process. The use of a symmetric cell, in which both electrodes are of the same material, will mean that the open cell voltage (OCV) should theoretically be zero and no galvanic couple will be formed. As such, the mechanism of ionic dissociation was treated as the most prominent self-discharge mechanism for this research and was addressed through the intentional design of individual components.

\subsection{Electrodes}

Often of most interest in development of EDLCs is the electrode material. To allow for comparison between the performance of different materials, capacitance is reported as specific capacitance in literature, measured in Farads per gram $\left(\mathrm{F} \mathrm{g}^{-1}\right)$. Values of specific capacitance have been achieved of over $1000 \mathrm{~F} \mathrm{~g}^{-1}$ with costly, high-performance materials such as $\mathrm{RuO}_{2}$ reaching their theoretical capacity. ${ }^{[66]}{ }^{[67]}$ Wang et al. fabricated ruthenium oxide electrodes with a specific capacitance of $1099 \mathrm{~F} \mathrm{~g}^{-1}$ using $\mathrm{RuO}_{2}$ nanoclusters supported by graphene oxide to increase the available surface area. ${ }^{[68]}$

The maximum capacitance of $\mathrm{RuO}_{2}$ electrodes has been shown to depend heavily on the degree of crystallinity and the amount of hydration of the crystals, where a variation from anhydrous $\mathrm{RuO}_{2}$ to $\mathrm{RuO}_{2} \cdot 0.5 \mathrm{H}_{2} \mathrm{O}$ increased the capacitance from $0.75 \mathrm{~F} \mathrm{~g}^{-1}$ to $900 \mathrm{~F} \mathrm{~g}^{-1}$. [69]

Another metal oxide, nickel oxide, has a theoretical specific capacitance of around $2500 \mathrm{~F} \mathrm{~g}^{-1}$ [70] but this value has not been able to be reached in practice due to inherently high resistivity, with attempts only reaching hundreds of Farads per gram and electrodes suffering from low cycle performance as a result of material degradation. ${ }^{[66]}$ [71]

Carbon materials feature much more stability ${ }^{[72]}$ [73] $^{[3 n d ~ c a n ~ p e r f o r m ~ w i t h ~ c o m p e t i t i v e ~ s p e c i f i c ~}$ capacitance values. ${ }^{[74]}{ }^{[75]}$ Using a "pollution-free" method, bamboo char was used to create graphitic carbon electrodes which exhibited a specific capacitance of $222 \mathrm{~F} \mathrm{~g}^{-1}$. ${ }^{[76]}$ While this value is several times lower than the theoretical value for some metal oxide materials, it is still practically competitive, with the device having an energy density of $6.68 \mathrm{~W} \mathrm{~h} \mathrm{~kg}^{-1}$. 
A similar energy density of $10.96 \mathrm{~W} \mathrm{~h} \mathrm{~kg}^{-1}$ was found in carbon nanofibre electrodes ${ }^{[77]}$ with a maximum specific capacitance of $307.2 \mathrm{~F} \mathrm{~g}^{-1}$. They had been doped with nitrogen to enhance the electrochemical activity and were formed from polyacrylonitrile (PAN) solution using a process known as electrospinning.

\section{Electrospinning}

Electrospinning has emerged as a simple process to obtain a variety of nanofibrous materials with variable properties, such as thickness and directionality, based on the parameters chosen in the electrospinning setup. Precursor solution is pushed from a syringe using a syringe pump which is drawn across some distance to a collector plate due to the presence of an electric field, caused by a large potential difference between the syringe nozzle tip and the collector plate. There are many parameters which affect the morphology and diameter of the resulting nanofibre sheet, including voltage, precursor concentration, and distance from needle to plate.

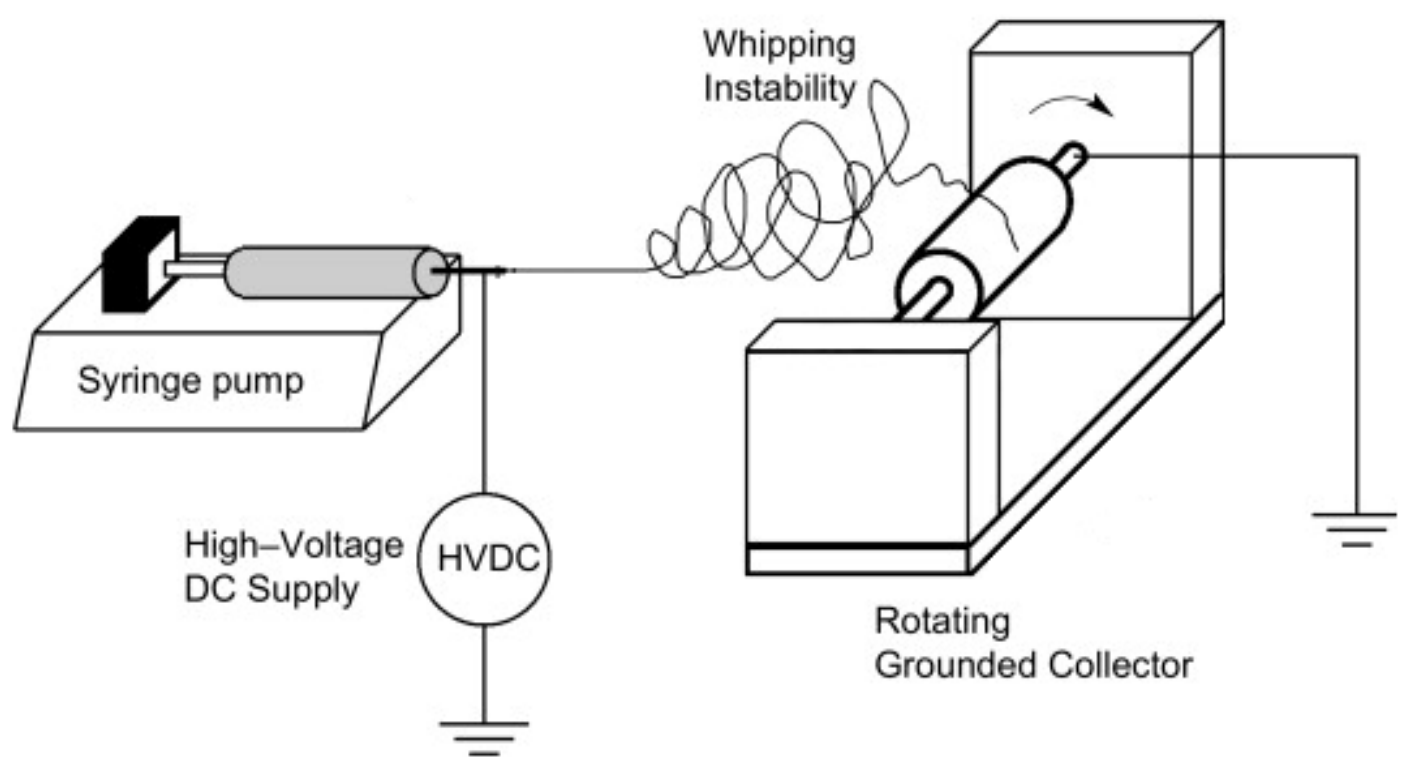

Figure 5: Schematic of an electrospinning setup as described. A high voltage source is connected to the syringe nozzle with one electrode and the collector drum with the other. ${ }^{[78]}$

For carbon precursor solutions, some post-spinning heating steps are often necessary to carbonise the nanofibres, ${ }^{[79]}$ removing surface groups that would otherwise be oxidised or reduced in solution, as well as increasing conductivity for use as electrodes at the cost of more processing. 
Chen et al. used PAN dissolved in N,N-dimethylformamide (DMF) to electrospin a nanofibre sheet that underwent heating to $280^{\circ} \mathrm{C}$ and then to $1000{ }^{\circ} \mathrm{C}$ to obtain a carbon nanofibre film. Several treatments were then used to incorporate polypyyrole (PPy) and graphene oxide onto the carbon nanofibres, followed by immersion in the chosen electrolyte, to further enhance the surface area and capacitance. After all these post-modification steps, they obtained a maximum specific capacitance of $336.2 \mathrm{~F} \mathrm{~g}^{-1}$. [79]

There are numerous other examples of modified carbon nanofibres produced via electrospinning, a collection of which is given in the review by Lu et al. in their table $1{ }^{[80]}$ with typical capacitance values ranging from 43 to $432 \mathrm{~F} \mathrm{~g}^{-1}$.

\section{Slurry}

Another, even simpler way of fabricating carbon electrodes is through the use of a slurry which often consists of conductive powders and a binder, dissolved in a solvent. They can be coated on any conductive surface to create an electrode through techniques such as drop-casting ${ }^{[81]}$ and spin-coating. ${ }^{[82]}$ Doctor blading is another technique that has been used to create electrodes using slurries ${ }^{[83]}$ and requires minimal equipment for manual application. A conductive surface must first be taped down by the edges, with an exposed central area for slurry application, which then gets smoothed out over the entire exposed surface with a blade to create a flat coating of the slurry. The slurry is then left to dry at some chosen temperature, either in an oven or at room temperature.

Font et al. found that slower drying rates led to a more homogenous distribution of the binder, both theoretically and experimentally, leading to better cell performance. ${ }^{[84]}$ They also state that an initial fast drying rate, followed by a slower drying rate can be used to reduce drying time, while maintaining homogeneity. A two-step drying step near room temperature is also proposed by Stein et al. to produce better performing electrodes. ${ }^{[85]}$

Cell performance can also be affected depending on the type of carbon used. Carbon-containing slurries can be synthesised using any source of carbon, and electrodes have been fabricated with carbon slurries that exhibit moderately high specific capacitances, ${ }^{[86]}$ but lower values of 0.5 to $85 \mathrm{~F} \mathrm{~g}^{-1}$ are typical for this type of method. [87] [88] [89] [90] 


\subsection{Electrolytes}

The other main component in supercapacitors is the electrolyte, the choice of which can have an effect on cell performance and electrode stability. The three main types of electrolyte are ionic liquids, organic solvents, and aqueous solutions.

\section{lonic liquids}

lonic liquids are salts that are liquid below an arbitrarily low temperature; often stated as $100{ }^{\circ} \mathrm{C}$, but especially at room temperature. ${ }^{[91]}{ }^{[92]}$ This means that the entire liquid is made of two conducting ions; one typically being much larger than the other, for example $\left[\mathrm{EtMelm}^{+}\left[\mathrm{BF}_{4}\right]^{-}{ }^{-[93]}\right.$ and [BuMelm] ${ }^{+}\left[\mathrm{PF}_{6}\right]^{-}$as demonstrated in fig. 6. ${ }^{[94]}$

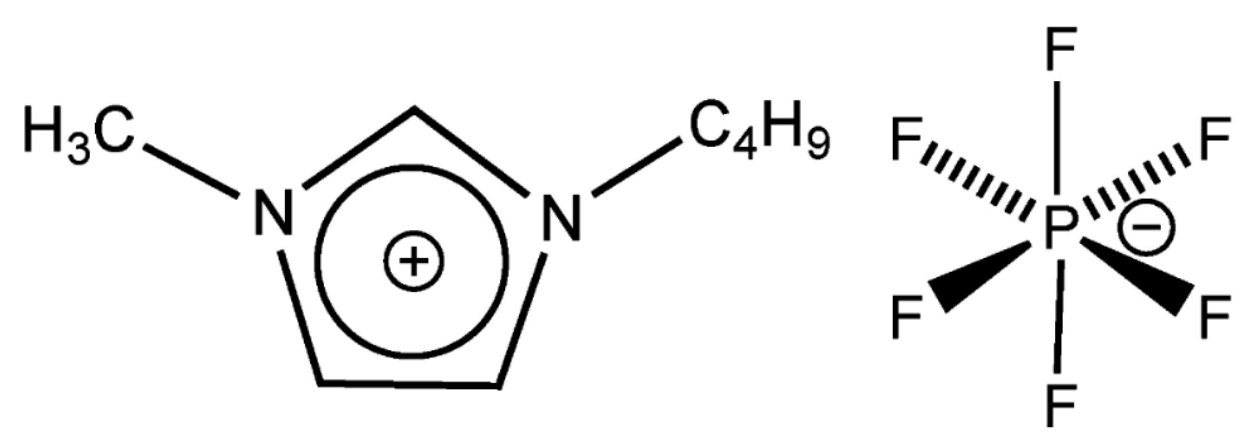

Figure 6: Structure of the ions that make up the ionic liquid [BuMelm $]^{+}\left[\mathrm{PF}_{6}\right]^{-}{ }^{\text {[95] }}$

This affords ionic liquids a very wide voltage window, which is the range of voltages that the solution can be used without decomposition. ${ }^{[95]} \mathrm{A}$ wide voltage window is an attractive feature for an electrolyte to have for electrochemical storage devices, as it means the device can be reliably charged up to a higher voltage, subsequently resulting in a higher energy density. Depending on the ionic pair, ionic liquids have been found to have a stable voltage range of up to $7 \mathrm{~V}$, with most having a value of between 3 and $5 \mathrm{~V}$. [96] [97]

Their use has been industrially limited due to high cost and difficulty in handling, as even small amounts of water introduced into the supercapacitor system results in performance drops. ${ }^{[60]}$ Due to the lack of solvent, ionic liquids are also relatively viscous and have reduced ionic conductivities at low temperatures, further limiting the power output of devices with ionic liquids as an electrolyte. 
A carbon nanotube electrode was used in a three-electrode cell with a number of different ionic liquids, with available voltage windows ranging from 2.7 to $5.3 \mathrm{~V}$. ${ }^{[98]}$ However, despite this extended voltage window the highest capacitance achieved was just $24.3 \mathrm{~F} \mathrm{~g}^{-1}$, likely due to carbon materials not being well matched for use with ionic liquids.

\section{Organic solvents}

Organic solvents are better suited for use with carbon electrodes while retaining an extended voltage window of up to $3 \mathrm{~V}$. [99] [60] This, in use with a slurry-coated electrode containing 85 wt\% porous silicon carbide spheres, gave an organic electrolyte system a higher energy density of 102.59 $\mathrm{W} \mathrm{h} \mathrm{kg}^{-1}$ compared to an aqueous system, which attained $29.47 \mathrm{~W} \mathrm{~h} \mathrm{~kg}^{-1}$. ${ }^{[100]}$ The roughly three times increase in energy density comes at the cost of lowered capacitance, however, with the aqueous electrolyte: $82.9 \mathrm{~F} \mathrm{~g}^{-1}$ and organic electrolyte: $60.3 \mathrm{~F} \mathrm{~g}^{-1}$.

The IR drop experienced in organic electrolytes is also much larger in organic electrolytes, measured to be one order of magnitude by Tanahasi et al. ${ }^{[101]}$ This is the instantaneous drop in voltage experienced at the start of a discharge cycle and is essentially wasted voltage that cannot be harnessed, as it is instead used to overcome the inherent electrode resistance.

This is typical of all organic electrolytes, along with increased cost and reduced safety, with many organic solvents being volatile, flammable, or toxic. ${ }^{[59]}$ Similarly to ionic liquids, organic solvents must be handled carefully to avoid moisture contamination.

\section{Aqueous solutions}

Water can instead be used as the solvent to dissolve ionic species in. It is stable at room temperature, poses little risk in small volumes, and is not affected by the presence of moisture, since it is made of water. As such, supercapacitor cells using aqueous electrolytes can be made

on the benchtop and industrially without the need for expensive dry rooms. ${ }^{[102]}$ Aqueous solutions also have much cheaper components than ionic liquids or organic solvents, so seem like an excellent choice of electrolyte for lowering the cost of supercapacitor production.

They are well matched for use with low-cost carbon electrodes, yielding higher-than-organic capacitance values, despite the lower voltage window of around $1.2 \mathrm{~V}$, as shown. [100] [101] [103] Stoller et al. used chemically modified graphene electrodes with both organic and aqueous 
electrolytes and found capacitance values of 99 and $135 \mathrm{~F} \mathrm{~g}^{-1}$ respectively, even though the organic cell was charged up to almost three times the voltage.

The higher capacitance values found in aqueous systems is likely due to their high ionic conductivity values. ${ }^{[104]}$ This is mainly due to the difference in size between transport ions, and it has been found that typical aqueous ions have conductivities on the order of magnitude larger than those for ionic or organic electrolytes. There are many simple ionic species that could be considered for use in an EDLC. Singly-charged ions tend to have slightly lower ionic conductivities than some ions with $2^{+/-}$charges, due to each individual ion carrying half the charge.

Table 1: Ionic conductivity values for various species, taken from the work of Zhong et al. ${ }^{\text {[59] }}$

\begin{tabular}{|c|c|}
\hline Ionic species & Ionic conductivity $\left(\mathbf{S ~ c m}^{\mathbf{2}} \mathbf{~ m o l}^{-1}\right)$ \\
\hline $\mathrm{Na}^{+}$ & 50.11 \\
\hline $\mathrm{K}^{+}$ & 73.50 \\
\hline $\mathrm{Cl}^{-}$ & 76.31 \\
\hline $\mathrm{NO}_{3}{ }^{-}$ & 71.42 \\
\hline $\mathrm{Mg}^{2+}$ & 106.12 \\
\hline $\mathrm{SO}_{4}{ }^{2-}$ & 160.0 \\
\hline
\end{tabular}

In their review, Zhong et al. state that the ideal supercapacitor electrolyte must have a wide voltage window, a wide temperature window, high ionic conductivity, high stability, good matching with the electrode, low reactivity to the electrode, low volatility, low economic cost, and low environmental cost. It is difficult for any category of electrolyte to match with all of these requirements, highlighted in table 2 below, so researchers must choose one that displays several of these quantities and as a result of this, it was reported that $84.8 \%$ of literature published about supercapacitors in 2014 used aqueous electrolytes. [59] 
Table 2: List of how each type of electrolyte displays "ideal electrolyte" properties

\begin{tabular}{|c|c|c|c|}
\hline Property & Ionic & Organic & Aqueous \\
\hline Wide voltage window & $\checkmark$ & $\checkmark$ & $x$ \\
\hline Wide temperature window & $x$ & $x$ & $\checkmark$ \\
\hline High ionic conductivity & $x$ & $x$ & $\checkmark$ \\
\hline High stability & $\checkmark$ & $\checkmark$ & $\checkmark$ \\
\hline Well matched to electrodes (For carbon) & $x$ & $\sim$ & $\checkmark$ \\
\hline Does not react to electrodes & $x$ & $\checkmark$ & $\checkmark$ \\
\hline Low volatility & $\checkmark$ & $x$ & $\checkmark$ \\
\hline Low cost & $x$ & $\sim$ & $\checkmark$ \\
\hline Environmentally friendly & $\checkmark$ & $x$ & $\checkmark$ \\
\hline
\end{tabular}

However, the higher conductivity of aqueous electrolytes also means that, once fully charged, the ions have a greater ability to diffuse back into solution from the electrode through ionic dissolution, exacerbating the self-discharge mechanism. The charge retention capabilities of an electrode material are seldom reported alongside the usual EDLC parameters, but some groups have specifically looked at trying to reduce the rate at which charge is lost, as reported below.

\subsection{Charge retention}

Using activated carbon electrodes and bulky triethylmethylammonium tetrafluoroborate electrolyte dissolved in organic acetonitrile, Xia et al. constructed a supercapacitor cell that could be charged up to $2.0 \mathrm{~V}$. They found that by adding 4-n-pentyl-4'-cyanobiphenyl liquid crystals to the electrolyte at a concentration of $2 \%$, the voltage decay was reduced for a fully charged cell, dropping to $1.5 \mathrm{~V}$ in 16.5 hours compared with 2.2 hours for the standard electrolyte. ${ }^{[105]}$ This was due to the increased viscosity from alignment of the liquid crystals in the electric field between the supercapacitor electrodes, however this phase was only present between 23 and $35^{\circ} \mathrm{C}$, severely limiting it's potential application.

Modifying the electrodes rather than the electrolyte can create a more stable and usable cell. In an attempt to provide a "backwards galvanic couple" to mitigate self-discharge, a supercapacitor 
was constructed using asymmetric electrodes of activated carbon on zinc and on copper foil as the cathode and anode respectively. ${ }^{[106]}$ The galvanic couple was proposed to provide a microcurrent to mitigate any charge redistribution, leading to a drop of only $5.6 \%$ in voltage over 810 hours with an aqueous $\mathrm{ZnSO}_{4}$ electrolyte, compared to the control (symmetric gold foils instead of asymmetric zinc and copper) which dropped $44.4 \%$ in the same amount of time. This is incredibly impressive charge retention for an EDLC, but it becomes unsurprising when it is realised that the galvanic cell is essentially charging the supercapacitor constantly, using up metal from the foil through redox reactions; that is, using up the energy required in the formation of those metal foils, rather than preventing energy loss.

Modifying the chemistry of graphene oxide electrodes to introduce more nitrogen atoms and reduce the number of oxygen atoms almost tripled its charge retention. ${ }^{[107]}$ Using the ionic liquid 1-ethyl-3-methylimidazolium tetrafluoroborate $\left(\mathrm{EMIMBF}_{4}\right)$ as electrolyte and charging the cell up to $3.0 \mathrm{~V}$, the cell retained half of its charge for 4.10 hours, compared to 1.36 hours for unmodified graphene oxide. This was achieved through the adjustment of heteroatoms, as nitrogen provides stronger binding for the electrolyte ions whereas oxygen creates relatively loosely-bound ions which can diffuse back into solution more easily.

Lastly, Tevi et al. ${ }^{[108]}$ applied poly(p-phenylene oxide) (PPO) to a glassy carbon electrode. PPO is an insulating material and covering the electrode with a layer of this reduced the capacitance of the cell by about $56 \%$, from 12.99 to $5.70 \mathrm{~F} \mathrm{~g}^{-1}$, but it did have the effect of reducing the selfdischarge rate by about 78\%. The layer was said to create an energy barrier for parasitic Faradic reactions and not hinder the double-layer formation, but the drop in capacitance shows that it was affected by the addition of the insulating layer.

In an attempt to reduce the self-discharge of a supercapacitor device without impacting the capacitance and electrochemical performance, while also using readily available and low-cost materials and minimal production steps, the following design was constructed.

\subsection{Aims of my project}

The electrolytic ions in solution needed to be able to adsorb onto the electrode surface and then have a reduced affinity to diffuse back into the bulk solution. By introducing a porous structure 
to the electrode, the ions had a cup-like cavity to fit into which provided some energetic barrier to dissolution. It was crucial that the pore size was of an appropriate size to accommodate the ions; not too big that there was no effect on diffusion rate, and not too small that the ions could not enter the pores. This was achieved through the addition of zeolite powder.

To address the issues of self-discharge and cost, a novel supercapacitor design was proposed. Each aspect will be explained in detail, but briefly, low-cost materials with minimal processing were used for both the electrode and the electrolyte, and a porous zeolite structure was introduced into the electrode to reduce the rate of self-discharge. This is represented by the schematic in fig. 7.

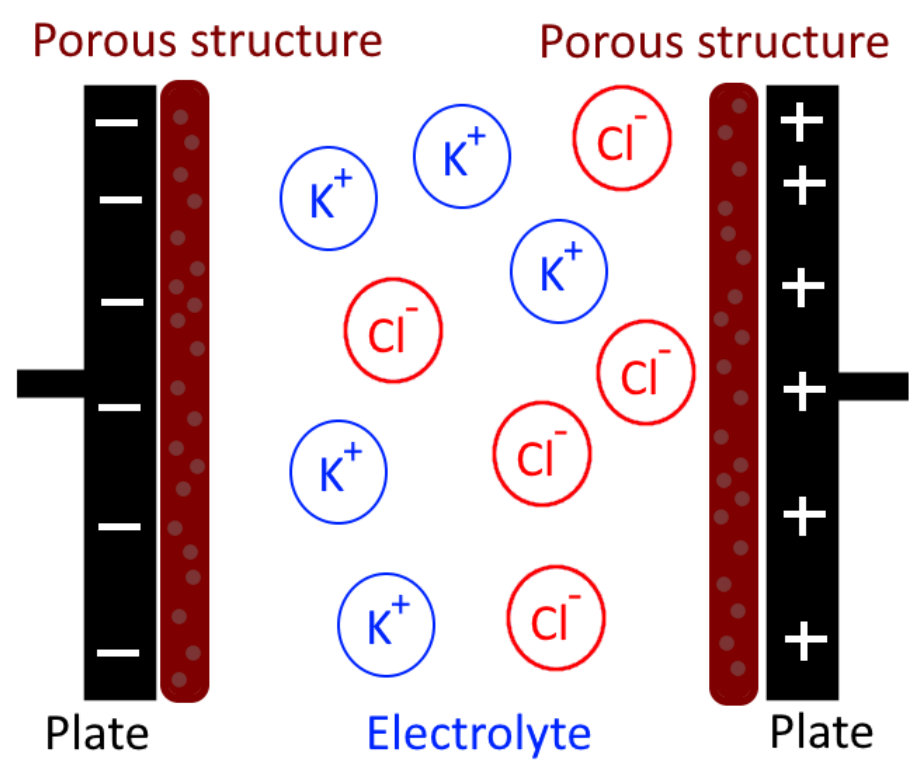

Figure 7: Schematic of the constructed supercapacitor, shown with carbon paper as the plate and zeolite slurry as the porous structure. Potassium chloride was used as the electrolyte.

\section{Low-cost carbon electrode}

As stated, electrodes need to be conductive and have a high surface area for use in EDLCs. Carbon-based materials display both of these properties whilst also being abundant in nature, making them cheap to acquire and it has been shown that they can be used to fabricate workable supercapacitor electrodes. Carbon can be obtained from a variety of different sources including polymers, biomass, and minerals. In this work, PAN, carbon black, carbon paper, carbon cloth and carbon felt were the different types of carbon used. 
PAN was used to form carbon nanofibres, a conductive mesh of fibres with diameters on the order of nanometres, yielding a high surface area-to-volume ratio. Carbon black has a lower surface area than nanofibres or activated carbon but is conductive and formed as a waste product of incomplete combustion. Carbon paper, cloth, and felt are sheets of different texture with relatively low surface areas, instead providing a convenient flat surface for electrode construction.

\section{Safe, cheap salt water}

Aqueous solutions have superior qualities for use in an EDLC with carbon electrodes. They reliably give higher capacitance values than organic electrolytes for the same electrode and can be prepared and handled on the benchtop, which made the construction of supercapacitor cells trivially easy.

Sodium chloride was initially considered as the salt for electrolytic use, due to it being a common commodity and a large component of seawater ${ }^{[109]}$ and constant manufacture, but potassium chloride was instead chosen. This is because of the similarity in sizes between the hydrated potassium and chloride ions (Ionic diameters given as $\mathrm{K}^{+}: 3.31 \AA \mathrm{Cl}^{-}: 3.32 \AA, \mathrm{Na}^{+}: 3.58 \AA$ ), as well as conductivity and mobility, [59] [110] allowing the same zeolitic structure to be used for both electrodes in the construction of a symmetric EDLC. Potassium ions have also been found to yield higher capacitance values than sodium ions when used in the same system, with increased conductivity of $\mathrm{K}^{+}$compared to $\mathrm{Na}^{+}$. ${ }^{[111]}$

\section{Zeolites for charge retention}

Zeolites are naturally occurring hydrated aluminosilicate frameworks, with pore sizes typically ranging from 3 to $10 \AA$, depending on the structure. ${ }^{[112]}$ This means that small-pore zeolite structures would be well suited to accommodate hydrated $\mathrm{K}^{+}$and $\mathrm{Cl}^{-}$. Among the 200 + framework types of discovered zeolite structures, three examples of small-pore zeolite frameworks (BIK, LTA, and MON) are shown in fig. 8 as they are able to accommodate maximum spherical particles of $4.17,4.21$, and $4.24 \AA$ respectively. ${ }^{[113]}$ The LTA structure is commonly available as molecular sieves and provides an appropriate size for the chosen $3.3 \AA$ ions. ${ }^{[114]}$ 


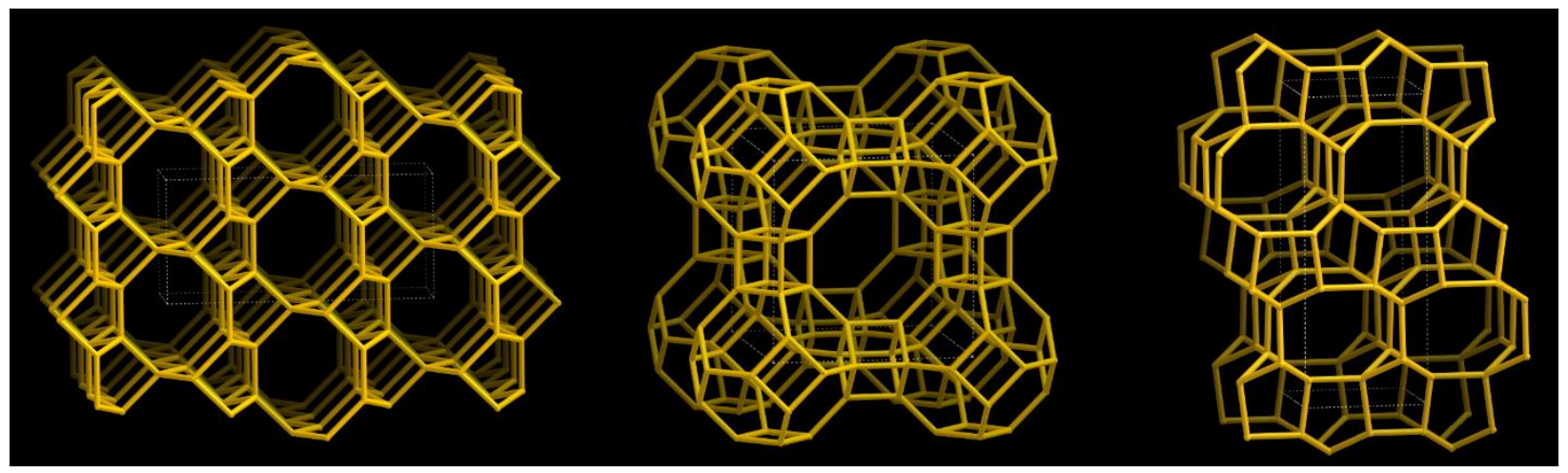

Figure 8: From left to right, framework images of BIK, LTA, MON zeolite structures. ${ }^{[113]}$

As zeolites are found in nature, they are one of the cheapest porous materials available, making them a great candidate for use in a low-cost supercapacitor. Manmade zeolites have been synthesised, however, allowing for greater customisation in structure and pore size. [115] The synthesis of zeolite nanoparticles often involves using organic templates for the zeolite growth, and most procedures involve high temperatures to combine alumina- and silica-containing compounds, but a few room temperature procedures have been reported. ${ }^{[116][117][118]}$ Valtchev et al. achieved a yield of around $83 \%$ in their room temperature synthesis without the assistance of organic components. They investigated the process time and quality of various composition ratios of the form $x \mathrm{Na}_{2} \mathrm{O} / y \mathrm{Al}_{2} \mathrm{O}_{3} / 1 \mathrm{SiO}_{2} / z \mathrm{H}_{2} \mathrm{O}$ with $x=3-8, y=0.4-0.55$, and $z=80-150$, and found that $x=6, y=0.55$, and $z=80-150$ formed zeolite nanoparticles in the shortest time. ${ }^{[116]}$

The LTA framework was chosen to be used with the carbon electrodes, in the form of $4 \AA$ molecular sieves, due to their availability. These are a synthetic zeolite, that have pores purged by heat and a carrier gas to remove cation impurities via a regeneration process by the supplier.

\section{Methods and materials}

With so much potential development in the supercapacitor field and many options for electrode material and electrolyte solutions, clear comparison between novel materials is crucial. Unfortunately, characterisation of supercapacitor components is not well standardised. Along with differences in electrode and electrolyte, variable voltage windows, different rates of charging, different times of charging, and different test configurations are all too common in literature. This was highlighted in an excellent paper by Stoller and Ruoff ${ }^{[119]}$ that attempted to establish a "best practice" for characterisation of supercapacitor electrodes. 
To incorporate the zeolite into the carbon electrodes, three methods were attempted: electrospinning, electrodeposition, and doctor blading. As will be mentioned, the slurry approach, via doctor blading, produced high quality electrodes without the need for high temperature or high voltage, and so further characterisation was performed using this method.

\subsection{Cyclic voltammetry}

Measuring the current while increasing the voltage applied to a cell at a certain scan rate, measured in $\mathrm{mV} \mathrm{s}^{-1}$, will generate a cyclic voltammogram (CV). It is called 'cyclic' because at the maximum voltage point, the voltage sweeps back to minimum and generates a curve similar to the shape of that seen in fig. 9 below. Any peaks seen in the curve represent chemical reactions, typically redox reactions, so an ideal EDLC would have a rectangular shape. ${ }^{[120]}$ Capacitance can be calculated as the area within this rectangular shape; essentially the area within the cyclic voltammogram, but as the shape becomes less rectangular, this method becomes less accurate.

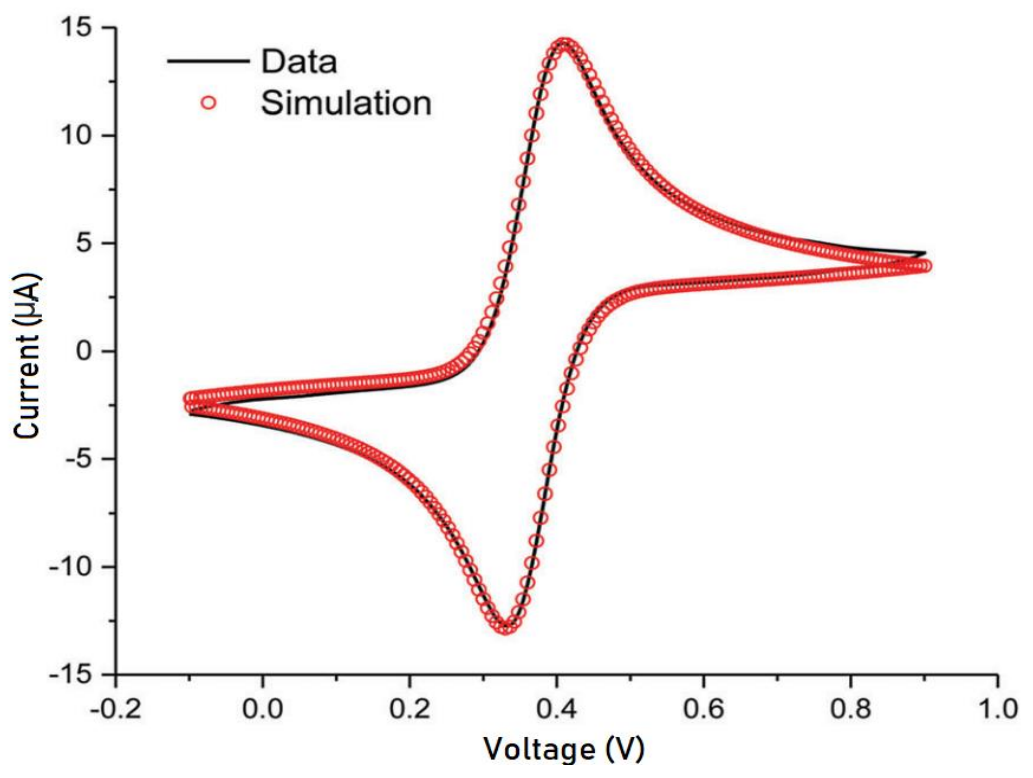

Figure 9: Cyclic voltammogram of $10 \mathrm{mM}$ ferrocene, with peaks at about 0.33 and $0.41 \mathrm{~V}{ }^{[121]}$

CVs can be obtained from two- or three-electrode cell setups as shown in fig. 10. A threeelectrode cell is often more common and is called such due to the presence of a reference electrode, working electrode, and counter electrode, all suspended in an electrolyte solution. The working electrode is the sample material being measured and the reference electrode is the potential reference to which voltage is measured from. This voltage reference is stabilised using 
a counter electrode, which acts as the anode/cathode for the working electrode as needed, minimising the amount of current that passes through the reference electrode.
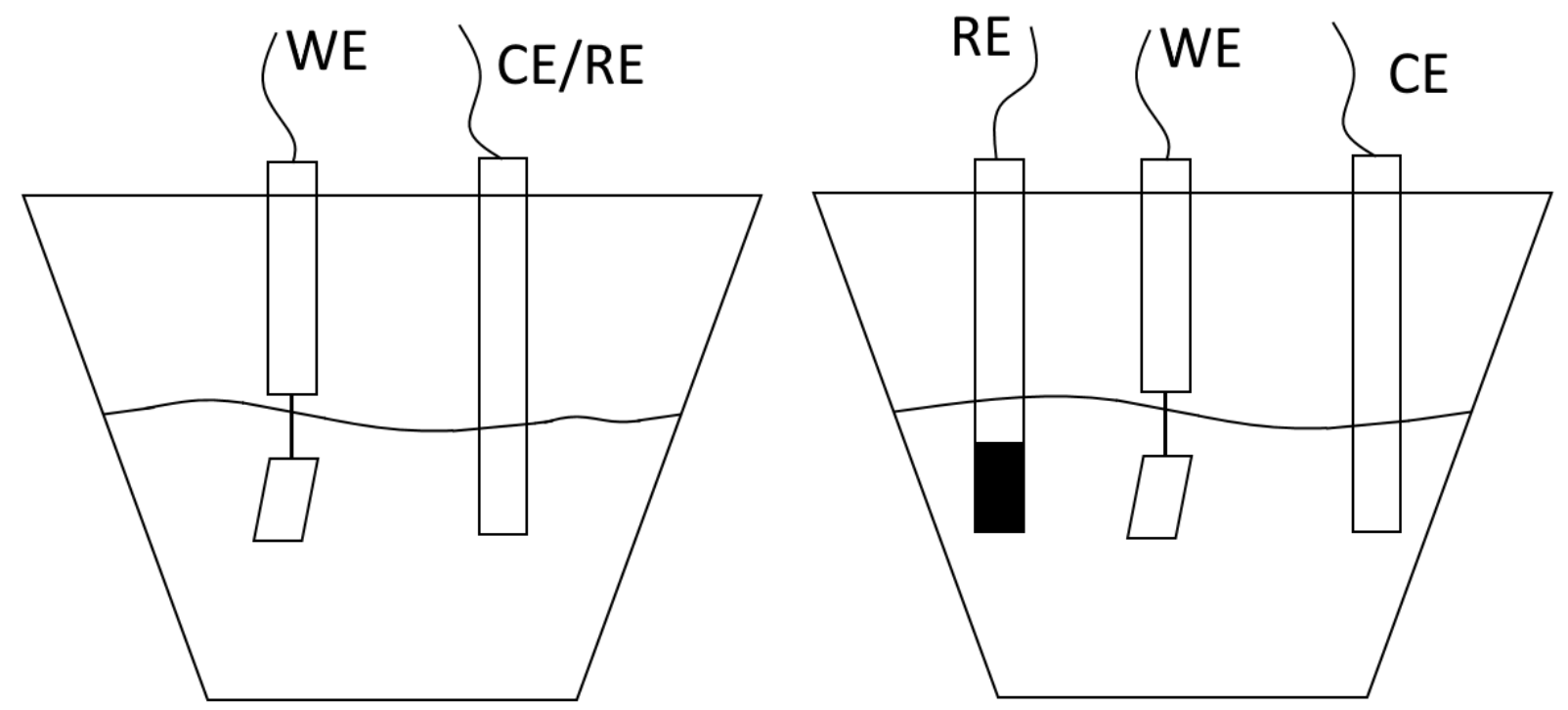

Figure 10: Schematic showing a two-electrode cell (left) and a three-electrode cell (right), where WE is working electrode, RE is reference electrode, and CE is counter electrode.

A two-electrode system has the same components, but effectively combines the counter and reference electrode into one electrode by having current flow through the reference electrode. This system better reflects the real-life situation of electrodes in a supercapacitor cell, since it uses two electrodes. Despite the two- and three-electrode systems sharing so many design similarities, the slight change in design means that the voltage shown on a CV for the threeelectrode cell is double that of the two-electrode cell, leading to different values being obtained from each one, even when using the same material. ${ }^{[119] ~[122] ~}$

Electrodes constructed of a composite material containing 20 wt\% carbon nanotubes and 80 wt\% conducting polymers were tested in a two-electrode cell and a three-electrode cell under the same conditions. When the conducting polymer was polypyyrole, the three-electrode cell measured capacitance to be $506 \mathrm{~F} \mathrm{~g}^{-1}$ compared with a value less than half as much for the twoelectrode cell of $192 \mathrm{~F} \mathrm{~g}^{-1}$. Similarly, with polyaniline (PANI), the three-electrode cell exhibited a capacitance of around double: $670 \mathrm{~F} \mathrm{~g}^{-1}$ as opposed to $344 \mathrm{~F} \mathrm{~g}^{-1}$. [122] 
This mismatch introduces serious inaccuracies into reported work. Simply by using a different test configuration, capacitance values could be reported as double that which would be exhibited by a real supercapacitor system. Stoller and Ruoff note that a three-electrode cell is useful for observing Faradaic reactions but suggest using a two-electrode cell to report capacitance as it better reflects the actual energy storage performance of a material intended for use in a supercapacitor. ${ }^{[119]}$

A two-electrode cell was used to perform cyclic voltammetry measurements in a $3 \mathrm{M} \mathrm{KCl}$ electrolyte. The reference/counter electrode was platinum mesh and the working electrode was the sample being measured. Small pieces of molybdenum were used to sandwich the electrode to prevent the crocodile clips tearing the electrode but were not immersed in the electrolyte. An Metrohm Autolab potentiostat was used to record current over a voltage range of 0.2 to $1.2 \mathrm{~V}$ on the Nova software. Current was reported as specific areal current $\left(A \mathrm{~cm}^{-2}\right)$ to allow for comparison between differently sized electrodes.

\subsection{Charge-discharge curves}

A galvanostatic charge-discharge curve $(C D C)$ can be obtained by charging and then discharging a cell at a constant current rate, measured in $\mathrm{A} \mathrm{g}^{-1}$. This reflects how a cell would perform in practical use, if a constant current was used for the entire discharge, and is stated to be the accepted measure of capacitance. ${ }^{[119]}$ Capacitance can be calculated from the discharge curve using equation 2 , where $C$ is cell capacitance $(F), I$ is the applied current $(A)$, and $d V / d t$ is the slope of the discharge curve $\left(\mathrm{V} \mathrm{s}^{-1}\right)$.

$$
C=\frac{2 I}{d V / d t}
$$

This is the capacitance of the whole cell, with the ' 2 ' multiplier used to account for the halved voltage due to use of a two-electrode cell. This can be converted to specific capacitance of a single electrode using equation 3 , with $\mathrm{C}_{\mathrm{sp}}$ as specific capacitance in $\mathrm{F} \mathrm{g}^{-1}$, and $\mathrm{m}$ as mass in $\mathrm{g}$. This time, there is a multiplication of 2 to separate the cell capacitance into individual electrode capacitance. ${ }^{[119]}[123][124]$ 


$$
C_{s p}=\frac{2 C}{m}
$$

Stoller and Ruoff advise to take the slope of the discharge curve between $V_{\max }$ and $V_{1 / 2}$ as this is representative of the voltage window that will typically be used for supercapacitor application, but the excellent stability of supercapacitors means they can be fully discharged with little degradation, affording a lower minimum voltage value to be chosen. ${ }^{[125]}$

Using these supercapacitor cells, data for charge-discharge curves were obtained by connecting the polyether ether ketone (PEEK) cells to a Neware Battery Testing Station and voltage/current was controlled by their software. Prior to data collection, a premeasurement cycle was performed to flush the electrodes with electrolyte and ions ${ }^{[126]}$ which involved a short, 10 -cycle charge-discharge process between 0.1-1.1 V. Cells were typically cycled between 0.2 and $1.2 \mathrm{~V}$ at a constant current of $0.5 \mathrm{~A} \mathrm{~g}^{-1}$, but other voltage ranges and charging currents were investigated. A charge rate of $0.5 \mathrm{~A} \mathrm{~g}^{-1}$ gave a charge/discharge time that would be realistic for actual supercapacitor use with the slurry coated electrodes, but this was found to be too high of a charge rate for the uncoated carbon paper electrodes. Instead, they were cycled with a current of $0.1 \mathrm{~A} \mathrm{~g}^{-1}$.

Lifetime and stability are important parameters for supercapacitor electrodes, and so cells were cycled for a number of different charge-discharge cycles, including 10, 1000, 5000, and 10000. Capacitance was calculated from the discharge curve of the charge-discharge curves, using equation 2.

\subsection{Charge retention}

As previously mentioned, charge retention is not extensively reported in literature as a standard parameter of EDLCs. This is surprising, as it is an important factor to consider for an electrode material and overall supercapacitor design. One noted discrepancy in charge retention tests is the amount of time that a cell is charged for, before being left to self-discharge. A longer charge time means that charges on the electrode surface are able to redistribute themselves during the charging phase, rather than instantly after current has stopped being applied. While this 
approach is beneficial to the reduction of self-discharge, it does not accurately reflect how a reallife system would be charged in practical application, where charge time may be minimal. [108] [54]

To measure how well the slurry coating improved charge retention of the electrodes, cells were charged up to $1.2 \mathrm{~V}$ using the same charge current as for CDC tests, but instead of being discharged at the same current upon reaching $1.2 \mathrm{~V}$, the cell was left in its charged state while still measuring voltage continuously. This allowed the self-discharge mechanisms to occur and see how this affected cell voltage. Different maximum voltages were explored, as well as changing the charge current. A lower charge current meant that it took longer to fully charge the cell, which allowed the charges to undergo some redistribution and so the effect of this on charge retention could be examined.

\subsection{Gas adsorption}

For materials that exhibit high surface area-to-volume ratios, such as some carbon materials, specific surface area (SSA) is commonly mentioned. This is the total available surface area of a material, measured in $\mathrm{m}^{2} \mathrm{~g}^{-1}$. This value can differ depending on the method used to determine it, but Brunauer-Emmett-Teller (BET) gas adsorption has emerged as the most commonly used technique among supercapacitor electrode materials. ${ }^{[127]}$

BET theory is named after Brunauer, Emmett, and Teller, who proposed it in 1938. ${ }^{[128]}$ It makes use of nitrogen gas adsorption at its boiling point of $77 \mathrm{~K}$, with the assumption that the nitrogen atoms adsorb in a monolayer. Based on pressure differences from the gas adsorbing to the material when temperature is reduced to $77 \mathrm{~K}$, and with the knowledge of the cross-sectional area of one nitrogen atom, specific surface area can be determined. ${ }^{[129][76]}$

Gas adsorption was performed using a Micromeritrics Flowsorb || 2300 gas adsorption machine, shown in fig.11, with voltage reading through a Megger M8057 multimeter. Samples were degassed at $115{ }^{\circ} \mathrm{C}$ for over one hour before measurements were taken to ensure minimal moisture content. Adsorption readings were taken at $77 \mathrm{~K}$ by immersing the sample tube in a liquid nitrogen dewar, while desorption readings were recorded by warming the sample back up to room temperature in water. 


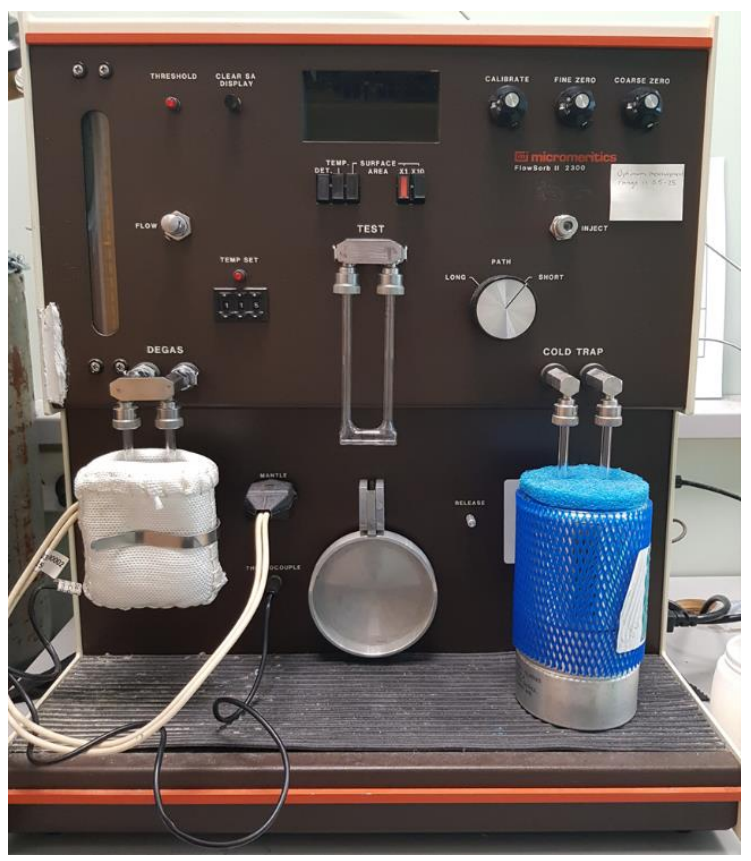

Figure 11: Micromeritrics Flowsorb II 2300 gas adsorption machine used to determine the specific surface area of substances. The heating mantle used for degassing can be seen as the white pouch on the left, and a liquid nitrogen dewar was placed around the right glass tube. The sample was placed in the centre glass tube, with another liquid nitrogen dewar placed around this during measurements.

\subsection{Microscopy techniques}

Advanced microscope techniques now allow for the morphology of nanomaterials to be examined in great detail. [130] Scanning electron microscopy (SEM) can elucidate how homogenous a sample is, or what shape certain features are. The molecular sieves used as the zeolite source in this project have a typical aluminosilicate framework containing sodium, aluminium, silicon, and oxygen. As such, energy-dispersive X-ray spectroscopy (EDS) can be used in tandem with SEM to determine the composition and presence of elements in a sample.

\subsection{Electrospinning}

With the addition of zeolites to a polymer solution, zeolite-embedded carbon nanofibres were produced through the use of electrospinning.

\section{Polymer solution}

To make zeolite-embedded carbon nanofibres, a $12.5 \% \mathrm{w} / \mathrm{w}$ zeolite solution was first made, containing $1.0 \mathrm{~g}$ of polyacrylonitrile $\left(\mathrm{M}_{\mathrm{w}}=150,000 \mathrm{~g} \mathrm{~mol}^{-1}\right)$ and $1.25 \mathrm{~g}$ of $4 \AA$ molecular sieves ( $<50 \mu \mathrm{m}$ powder) dissolved in $10 \mathrm{~mL}$ of dimethylformamide was used. This formed a cloudy 
brown solution that was magnetically stirred overnight and then loaded into a blunt $1.2 \mathrm{~mm}$ diameter syringe for use with the electrospinning setup.

\section{Electrospinning parameters}

Parameters were based on those used by Annamalai et al. ${ }^{[131]}$ for zeolite-templated carbon nanofibres. The loaded syringe was placed into a Harvard PHD 2000 syringe pump which was placed $12 \mathrm{~cm}$ away from a house-built collecting drum, spinning at $70 \mathrm{rpm}$ to align the nanofibres in the same direction. The potential difference of $15 \mathrm{kV}$ was established using a Gamma High Voltage Research high voltage source. The syringe pump was set to a pump rate of $1 \mathrm{~mL} \mathrm{hour}^{-1}$ for a total spin time of 4 hours to produce a white sheet of nanofibres collected on tinfoil wrapped around the collector drum.

\section{Heat treatment}

Following this, the nanofibrous sheet underwent a heat treatment to form carbon nanofibres. The first step was heating at a rate of $1{ }^{\circ} \mathrm{C} \mathrm{min}^{-1}$ up to a final temperature of $220^{\circ} \mathrm{C}$ for one hour in air to stabilise the fibres. For this step, the nanofibrous sheet was placed between two Teflon sheets to keep them flat and prevent curling up and resulted in the white nanofibres turning brown. The second step involved heating the stabilized fibres up to $1100{ }^{\circ} \mathrm{C}$ at a maximum rate of $5{ }^{\circ} \mathrm{C} \mathrm{min}^{-1}$ in a nitrogen atmosphere, producing brittle, black carbon nanofibres. This process is shown below in fig. 12 to illustrate the appearance of the nanofibre sheet following each step. Instrument-specific constraints meant that it was necessary to hold the temperature at several different points before reaching $1100^{\circ} \mathrm{C}$, and so a full heat protocol can be found in the appendix.

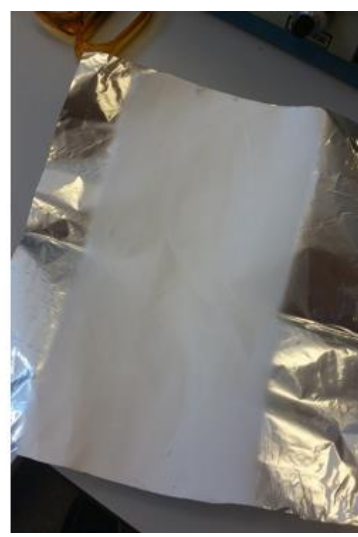

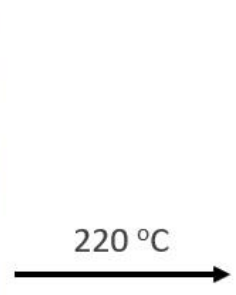

In air

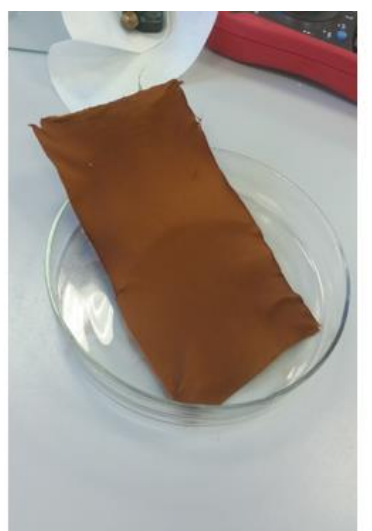

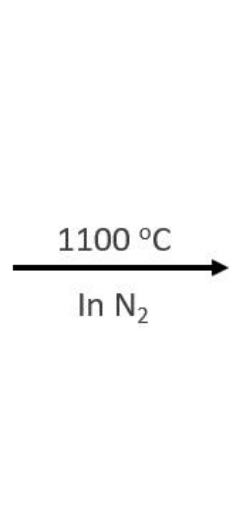

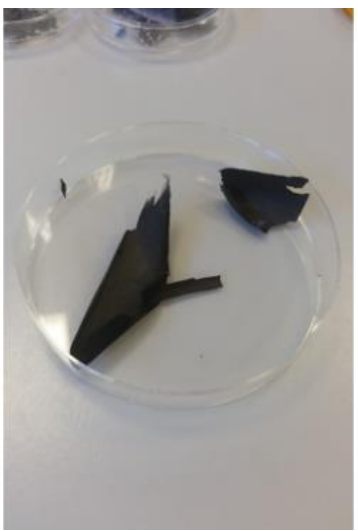

Figure 12: Appearance of carbon nanofibres during the heat treatment process 


\subsection{Electrophoretic deposition}

Based on a method outlined in the work of Ahlers and Talbot, ${ }^{[132]}$ a $200 \mathrm{~mL}$ solution was prepared with $4 \mathrm{~g} \mathrm{~L}^{-1}$ concentration of molecular sieves in a $1 \times 10^{-3} \mathrm{M}$ solution of $\mathrm{Mg}\left(\mathrm{NO}_{3}\right)_{2}$ dissolved in isopropyl alcohol (IPA). A platinum mesh electrode was placed between two Teflon sheets at the bottom of the solution as the anode, and a carbon nanofibre sample was suspended $3.2 \mathrm{~cm}$ above this which acted as the cathode. Using the same high-voltage source used for electrospinning, $200 \mathrm{~V}$ were applied for 12 seconds to deposit the zeolite onto the electrode surface. The coated nanofibre sheet was then left to dry on the benchtop to evaporate any remaining IPA.

\subsection{Slurry preparation}

A 70 wt\% slurry solution was prepared by adding $\mathrm{N}$-methyl-2-pyrrolidone (NMP) dropwise until it completely dissolved $0.05 \mathrm{~g}$ of polyvinylidene fluoride (PVDF) $\left(600,000 \mathrm{~g} \mathrm{~mol}^{-1}\right)$. This was found to be about $2 \mathrm{~mL}$. To this solution, $0.1 \mathrm{~g}$ of carbon black (Super P) and $0.35 \mathrm{~g}$ of $4 \AA$ molecular sieves were added, which formed a viscous black slurry that was left magnetically stirring overnight. The ratio of slurry components was based on a similar slurry formed by Wang et al. [133]

Out of the three methods for zeolite attachment of electrospinning, electrophoretic deposition, and slurry preparation, slurry preparation was the one that required minimal processing steps and had no energy intensive steps, so different weight loadings of zeolite were explored and used for subsequent electrochemical characterisation.

All produced slurries were applied to a conductive surface using the doctor blade method. This is also known as tape-casting, as the surface is taped down with an exposed central area. Carbon paper was used as the main surface for coating, and typically a $3.5 \times 3.5 \mathrm{~cm}$ square was taped down with a $1.5 \times 1.5 \mathrm{~cm}$ exposed area. Slurry was dropped along the top side of an exposed area and then smoothed over the entire area using a microscope slide. Measurements of specific capacitance already take mass into account, but the height of the tape meant that the slurry thickness was moderately uniform between all electrode samples. The coated surfaces were left to dry at room temperature on the benchtop for 72 hours, until the NMP had evaporated and left a dry, black coating. Some cracking was observed but, in general, the coating was continuous and the electrodes used were taken from areas with no cracking. 
Other carbon sheets were also investigated as conductive surfaces. Carbon cloth and carbon felt electrodes were also prepared in an identical way.

\subsection{Construction of PEEK cells}

Supercapacitor cells were constructed using a custom-made PEEK body casing, as shown in fig. 13 with separator, electrode, and current collector discs having a diameter of $1 \mathrm{~cm}$. 7-8 drops of $3 \mathrm{M} \mathrm{KCl}$ electrolyte was dropped onto two glass micro separator discs (Whatman Glass Microfibre Filters); just enough to fully saturate it. The current collector discs were punched from a $0.1 \mathrm{~mm}$ thick molybdenum sheet, and the entire cell was constructed on the benchtop in open air.

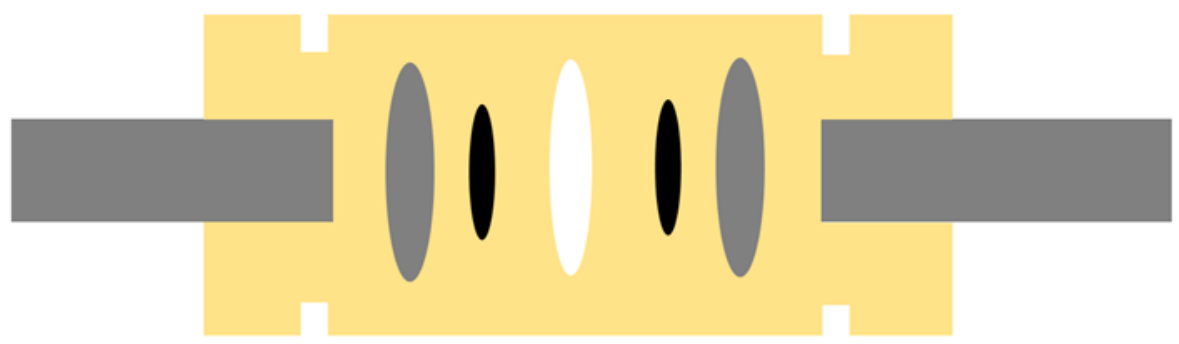

Figure 13: PEEK cell casing with, from left to right, steel rod, molybdenum current collector, sample electrode, glass microfibre separator, sample electrode, molybdenum current collector, and steel rod.

Electrode were punched into $1 \mathrm{~cm}$ diameter circles and their weight varied between sample, but typically had around 1-2 mg of slurry per electrode, on $2.8 \mathrm{mg}$ of carbon paper. The process of constructing a supercapacitor cell from the slurry coated carbon paper is shown in fig. 14. All constructed cells used electrodes as close together in weight as possible and were found to have an open circuit potential of very close to zero volts, due to the symmetric electrodes used.
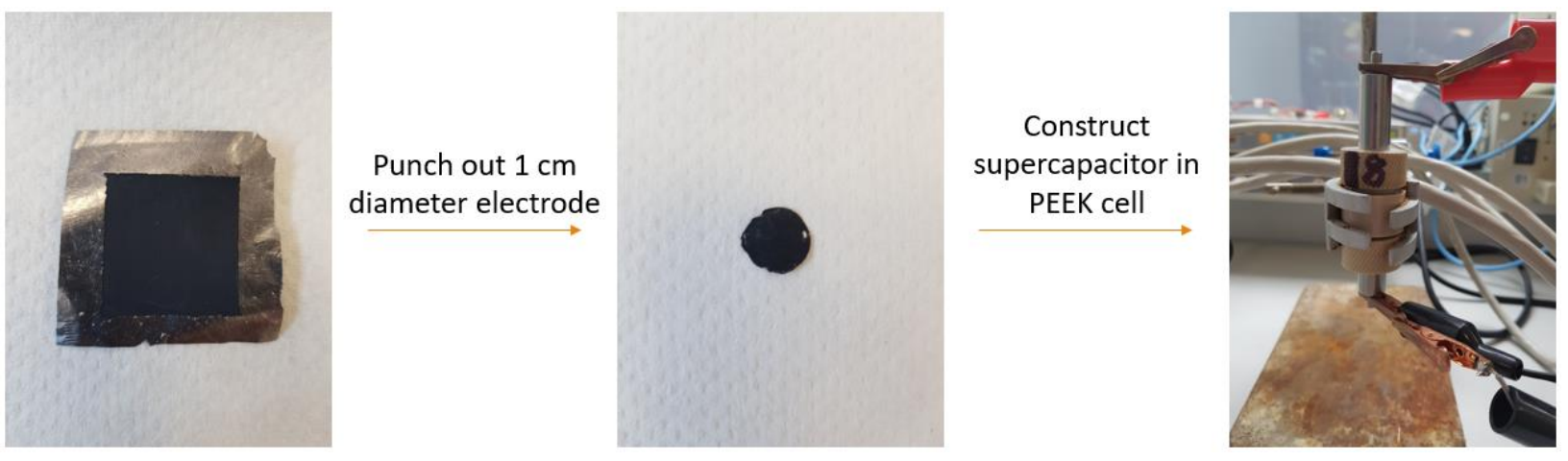

Figure 14: Process from doctor-bladed, slurry-coated electrode after drying (left) to constructed PEEK supercapacitor cell in testing apparatus (right) 


\section{Results and discussion}

\subsection{Zeolite attachment method}

The three different methods of zeolite attachment to carbon nanofibres resulted in macroscopically similar-looking black paper sheets, but SEM analysis shown in fig. 15 revealed slight differences in morphology and zeolite dispersion. 2,000x magnification was chosen to demonstrate the overall sample morphology, while 10,000x magnification provided localised attachment details.

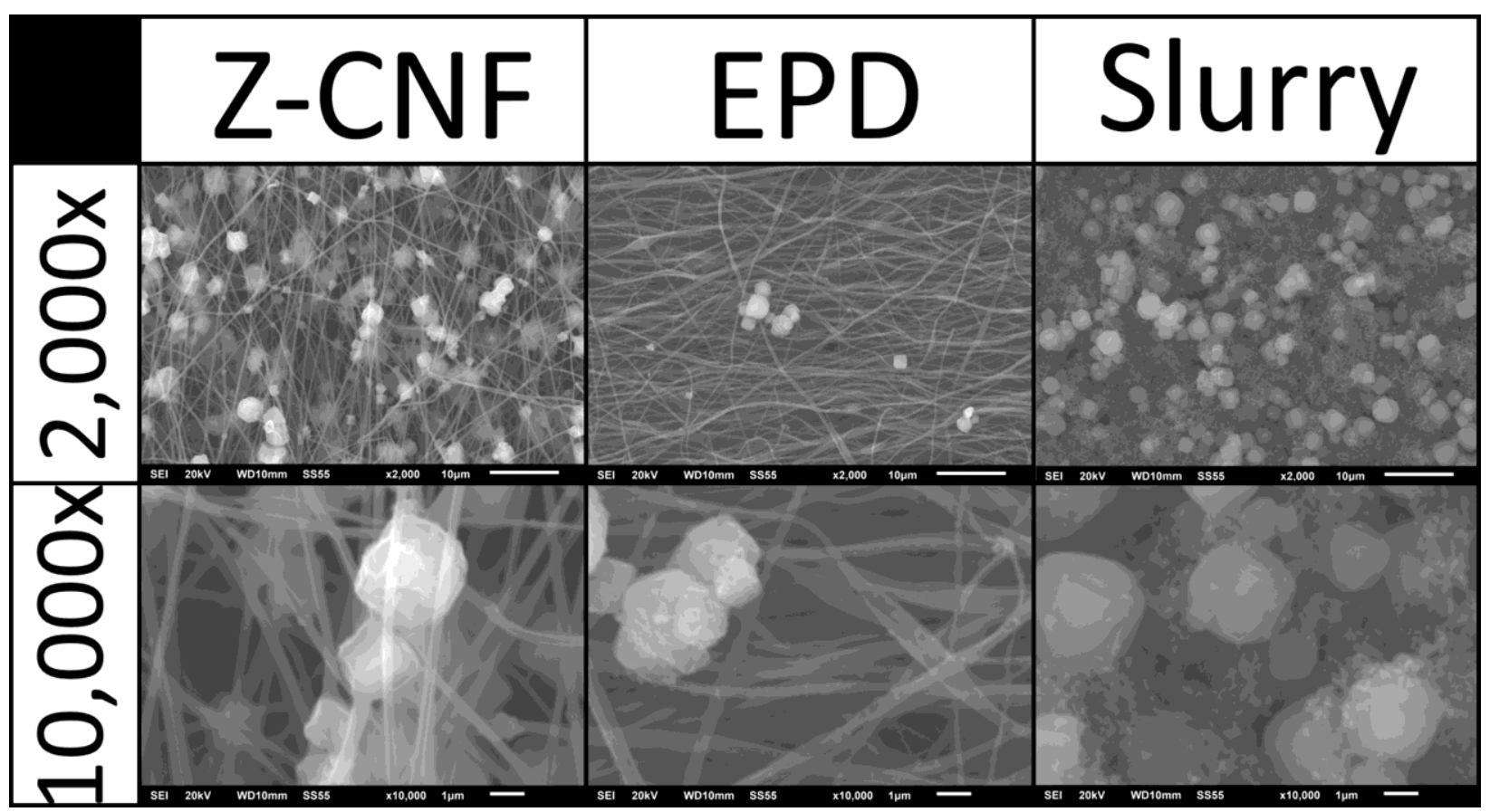

Figure 15: SEM images of zeolite-embedded carbon nanofibes (Z-CNF), electrophoretically deposited zeolite onto carbon nanofibres (EPD), and zeolite-slurry coated carbon nanofibres at 2,000x and $10,000 x$ magnification 


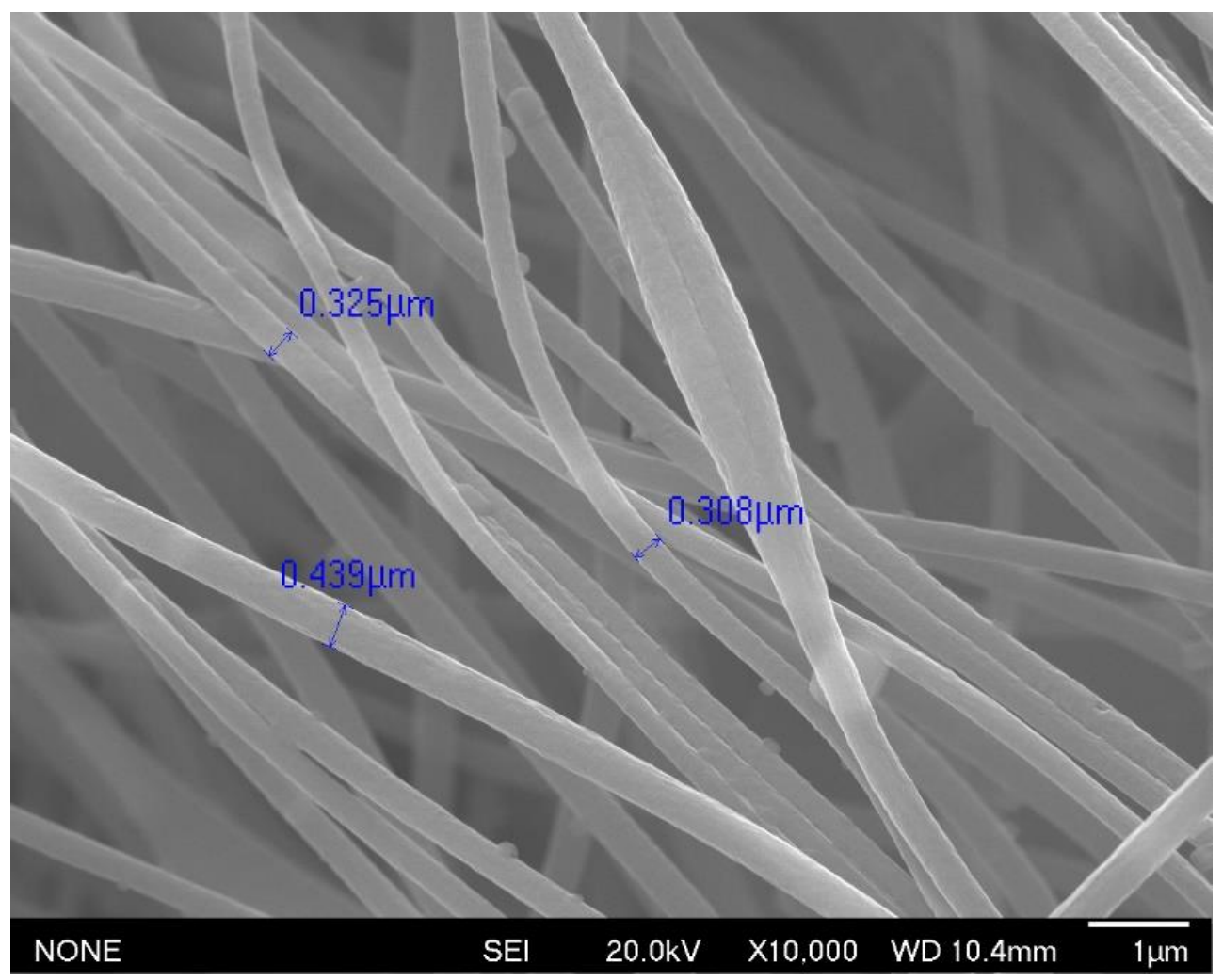

Figure 16: SEM image of pristine carbon nanofibres at 10,000x magnification. Diameter was measured to be between $300-400 \mu \mathrm{m}$

The pristine carbon nanofibres had diameters between 300-500 nm and well-formed long, smooth surfaces, as can be seen in fig. 16. When zeolite was introduced, it appeared as larger, lighter-coloured particles of about 2-3 $\mu \mathrm{m}$, confirmed through EDS measurements. Especially in the zeolite-embedded carbon nanofibre sample, zeolite particles were dispersed throughout fibre strands, which showed good incorporation and overall dispersion. This compared with the electrophoretic deposited zeolite sample, which had very little zeolite coverage. 

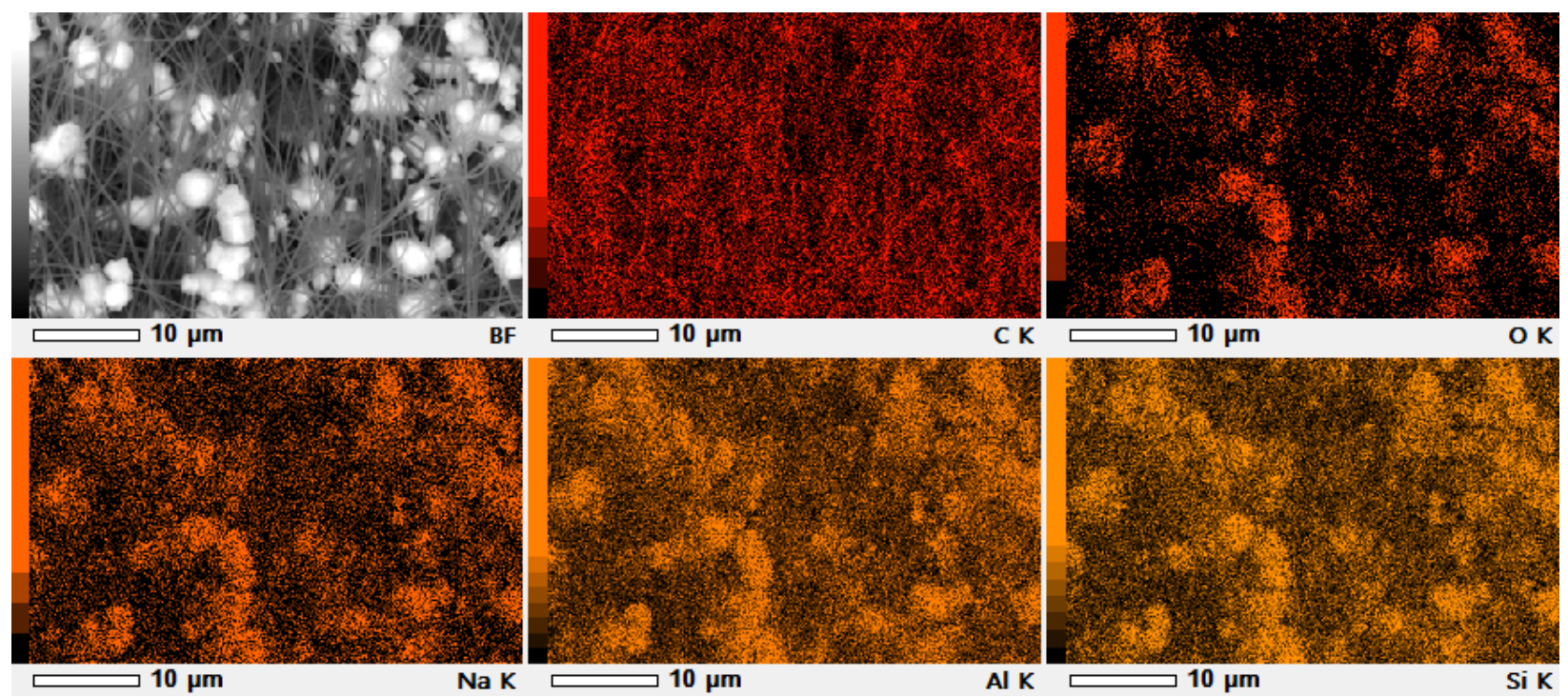

Figure 17: Backscattered image (top-left) and EDS elemental distribution data showing the presence and position of different elements (rest) for zeolite-embedded carbon nanofibres.
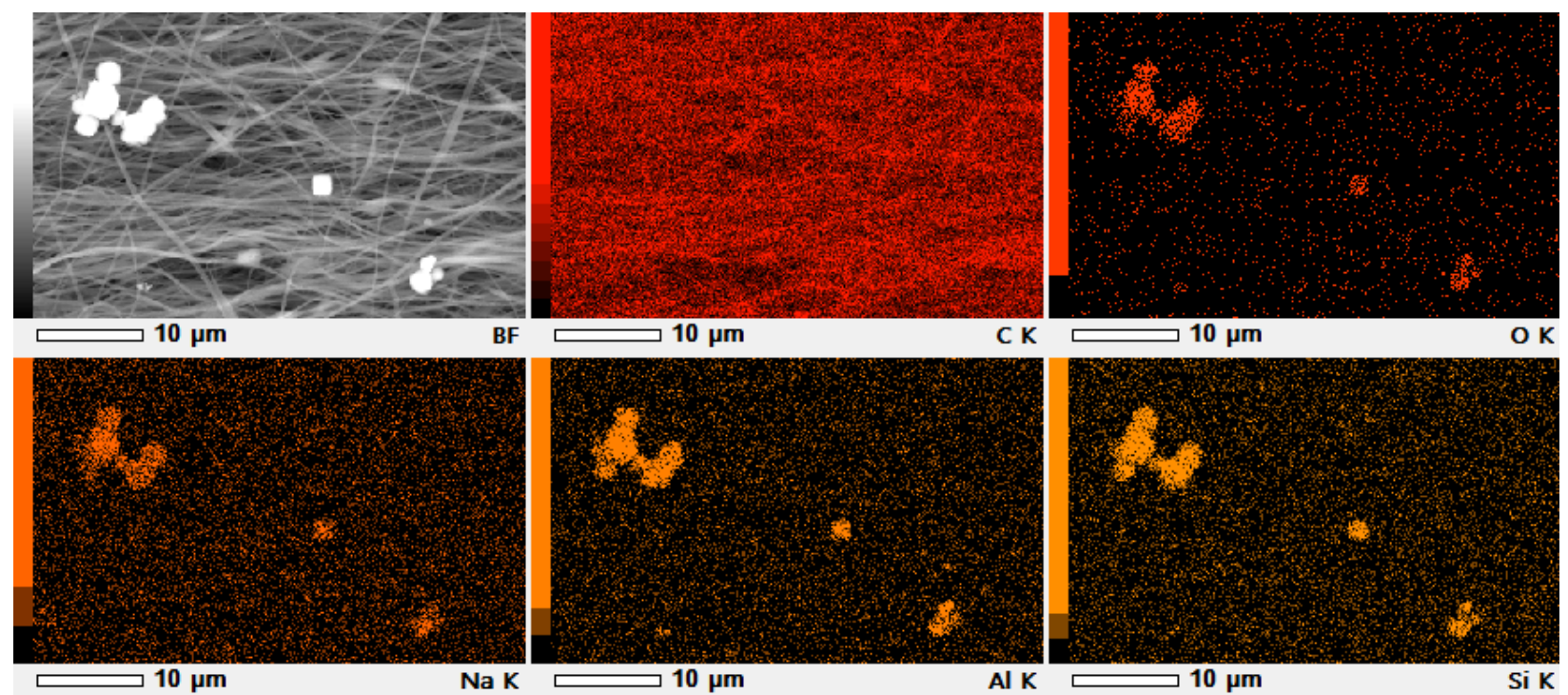

Figure 18: Backscattered image (top-left) and EDS elemental distribution data showing the presence and position of different elements (rest) for the electrophoretic deposition of zeolite onto carbon nanofibres. 

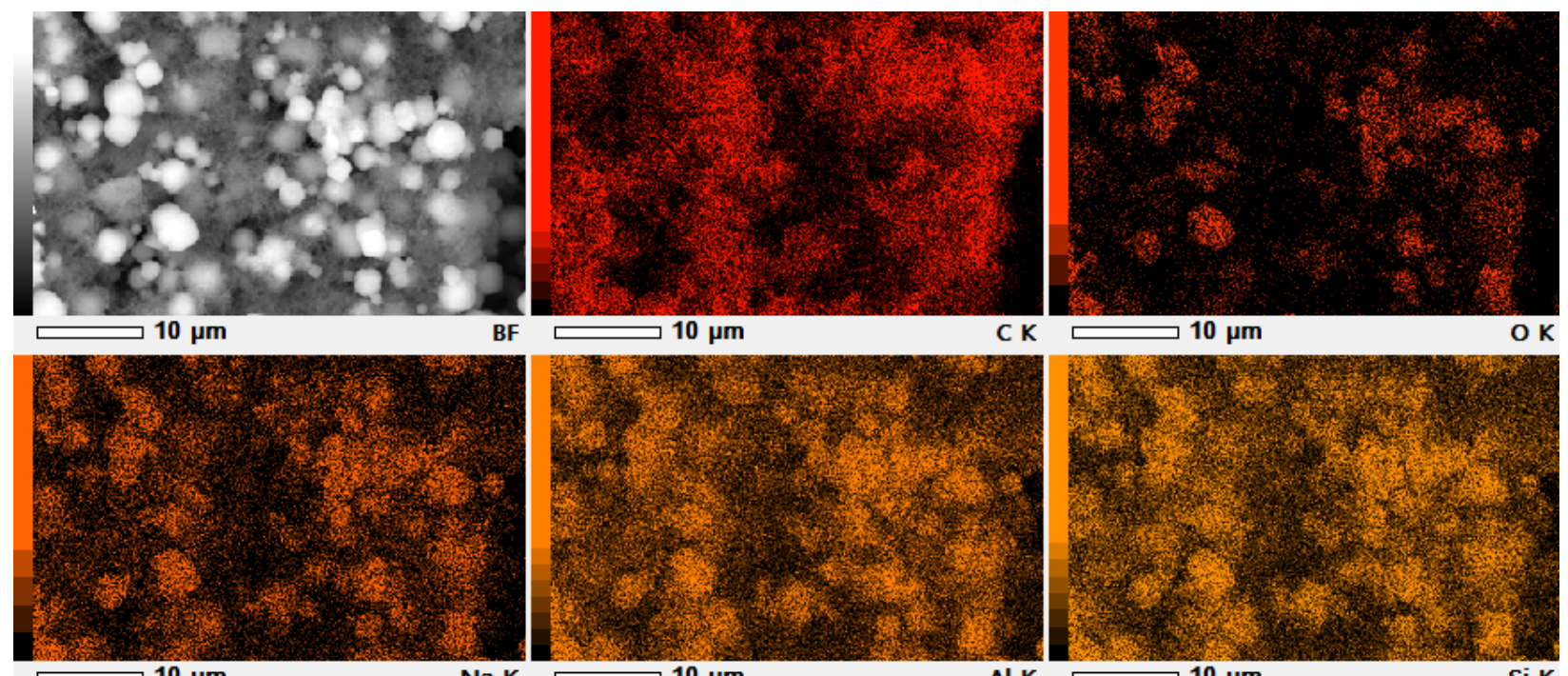

O K

$10 \mu \mathrm{m}$

$\mathrm{Na} \mathrm{K}$

$10 \mu \mathrm{m}$

Al $\mathrm{K}$

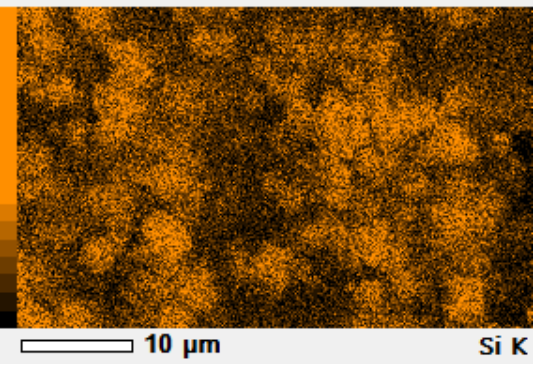

Figure 19: Backscattered image (top-left) and EDS elemental distribution data showing the presence and position of different elements (rest) for the zeolite-slurry coated carbon nanofibres.

The more concentrated areas of colour in the EDS images signified a higher concentration of that particular element and it can be seen that the four elemental constituents were detected in the same position for any particular sample, confirming the zeolites presence as bright white particles in the SEM images. When looking at the images in figs. 17-19, the zeolite-embedded and zeolite-slurry coated carbon nanofibres both showed a wide distribution of zeolite, indicating favourable attachment whereas the electrophoretic deposition method resulted in poor attachment, likely due to the difficulty in electrodepositing an insulting material. Carbon was detected almost everywhere due to the surface of carbon nanofibres.

The slurry coating exhibited good dispersion of zeolite throughout the carbon black/PVDF slurry, but completely covered the carbon nanofibre sheet that it was cast onto. This meant that the slurry coating could be coated on any conductive surface to form a working electrode; not specifically carbon nanofibres. Since the formation of carbon nanofibres involved two separate heating steps, one above $1000^{\circ} \mathrm{C}$, a different surface for slurry application would be preferred to reduce production cost and carbon emission. As such, carbon paper was used as the surface for application and the slurry method of zeolite attachment via doctor blading was subsequently chosen for further investigation. 


\subsection{Weight loadings of slurry}

The slurry formed with a $70 \%$ zeolite loading was based off a literature method ${ }^{[133]}$ and exhibited appropriate viscosity and zeolite coverage, but different weight loadings were also investigated in case further optimisation could be achieved. Slurries containing 60 and 80 wt\% zeolites were also produced, with the added/reduced amount of zeolite being balanced by reducing/adding carbon black; that is, the $60 \%$ slurry contained $0.05 \mathrm{~g}$ of PVDF, $0.15 \mathrm{~g}$ of carbon black, and $0.30 \mathrm{~g}$ of molecular sieves, and the $80 \%$ slurry contained $0.05 \mathrm{~g}$ of PVDF, $0.05 \mathrm{~g}$ of carbon black, and $0.40 \mathrm{~g}$ of molecular sieves. Note that a $0 \%$ slurry solution was also made, to compare how the zeolite addition affected performance, but this did not yield a usable electrode and so uncoated carbon paper was used as a comparison instead. The higher the weight loading of zeolites was, the lower the viscosity of the slurry. These were all doctor bladed onto carbon paper and left to dry, as before.

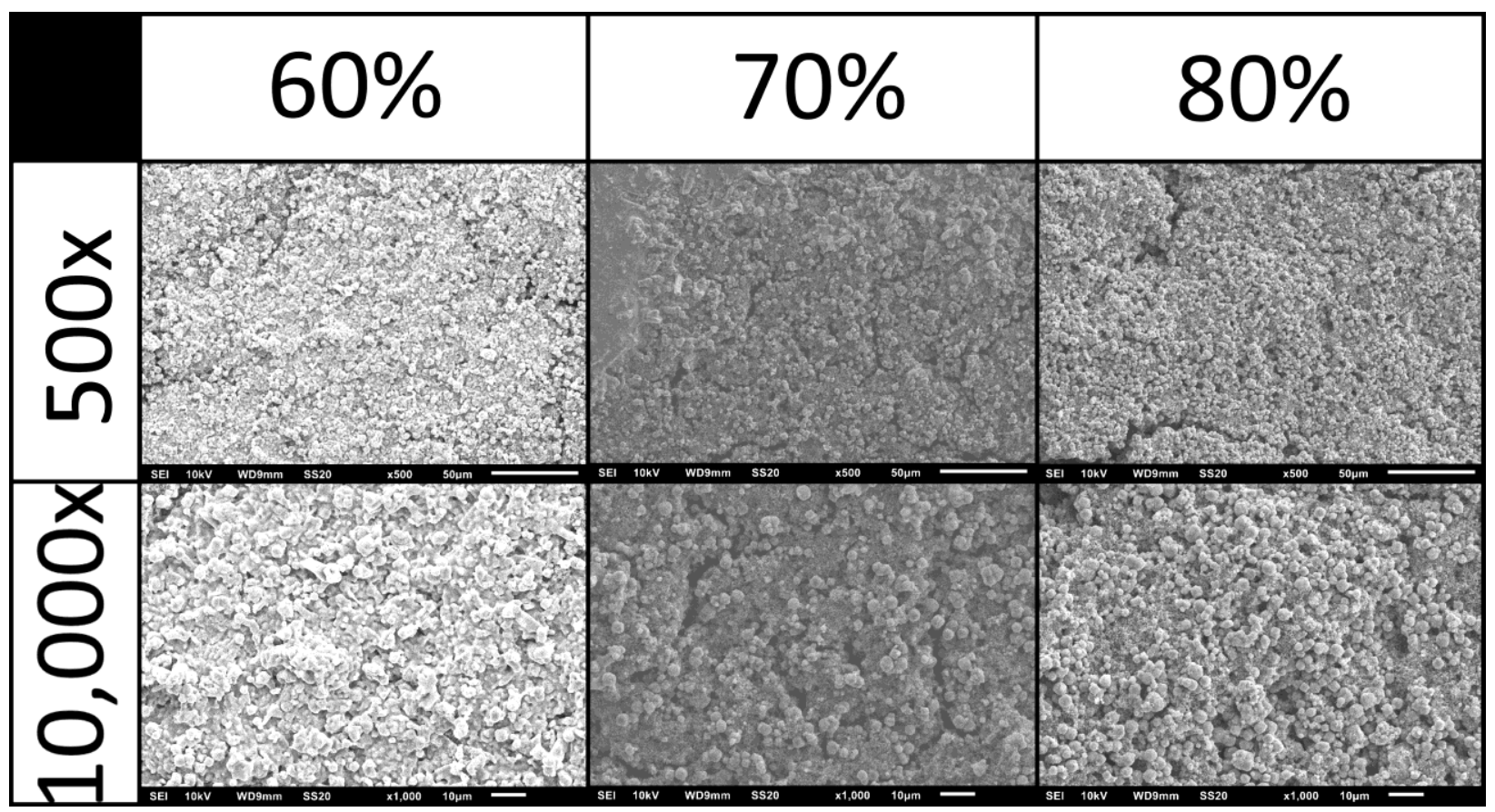

Figure 20: SEM images of the 60,70 , and 80 wt\% zeolite-slurry coated carbon paper samples at $500 x$ and $10,000 x$ magnification

All slurry samples showed coverage of the carbon paper sheet and dispersion of the zeolite particles throughout the coating, as can be seen in fig. 20. As expected, the zeolite dispersion was slightly denser in the $80 \mathrm{wt} \%$ slurry when compared to the other two weight loadings. This 
increased amount of insulating zeolite might have affected the conductance and capacitive properties of the electrode and so cyclic voltammetry was performed on each sample, with the results shown below in fig. 21.
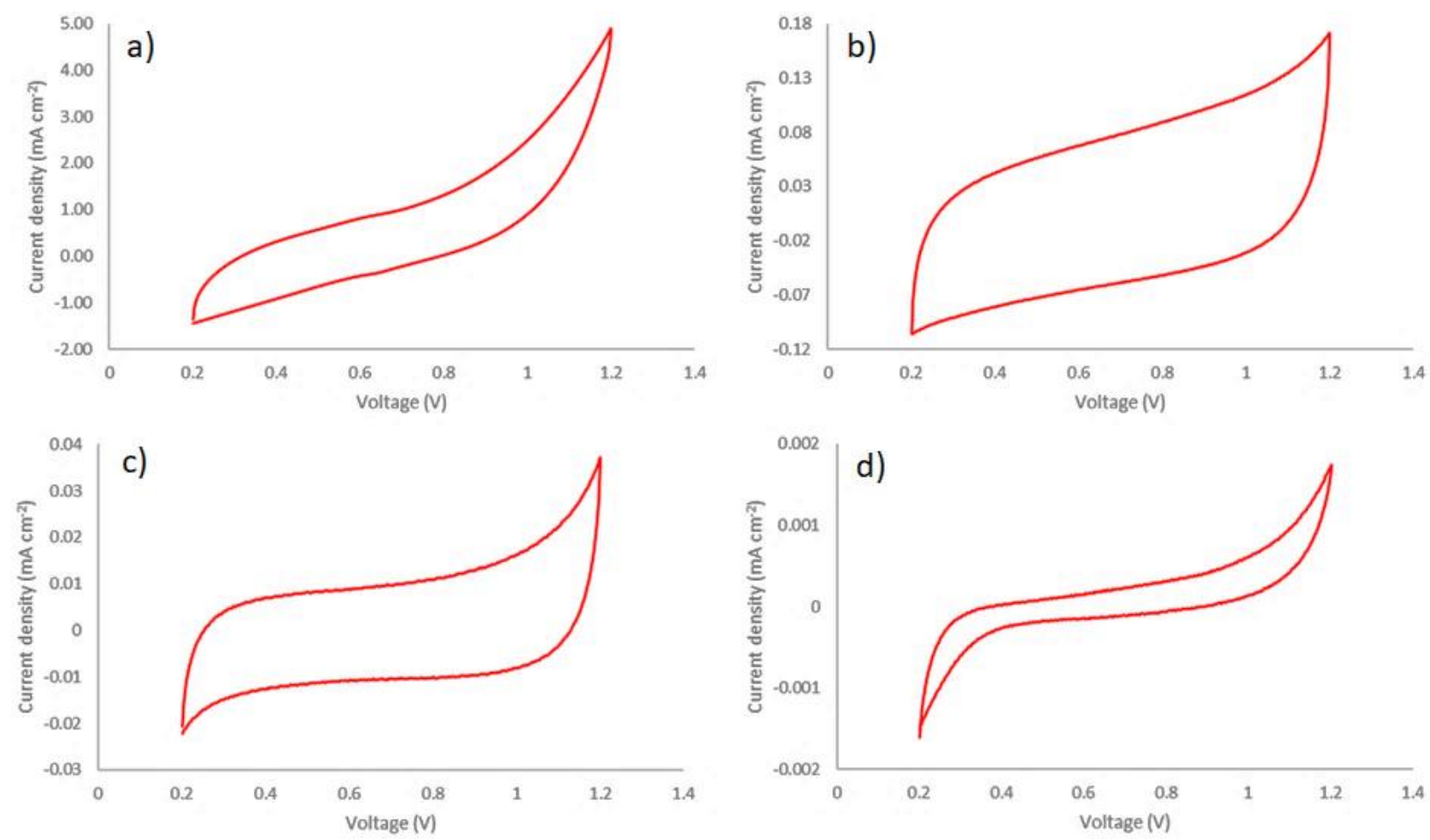

Figure 21: Cyclic voltammograms for a) 60\% zeolite slurry-coated carbon paper (OCV: $0.485 \mathrm{~V}$, electrode area: $0.63 \mathrm{~cm}^{2}$ ), b) $70 \%$ zeolite slurry-coated carbon paper (OCV: $0.351 \mathrm{~V}$, electrode area: $0.64 \mathrm{~cm}^{2}$ ), c) $80 \%$ zeolite slurry-coated carbon paper (OCV: $0.332 \mathrm{~V}$, electrode area: $0.72 \mathrm{~cm}^{2}$ ), and d) carbon paper (OCV: $0.406 \mathrm{~V}$, electrode area: $1.32 \mathrm{~cm}^{2}$ )

As previously mentioned, the shape of the CV plot indicates how much 'ideal' capacitance is exhibited by the electrode; a flatter, more rectangular CV is favourable for supercapacitor electrode materials. It can be seen that increasing the zeolite weighting flattens out the middle part of the cyclic voltammogram, an observation that is pronounced with the $100 \mathrm{mV} \mathrm{s}^{-1}$ scan rate where there is less time for surface reactions to occur compared to the $50 \mathrm{mV} \mathrm{s}^{-1}$ scan rate, data for which can be found in the appendix. Going from $60 \%$ to $70 \%$ (from fig. 21a to fig. 21b) yields a much more rectangular shape, while further zeolite addition from $70 \%$ to $80 \%$ (from fig. $21 \mathrm{~b}$ to fig. 21c) shows a less drastic, but still noticeable flattening, at the cost of lowered current density values. 
The highest current density values were obtained in fig. 21 a with the $60 \%$ slurry, likely due to the higher loading of carbon black. As carbon black amounts decreased, the current density values decreased, down to the lowest in fig. 21d for uncoated carbon paper, where current densities were roughly three orders of magnitude lower than coated samples. This could also be a result of the amount of electrode surface area present, where the slurry coatings provided an increased amount of specific surface area as compared to plain carbon paper.

\subsection{Gas adsorption}

The model of gas adsorption machine used to measure the specific surface area of samples gave the data as a voltage readout on a multimeter for adsorption and desorption. Using the adsorption readout values, the $4 \AA$ molecular sieves were found to have an average specific surface area of $3.28 \mathrm{~m}^{2} \mathrm{~g}^{-1}$ as powder, and then when mixed into the $70 \%$ slurry and coated on carbon paper, this increased to $5.43 \mathrm{~m}^{2} \mathrm{~g}^{-1}$. This increase is likely due to the carbon black additive, as the carbon paper did not provide enough specific surface area to be detected by the machine, but Sakai et al. ${ }^{[134]}$ calculated this to be $0.3 \mathrm{~m}^{2} \mathrm{~g}^{-1}$. Super $\mathrm{P}$ carbon black has been found to have a specific surface area of $\sim 60 \mathrm{~m}^{2} \mathrm{~g}^{-1}$. [135]

These values are for the surface accessible by $N_{2}$ molecules (Molecular diameter of $3.62 \AA$ ) [111] and so it is assumed that the $\mathrm{K}^{+}$and $\mathrm{Cl}^{-}$ions (Hydrated ionic diameter of 3.31 and $3.32 \AA$ respectively) ${ }^{[59]}$ will be able to access a similar surface area.

Since the carbon paper had very little surface area and contributed relatively negligible current density, and therefore capacitance, compared to the overall slurry-coated electrode, it was assumed that the slurry provided all of the electrochemical properties of the measured electrodes. This meant that the applied constant current, measured in $\mathrm{A} \mathrm{g}^{-1}$, could be calculated using the mass of the slurry coating for CDC and charge retention measurements. It would have been interesting to see if slurry thickness affected capacitance, but instead, specific capacitance was reported to account for any difference in slurry loadings.

\subsection{CDC}

PEEK cells were used as described for galvanostatic charge-discharge measurements. Data shown is from one supercapacitor cell, which had electrode masses of 0.75 and $0.91 \mathrm{mg}$, for a total 
electrode mass of $1.66 \mathrm{mg}$. Two other cells were constructed - with total electrode masses of 1.37 and $2.88 \mathrm{mg}$ - and put through identical testing procedures to make sure that the observed data could be reproduced.

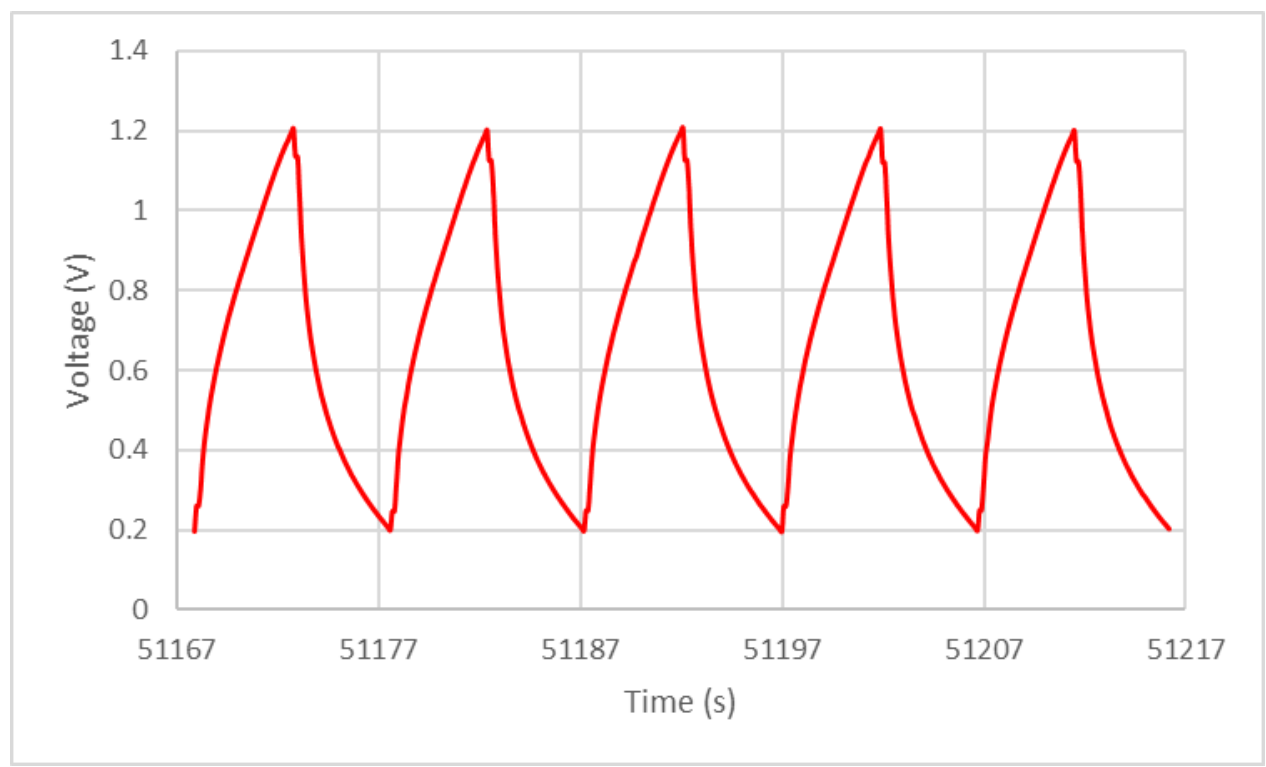

Figure 22: Galvanostatic charge-discharge curves for $\mathbf{7 0 \%}$ zeolite slurry-coated supercapacitor cell, taken from midway through a 5000-cycle procedure, using constant current of $0.5 \mathrm{~A} \mathrm{~g}^{-1}(0.83 \mathrm{~mA})$

CDC measurements for the supercapacitor cells with zeolite slurry-coated electrodes showed favourable performance. As demonstrated in fig. 22, a symmetric, triangular shape in the chargedischarge curve is characteristic of a double-layer formation and capacitive properties while the consistent spacing between peaks is indicative of high stability. Specific capacitance was calculated as the average value from a 1000-cycle run using the discharge portion of the curve with equations 2 and 3 and was found to be $17.25 \mathrm{~F} \mathrm{~g}^{-1}$.

Several thousand charge-discharge cycles were performed, including a 5000-cycle run and a 10,000 -cycle run, and it was found that the capacitance dropped over the course of the cycling procedures. After over 18,000 charge-discharge cycles at $0.5 \mathrm{~A} \mathrm{~g}^{-1}$, the capacitance was calculated as $10.16 \mathrm{~F} \mathrm{~g}^{-1}$. This meant that if the supercapacitor cell was charged and discharged once per day for half a century, almost $60 \%$ of its capacitance would be retained. This is reflected in the high coulombic efficiency on the device, shown in fig. 23. 


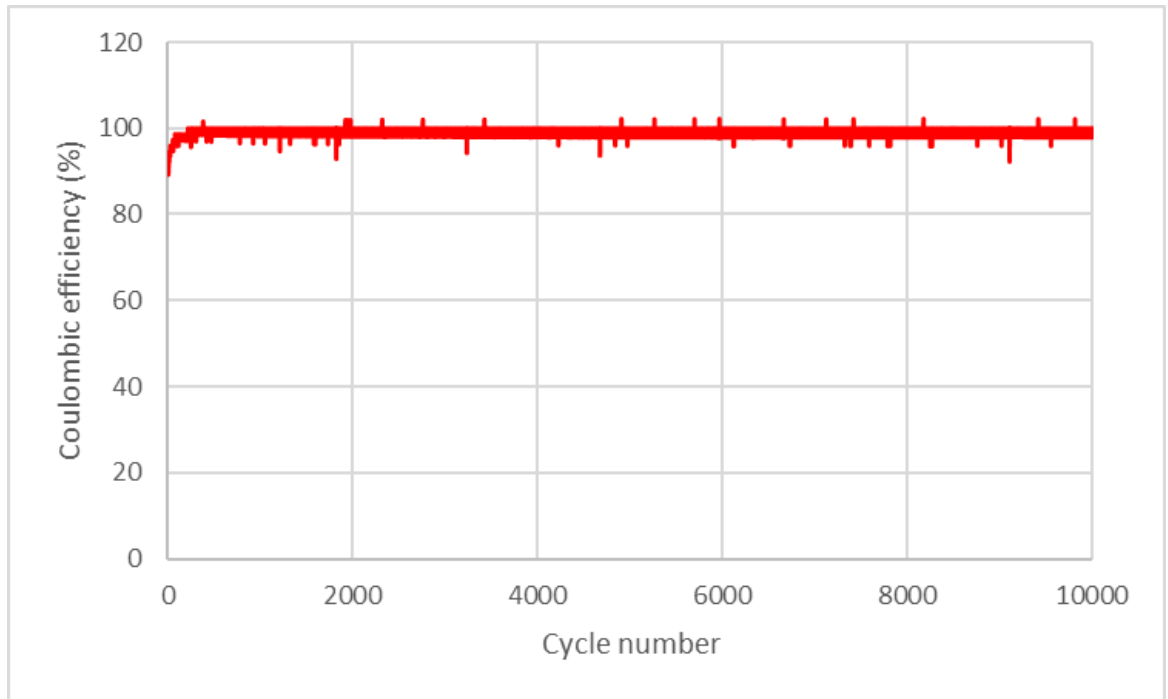

Figure 23: Coulombic efficiency for 10000 charge-discharge cycles at a constant current of $0.5 \mathrm{~A} \mathrm{~g}^{-1}$ (0.83 mA). Note this procedure was performed after over 15,000 previous charge-discharge cycles.

The high coulombic efficiency showed that there was minimal charge lost to Faradaic processes, likely affected by the $1 \mathrm{~V}$ charge window used. Aqueous electrolytes require a smaller voltage window than other electrolytes, as stated, as they often break down beyond much more than 1.2 V. Staying below this point aided in the coulombic efficiency of the cell and allowed it to remain at $100 \%$.

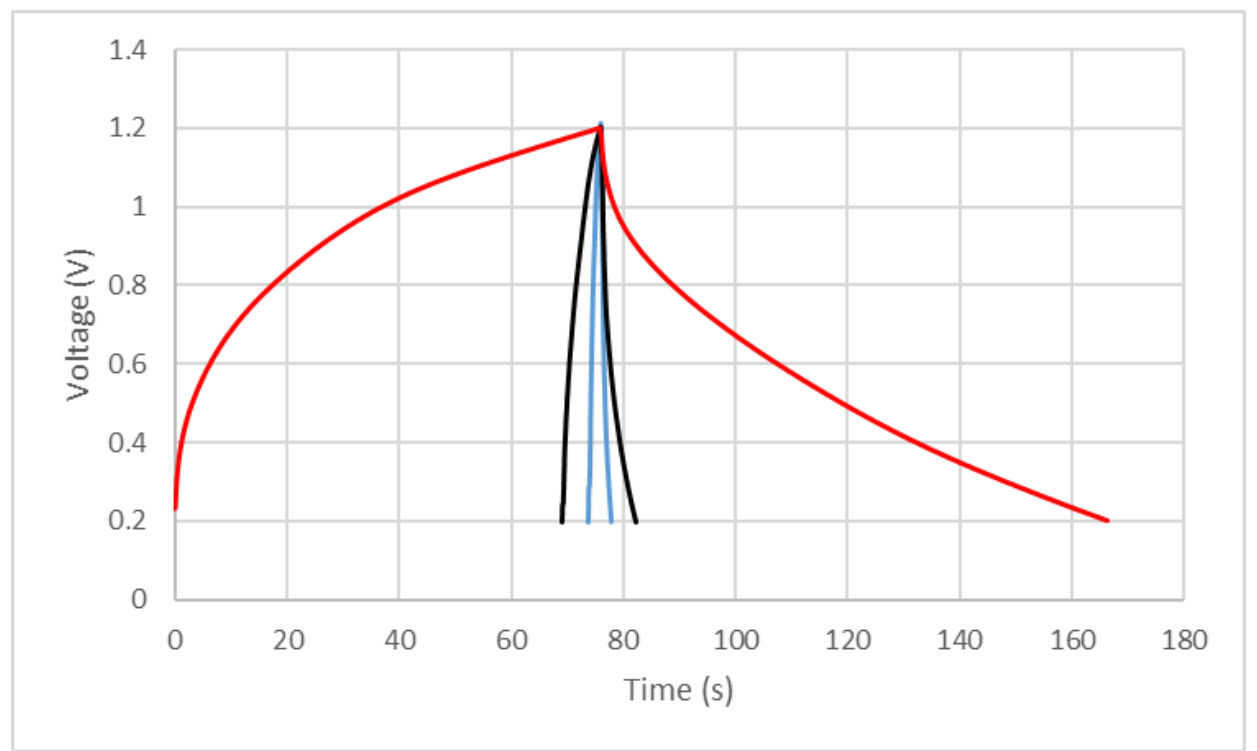

Figure 24: Galvanostatic charge-discharge curves for $70 \%$ zeolite slurry-coated supercapacitor cell, using a constant current of $0.1 \mathrm{~A} \mathrm{~g}^{-1}$ (red), $0.5 \mathrm{~A} \mathrm{~g}^{-1}$ (black), $1.0 \mathrm{~A} \mathrm{~g}^{-1}$ (blue). 
The constant current affected the time it took for the supercapacitor cell to fully charge and discharge. It can be seen from fig. 24 that a higher applied current drastically reduces the time taken for a complete cycle. A lower current of $0.01 \mathrm{~A} \mathrm{~g}^{-1}$ and higher currents of 2.0 and $5.0 \mathrm{~A} \mathrm{~g}^{-1}$ were also performed, but were much too slow and too fast, respectively, to be represented in detail on the same scale and the other current rates. The same symmetric triangular shape was observed, regardless of current rate, which showed that the cell could be operated at a range of rates of charging. This was unlike the uncoated carbon paper supercapacitor cell, which only displayed controlled, capacitive behaviour at $0.1 \mathrm{~A} \mathrm{~g}^{-1}$, severely limiting potential experiments and application.

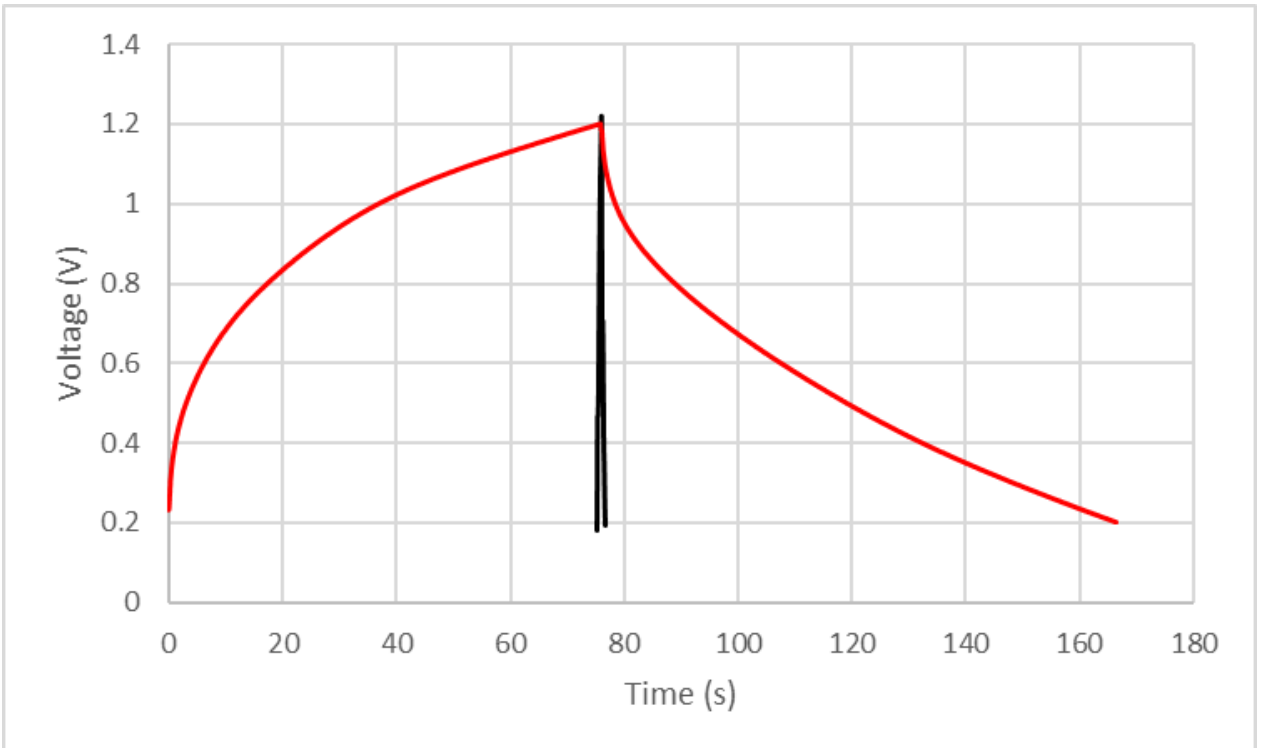

Figure 25: Comparison between the galvanostatic charge-discharge curves of $70 \%$ zeolite slurry-coated supercapacitor cell (red) and uncoated carbon paper supercapacitor cell (black) at the same constant current of $0.1 \mathrm{~A} \mathrm{~g}^{-1}$.

When tested with the same constant current of $0.1 \mathrm{~A} \mathrm{~g}^{-1}$, the zeolite-slurry electrodes yielded a more uniform curve on a practically reasonable and realistic timescale than the uncoated carbon paper electrodes. The uncoated electrodes built up and released charge at a relatively high rate, likely due to the low surface area, which meant that its full capacity was reached quickly. The addition of surface area and a porous surface, here in the form of a slurry, increased the supercapacitive properties of the cell. Without this, uncontrolled charging and discharging was 
observed for the uncoated supercapacitor, seen in black in fig. 25, where the voltage spikes above and below 1.2 and $0.2 \mathrm{~V}$ respectively. This is shown in more detail below in fig. 26 .

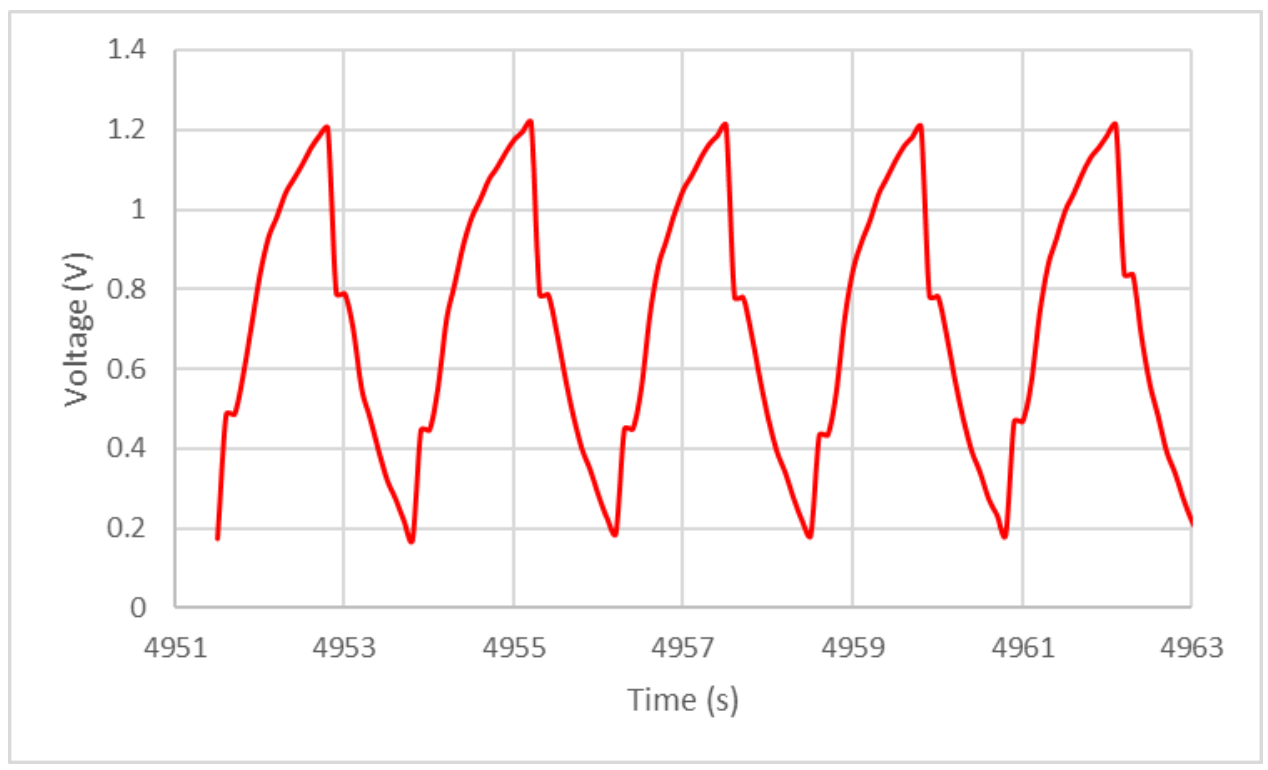

Figure 26: Galvanostatic charge-discharge curves for uncoated carbon paper supercapacitor cell, taken from midway through a 5000-cycle procedure, using constant current of $0.1 \mathrm{~A} \mathrm{~g}^{-1}(0.56 \mathrm{~mA})$.

Along with the uncontrolled charge-discharge voltages, significant IR drops were observed in every CDC for uncoated electrodes. This was a drop in over one third of the max voltage (from over 1.2 to under $0.8 \mathrm{~V}$ ), indicating a large internal cell resistance, especially as compared with the slurry-coated cell's IR drop of about 5\% (from 1.2 to above $1.1 \mathrm{~V}$ ).

Capacitance was determined as the average value from discharge curves of a 1000-cycle CDC and was found to be $0.40 \mathrm{~F} \mathrm{~g}^{-1}$. Over the $~ 50$-year experimental time (if charged and discharged once per day), capacitance dropped to $0.34 \mathrm{~F} \mathrm{~g}^{-1}$, which is a retention of $85 \%$. While this is impressive capacitance retention, less than $1 \mathrm{~F} \mathrm{~g}^{-1}$ is not very practical and the uncoated electrodes have shown poor capacitive behaviour. The fast charge-discharge times also meant that coulombic efficiency data was poorly recorded and yielded pitchy data, as shown in the appendix.

\subsection{Charge retention}

Of specific interest was the difference that the zeolite slurry made to the charge retention capabilities of the electrode by reducing the rate of self-discharge. 


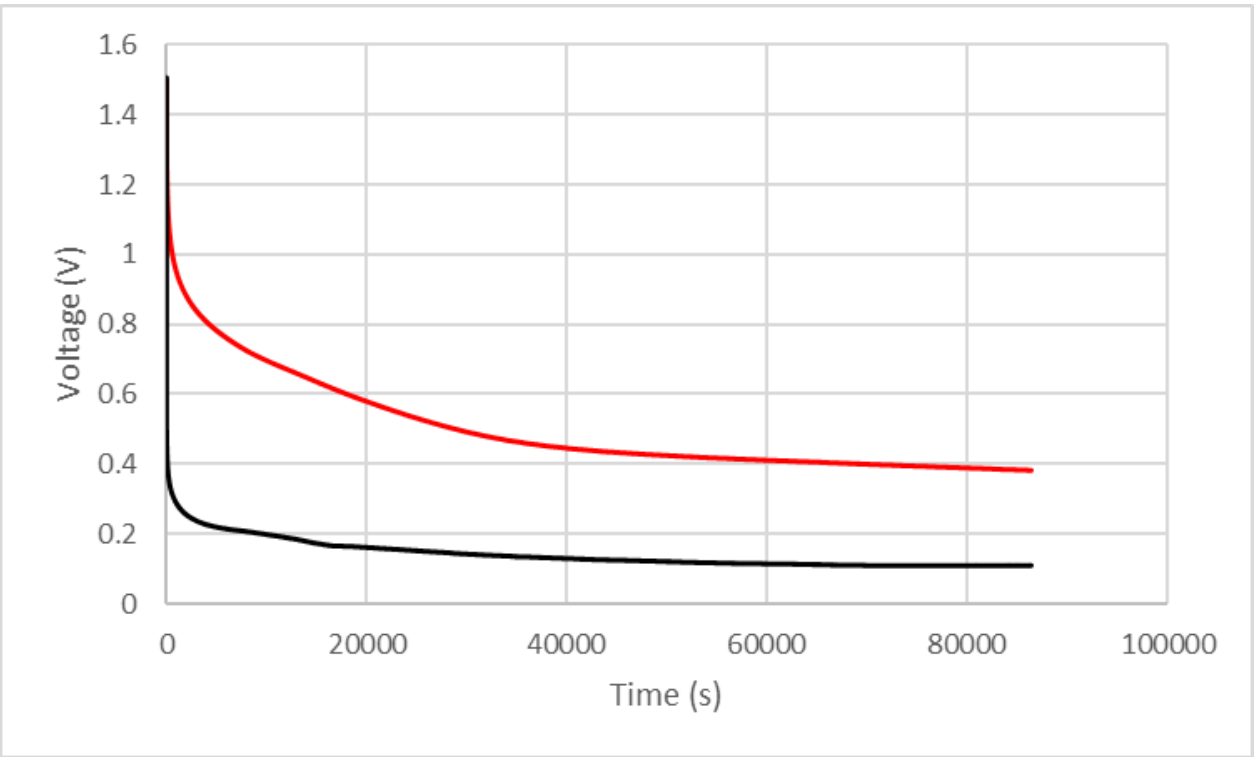

Figure 27: The measured voltage drop due to self-discharge for the $70 \%$ zeolite slurry-coated supercapacitor cell (red) and the uncoated carbon paper electrode (black), charged up to $1.5 \mathrm{~V}$ at a constant current of $0.1 \mathrm{~A} \mathrm{~g}^{-1}$.

The same PEEK cells were charged up to a voltage of $1.5 \mathrm{~V}$ using a constant current of $0.1 \mathrm{~A} \mathrm{~g}^{-1}$ which stopped being applied as soon as the cells reached $1.5 \mathrm{~V}$. Voltage continued to be measured for 24 hours after this cut-off, as shown in fig. 27, to monitor how the slurry coating affected charge retention. Overall, a great improvement can be seen in the cell voltage over the course of 24 hours, with the zeolite slurry-coated supercapacitor cell voltage still not plateauing by the end of the measured period. The uncoated carbon paper cell began to plateau after about 30,000 seconds (just over 8 hours) at a voltage of $0.11 \mathrm{~V}$. While this is not the open cell voltage of $0 \mathrm{~V}$, it would require an extended amount of time for absolutely all charge to dissipate from the electrodes, and so the plateau can be interpreted as essentially uncharged.

Both cells featured large instantaneous drops in voltage, and the biggest changes occurred in less than about 2000 seconds, which is better represented with a logarithmic scale, as shown in fig. 28 , to observe the shorter time period in greater detail. 


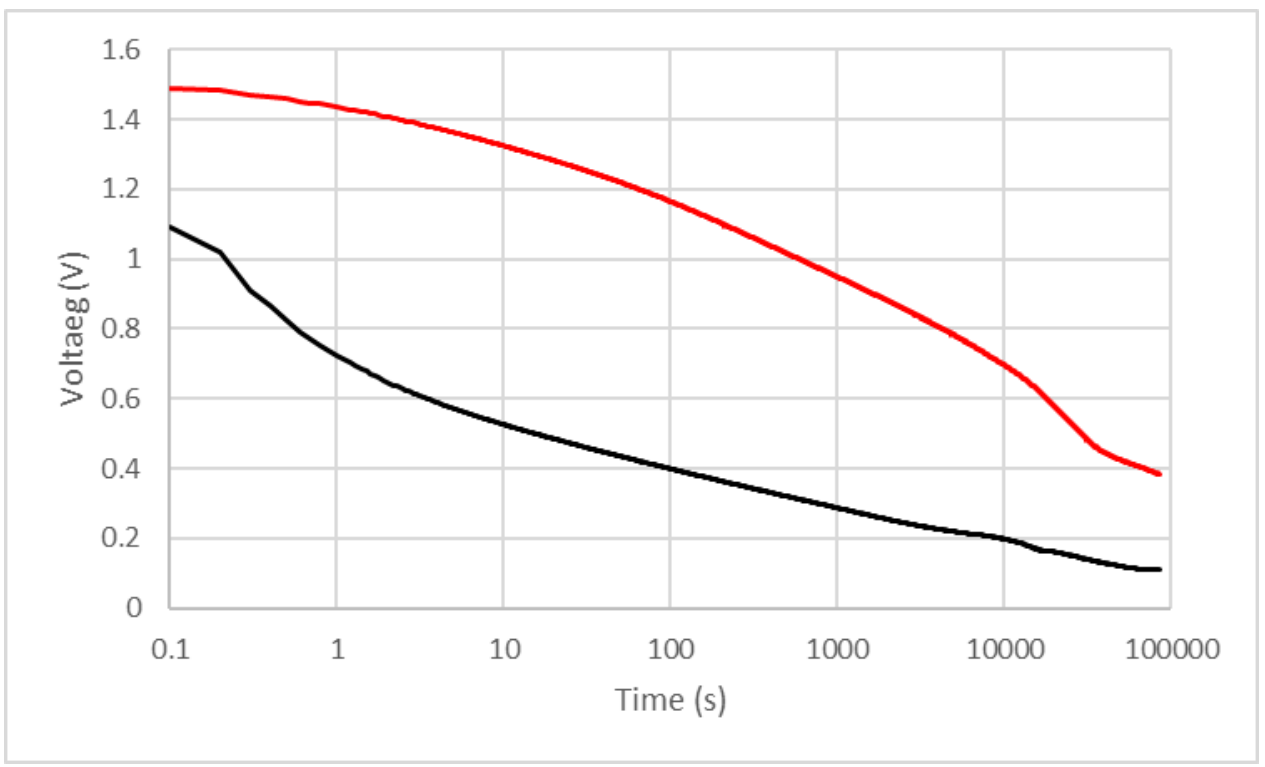

Figure 28: The measured voltage drop for the 70\% zeolite slurry-coated supercapacitor cell (red) and the uncoated carbon paper electrode (black), charged up to $1.5 \mathrm{~V}$ at a constant current of $0.1 \mathrm{~A} \mathrm{~g}^{-1}$, with time displayed as a logarithmic scale.

The slurry consisted of conductive carbon black and porous molecular sieves. The higher current densities and conductivity of the electrode is due to the carbon black additive, whereas the charge retention capabilities can be attributed to the zeolite. Both slurry components can be seen to contribute to the observed electrode performance.

As well as the logarithmic plot, table 3 highlights specific points and allows for direct comparison between the charge retention of each electrode design. Note that the lowest possible time interval for recorded data was $0.1 \mathrm{~s}$, which is why exact time values for the upper voltage range aren't given. 
Table 3: Table displaying the time it took for each electrode type to reach the specified voltage through self-discharge mechanisms after being charged to $1.5 \mathrm{~V}$ at $0.1 \mathrm{~A} \mathrm{~g}^{-1}$ current.

\begin{tabular}{|c|c|c|c|}
\hline \multirow[t]{2}{*}{ Voltage (V) } & \multicolumn{2}{|c|}{ Time (s) } & \multirow{2}{*}{$\begin{array}{l}\text { Charge retention } \\
\text { enhancement factor }\end{array}$} \\
\hline & Zeolite slurry coating & No coating & \\
\hline 1.5 & 0 & 0 & 0 \\
\hline 1.4 & 2.5 & $<0.1$ & $>25$ \\
\hline 1.3 & 15.1 & $<0.1$ & $>151$ \\
\hline 1.2 & 64.9 & $<0.1$ & $>649$ \\
\hline 1.1 & 207.1 & 0.1 & 2071 \\
\hline 1.0 & 591.8 & 0.4 & 1479 \\
\hline 0.9 & 1648 & 0.5 & 3296 \\
\hline 0.8 & 3916.8 & 0.7 & 5595 \\
\hline 0.7 & 9740.5 & 1.4 & 6958 \\
\hline 0.6 & 18044.3 & 3.6 & 5012 \\
\hline 0.5 & 28939.3 & 15.7 & 1843 \\
\hline 0.4 & 69516.1 & 98.5 & 705 \\
\hline 0.3 & Did not reach & 772.2 & $>111$ \\
\hline 0.2 & Did not reach & 9673.6 & $\gg 9$ \\
\hline 0.1 & Did not reach & Did not reach & - \\
\hline
\end{tabular}

The self-discharge rate of uncoated carbon paper was incredibly fast, and it was not until the lower, plateauing voltages of almost $0.1 \mathrm{~V}$ that the charge retention enhancement factor began to reduce significantly. This makes it difficult to state an exact amount by which the slurry coating reduced the effect of self-discharge, but it is clear that charge was retained for much longer than with the coating.

The zeolite slurry-coated supercapacitor cell maintained a voltage of $0.3822 \mathrm{~V}$ after $24 \mathrm{~h}$, while the uncoated carbon paper supercapacitor had a voltage of $0.1097 \mathrm{~V}$. This is a difference of $25.48 \%$ charge retention over $24 \mathrm{~h}$, compared to $7.31 \%$, for an initial cell voltage of $1.5 \mathrm{~V}$, which 
is an enhanced retention of $349 \%$. It is likely that this factor is much higher though, especially if the plateau voltage state is considered fully discharged.

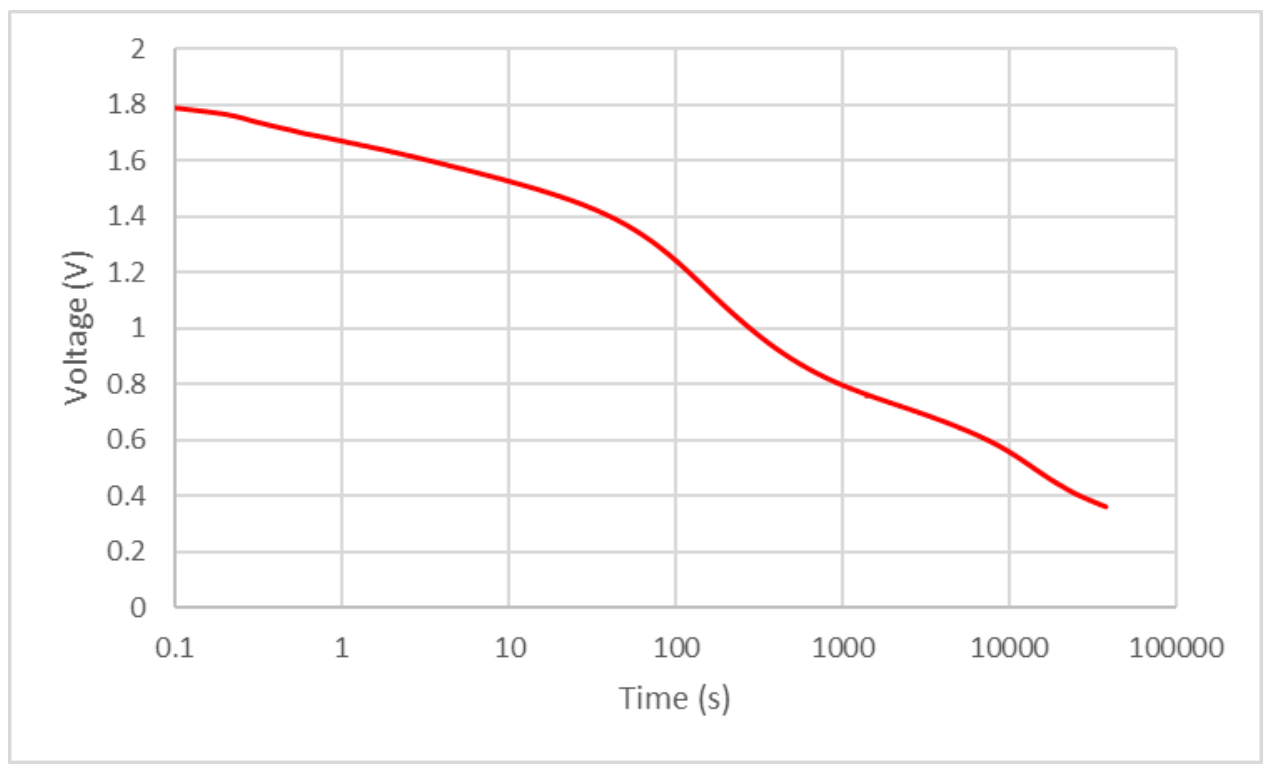

Figure 29: Logarithmic charge retention plot for $70 \mathrm{wt} \%$ zeolite-slurry coated electrodes charged up to a maximum of $1.8 \mathrm{~V}$. This initial voltage could not be achieved by uncoated carbon paper electrodes and so no comparison was presented.

These charge retention measurements were measured with an initial voltage of $1.5 \mathrm{~V}$. This is notably outside the $1.2 \mathrm{~V}$ potential window of water, meaning that some hydrogen or oxygen may have been evolved during charging. Shown in fig. 29, the zeolite-coated supercapacitor was later successfully charged up to a maximum of $1.8 \mathrm{~V}$. The uncoated carbon paper supercapacitor could only be charged up to $1.5 \mathrm{~V}$, regardless of the applied constant current, which might hint that zeolites could have a suppression effect on water splitting, but this was not explored further. 


\section{Conclusions and future work}

Most researchers in the supercapacitor field attempt to enhance capacitance by making materials more conductive and with a greater specific surface area. Our focus was on charge retention without specific regard to capacitance values, but despite this, a capacitance value of 17.25 $\mathrm{F} \mathrm{g}^{-1}$ was achieved. This is definitely in the realm of carbonaceous materials - albeit the low end - which is especially impressive considering that the slurry consisted of $70 \%$ molecular sieves; an insulator rather than a conductor. Improved charge retention was also observed, with more than $25 \%$ of the charge being retained over the measured 24 hours. These values compare with the electrode without the slurry-coating of $0.40 \mathrm{~F} \mathrm{~g}^{-1}$ specific capacitance and $7 \%$ charge retention over 24 hours.

A novel supercapacitor was constructed in air, on the benchtop, using low-cost carbon materials with aqueous potassium chloride electrolyte that exhibited $100 \%$ coulombic efficiency and excellent stability over the equivalent of almost 50 years of testing and cycling. This would provide an effective, low-cost supercapacitor design for implementation alongside electric vehicles and other applications with short storage time requirements. Given the low surface area of the carbon source and the insulating nature of the zeolites, the stated values could easily be improved upon, but it has been shown that this design can provide competitive stability and capacitance, while also increasing the charge retention capabilities.

Using another source of carbon, other than carbon black, could help to improve the capacitance value. Carbon black has a relatively low surface area for a carbonaceous material, and so another source such as graphite or carbon nanotubes could increase the surface area of the slurry coating, thereby increasing the capacitance.

Molecular sieves provided an excellent source of easily attainable zeolite with an appropriate pore size for the electrolytic ions, but the synthesis of other zeolite frameworks with larger or smaller pore sizes could allow for even further retention of charge. These could be specifically tailored for use with $\mathrm{K}^{+}$and $\mathrm{Cl}^{-}$ions, as well as any other aqueous electrolyte variations.

The behaviour of the electrolyte ions at the electrode surface were not fully explored in this work but could be achieved through EDS comparison of the electrode before and after electrochemical 
testing. One of the ions might not adsorb to the surface as well as the other or the slurry might block some pore access, and so it would be useful to determine what elements are present on the electrode after charging, compared with before charging. This would show how the ions are distributed along the electrode surface during the charging process, whether on the slurry surface or inside the zeolite pores.

Computational studies for the energy barrier of pores with ions inside and without ions inside would give an even deeper understanding for the surface processes and energies at work. This could be computationally demanding, depending on the number of atoms required to construct a zeolite unit cell, but would provide valuable insights and potentially allow for a more guided development of zeolite frameworks.

A cost comparison between the zeolite slurry-coated electrodes and some high-performance electrodes such as $\mathrm{RuO}_{2}$ would further justify the use of low-cost materials. 


\section{References}

[1] - “Fossil Fuel | Meaning, Types, \& Uses." Encyclopedia Britannica.

[2] - Forget, François, and Raymond T. Pierrehumbert. 1997. "Warming Early Mars with Carbon Dioxide Clouds That Scatter Infrared Radiation." Science 278 (5341): 1273-76.

[3] - Waters, Colin N., Jan Zalasiewicz, Colin Summerhayes, Anthony D. Barnosky, Clément Poirier, Agnieszka Gałuszka, Alejandro Cearreta, et al. 2016. “The Anthropocene Is Functionally and Stratigraphically Distinct from the Holocene." Science 351 (6269): aad2622.

[4] - Etheridge, D. M., L. P. Steele, R. L. Langenfelds, R. J. Francey, J.-M. Barnola, and V. I. Morgan. 1996. "Natural and Anthropogenic Changes in Atmospheric CO2 over the Last 1000 Years from Air in Antarctic Ice and Firn." Journal of Geophysical Research: Atmospheres 101 (D2): 4115-28.

[5] - Green, Martin A., Keith Emery, Yoshihiro Hishikawa, Wilhelm Warta, and Ewan D. Dunlop. 2016. "Solar Cell Efficiency Tables (Version 47)." Progress in Photovoltaics: Research and Applications 24 (1): 3-11.

[6] - Sage, Rowan F., Murilo Melo Peixoto, and Tammy L. Sage. 2013. “Photosynthesis in Sugarcane." In Sugarcane: Physiology, Biochemistry, and Functional Biology, 121-54. John Wiley \& Sons, Ltd.

[7] - Ehleringer, James R. 1978. “Implications of Quantum Yield Differences on the Distributions of C3 and C4 Grasses." Oecologia 31 (3): 255-67.

[8] - Miao, Shuwei, Guangtao Ning, Yingzhong Gu, Jiahao Yan, and Botao Ma. 2018. “Markov Chain Model for Solar Farm Generation and Its Application to Generation Performance Evaluation." Journal of Cleaner Production 186 (June): 905-17.

[9] - Kim, Myungkyu, Jaesic Hong, and Taehyun Tak. 2018. "The Implementation of KSTAR Fast Interlock System Using C-RIO," January, TUMPA03.

[10] - Shurtleff, Richard, and Edward Derringh. 1989. "The Most Tightly Bound Nucleus." American Journal of Physics 57 (6): 552-552. 
[11] - Fewell, M. P. 1995. "The Atomic Nuclide with the Highest Mean Binding Energy." American Journal of Physics 63 (7): 653-58.

[12] - Brook, Barry W., Agustin Alonso, Daniel A. Meneley, Jozef Misak, Tom Blees, and Jan B. van Erp. 2014. "Why Nuclear Energy Is Sustainable and Has to Be Part of the Energy Mix." Sustainable Materials and Technologies 1-2 (December): 8-16.

[13] - Evans, Annette, Vladimir Strezov, and Tim J. Evans. 2009. “Assessment of Sustainability Indicators for Renewable Energy Technologies." Renewable and Sustainable Energy Reviews 13 (5): 1082-88.

[14] - Abderrazzaq, M. H. 2004. "Energy Production Assessment of Small Wind Farms." Renewable Energy 29 (15): 2261-72.

[15] - Yang, Zhenguo, Jianlu Zhang, Michael C. W. Kintner-Meyer, Xiaochuan Lu, Daiwon Choi, John P. Lemmon, and Jun Liu. 2011. "Electrochemical Energy Storage for Green Grid." Chemical Reviews 111 (5): 3577-3613.

[16] - McLoughlin, Fintan, Aidan Duffy, and Michael Conlon. 2013. "Evaluation of Time Series Techniques to Characterise Domestic Electricity Demand." Energy 50 (February): 120-30.

[17] - Cimuca, G. O., C. Saudemont, B. Robyns, and M. M. Radulescu. 2006. “Control and Performance Evaluation of a Flywheel Energy-Storage System Associated to a Variable-Speed Wind Generator." IEEE Transactions on Industrial Electronics 53 (4): 1074-85.

[18] - Budt, Marcus, Daniel Wolf, Roland Span, and Jinyue Yan. 2016. "A Review on Compressed Air Energy Storage: Basic Principles, Past Milestones and Recent Developments." Applied Energy 170 (May): 250-68.

[19] - Halper, Marin S. 2006. "Supercapacitors: A Brief Overview," 41.

[20] - Choi, Jang Wook, and Doron Aurbach. 2016. "Promise and Reality of Post-Lithium-Ion Batteries with High Energy Densities." Nature Reviews Materials 1 (4): 16013. 
[21] - Wang, Jian-Gan, Feiyu Kang, and Bingqing Wei. 2015. “Engineering of MnO2-Based Nanocomposites for High-Performance Supercapacitors." Progress in Materials Science 74 (October): 51-124.

[22] - Tarascon, J.-M., and M. Armand. 2001. "Issues and Challenges Facing Rechargeable Lithium Batteries." Nature 414 (November): 359-67.

[23] - Blomgren, George E. 2017. "The Development and Future of Lithium Ion Batteries." Journal of The Electrochemical Society 164 (1): A5019-25.

[24] - Su, Jun, T. T. Lie, and Ramon Zamora. 2019. "Modelling of Large-Scale Electric Vehicles Charging Demand: A New Zealand Case Study." Electric Power Systems Research 167 (February): 171-82.

[25] - Agubra, Victor A., and Jeffrey W. Fergus. 2014. "The Formation and Stability of the Solid Electrolyte Interface on the Graphite Anode." Journal of Power Sources 268 (December): 15362.

[26] - Wang, Aiping, Sanket Kadam, Hong Li, Siqi Shi, and Yue Qi. 2018. "Review on Modeling of the Anode Solid Electrolyte Interphase (SEI) for Lithium-Ion Batteries." Npj Computational Materials 4 (1): 15.

[27] - Zhang, Wei-Jun. 2011. "A Review of the Electrochemical Performance of Alloy Anodes for Lithium-Ion Batteries." Journal of Power Sources 196 (1): 13-24.

[28] - Dahn, J. R., Tao Zheng, Yinghu Liu, and J. S. Xue. 1995. "Mechanisms for Lithium Insertion in Carbonaceous Materials." Science 270 (5236): 590-93.

[29] - Park, Myounggu, Xiangchun Zhang, Myoungdo Chung, Gregory B. Less, and Ann Marie Sastry. 2010. "A Review of Conduction Phenomena in Li-Ion Batteries." Journal of Power Sources 195 (24): 7904-29.

[30] - Nitta, Naoki, Feixiang Wu, Jung Tae Lee, and Gleb Yushin. 2015. “Li-Ion Battery Materials: Present and Future." Materials Today 18 (5): 252-64. 
[31] - Fergus, Jeffrey W. 2010. “Recent Developments in Cathode Materials for Lithium Ion Batteries." Journal of Power Sources 195 (4): 939-54.

[32] - Antolini, Ermete. 2004. "LiCoO2: Formation, Structure, Lithium and Oxygen Nonstoichiometry, Electrochemical Behaviour and Transport Properties." Solid State Ionics 170 (3): 159-71.

[33] - Sonoc, Alexandru, and Jack Jeswiet. 2014. "A Review of Lithium Supply and Demand and a Preliminary Investigation of a Room Temperature Method to Recycle Lithium Ion Batteries to Recover Lithium and Other Materials." Procedia CIRP, 21st CIRP Conference on Life Cycle Engineering, 15 (January): 289-93.

[34] - Narins, Thomas P. 2017. "The Battery Business: Lithium Availability and the Growth of the Global Electric Car Industry." The Extractive Industries and Society 4 (2): 321-28.

[35] - Yabuuchi, Naoaki, Kei Kubota, Mouad Dahbi, and Shinichi Komaba. 2014. "Research Development on Sodium-Ion Batteries." Chemical Reviews 114 (23): 11636-82.

[36] - Saha, Partha, Moni Kanchan Datta, Oleg I. Velikokhatnyi, Ayyakkannu Manivannan, David Alman, and Prashant N. Kumta. 2014. "Rechargeable Magnesium Battery: Current Status and Key Challenges for the Future." Progress in Materials Science 66 (October): 1-86.

[37] - K. Das, Shyamal, Sadhan Mahapatra, and Homen Lahan. 2017. “Aluminium-Ion Batteries: Developments and Challenges." Journal of Materials Chemistry A 5 (14): 6347-67.

[38] - Ambroz, Filip, Thomas J. Macdonald, and Thomas Nann. 2017. "Trends in AluminiumBased Intercalation Batteries." Advanced Energy Materials 7 (15): 1602093.

[39] - Bittner, A. M., M. Zhu, Y. Yang, H. F. Waibel, M. Konuma, U. Starke, and C. J. Weber. 2012. "Ageing of Electrochemical Double Layer Capacitors." Journal of Power Sources 203 (April): 262-73.

[40] - Zhang, Yong, Hui Feng, Xingbing Wu, Lizhen Wang, Aiqin Zhang, Tongchi Xia, Huichao Dong, Xiaofeng Li, and Linsen Zhang. 2009. “Progress of Electrochemical Capacitor Electrode 
Materials: A Review." International Journal of Hydrogen Energy, 2nd International Workshop on Hydrogen, 34 (11): 4889-99.

[41] - Becker, Howard I. 1957. Low voltage electrolytic capacitor. United States US2800616A, filed April 14, 1954, and issued July 23, 1957.

[42] - Rightmire, Robert A. 1966. Electrical energy storage apparatus. United States US3288641A, filed June 7, 1962, and issued November 29, 1966.

[43] - Zhang, Lei, Xiaosong Hu, Zhenpo Wang, Fengchun Sun, and David G. Dorrell. 2018. “A Review of Supercapacitor Modeling, Estimation, and Applications: A Control/Management Perspective." Renewable and Sustainable Energy Reviews 81 (January): 1868-78.

[44] - Kostecki, Robert, and Frank McLarnon. 2003. "Microprobe Study of the Effect of Li Intercalation on the Structure of Graphite." Journal of Power Sources, Selected papers presented at the 11th International Meeting on Lithium Batteries, 119-121 (June): 550-54.

[45] - Viera, J. C., M. Gonzalez, J. C. Anton, J. C. Campo, F. J. Ferrero, and M. Valledor. 2006. "NiMH vs NiCd Batteries under High Charging Rates." In IN TELEC 06 - Twenty-Eighth International Telecommunications Energy Conference, 1-6.

[46] - P. Cohn, Adam, Nitin Muralidharan, Rachel Carter, Keith Share, Landon Oakes, and Cary L. Pint. 2016. "Durable Potassium Ion Battery Electrodes from High-Rate Cointercalation into Graphitic Carbons." Journal of Materials Chemistry A 4 (39): 14954-59.

[47] - Pay, S., and Y. Baghzouz. 2003. "Effectiveness of Battery-Supercapacitor Combination in Electric Vehicles." In 2003 IEEE Bologna Power Tech Conference Proceedings, 3:728-33. Bologna, Italy: IEEE.

[48] - Stepanov, Andrew, and Ilja Galkin. n.d. “Development of Supercapacitor Based Uninterruptible Power Supply," 6.

[49] - Wei, H., W. Xin, G. Jiahuan, Z. Jianhua, and Y. Jingyan. 2009. “Discussion on Application of Super Capacitor Energy Storage System in Microgrid." In 2009 International Conference on Sustainable Power Generation and Supply, 1-4. 
[50] - Wang, Yujie, Chang Liu, Rui Pan, and Zonghai Chen. 2017. "Modeling and State-of-Charge Prediction of Lithium-Ion Battery and Ultracapacitor Hybrids with a Co-Estimator." Energy 121 (February): 739-50.

[51] - Namisnyk, Adam Marcus. n.d. "A SURVEY OF ELECTROCHEMICAL SUPERCAPACITOR TECHNOLOGY," 122.

[52] - Smith, T. A., J. P. Mars, and G. A. Turner. 2002. “Using Supercapacitors to Improve Battery Performance." In 2002 IEEE 33rd Annual IEEE Power Electronics Specialists Conference. Proceedings (Cat. No.02CH37289), 1:124-28 vol.1.

[53] - Ricardo, Barrero, Van Mierlo Joeri, Tackoen Xavier, and Leduc Bernard. 2008.

"Assessment of Energy Savings on Light Rail Vehicles and Hybrid Buses by Using Different Super Capacitor Based Energy Storage Systems," 12.

[54] - "CSR Unveils 100\% Supercapacitor-Powered Tram." 2014. International Railway Journal (blog). May 29, 2014.

[55] - Herrera, Victor, Aitor Milo, Haizea Gaztañaga, Ion Etxeberria-Otadui, Igor Villarreal, and Haritza Camblong. 2016. "Adaptive Energy Management Strategy and Optimal Sizing Applied on a Battery-Supercapacitor Based Tramway." Applied Energy 169 (May): 831-45.

[56] - Kötz, R., S. Müller, M. Bärtschi, B. Schnyder, P. Dietrich, F. N. Büchi, A. Tsukada, et al. 2001. "SUPERCAPACITORS FOR PEAK-POWER DEMAND IN FUEL-CELL-DRIVEN CARS."

[57] - Zhang, Guoge, Wenfang Li, Keyu Xie, Fei Yu, and Haitao Huang. 2013. "A One-Step and Binder-Free Method to Fabricate Hierarchical Nickel-Based Supercapacitor Electrodes with Excellent Performance." Advanced Functional Materials 23 (29): 3675-81.

[58] - Deng, Wentao, Xiaobo Ji, Qiyuan Chen, and Craig E. Banks. 2011. "Electrochemical Capacitors Utilising Transition Metal Oxides : An Update of Recent Developments." RSC Advances 1 (7): 1171-78. 
[59] - Zhong, Cheng, Yida Deng, Wenbin Hu, Jinli Qiao, Lei Zhang, and Jiujun Zhang. 2015. "A Review of Electrolyte Materials and Compositions for Electrochemical Supercapacitors." Chemical Society Reviews 44 (21): 7484-7539.

[60] - Béguin, François, Volker Presser, Andrea Balducci, and Elzbieta Frackowiak. 2014. "Carbons and Electrolytes for Advanced Supercapacitors." Advanced Materials 26 (14): 221951.

[61] - MacFarlane, Douglas R., Maria Forsyth, Patrick C. Howlett, Jennifer M. Pringle, Jiazeng Sun, Gary Annat, Wayne Neil, and Ekaterina I. Izgorodina. 2007. "Ionic Liquids in Electrochemical Devices and Processes: Managing Interfacial Electrochemistry." Accounts of Chemical Research 40 (11): 1165-73.

[62] - Kaus, Maximilian, Julia Kowal, and Dirk Uwe Sauer. 2010. "Modelling the Effects of Charge Redistribution during Self-Discharge of Supercapacitors." Electrochimica Acta, ENHANCED ELECTROCHEMICAL CAPACITORS, 55 (25): 7516-23.

[63] - Conway, Brian E., W. G. Pell, and T-C. Liu. 1997. "Diagnostic Analyses for Mechanisms of Self-Discharge of Electrochemical Capacitors and Batteries." Journal of Power Sources, The 20th International Power Sources Symposium, 65 (1): 53-59.

[64] - Oickle, Alicia M., and Heather A. Andreas. 2011. "Examination of Water Electrolysis and Oxygen Reduction As Self-Discharge Mechanisms for Carbon-Based, Aqueous Electrolyte Electrochemical Capacitors." The Journal of Physical Chemistry C 115 (10): 4283-88.

[65] - Ricketts, B. W., and C. Ton-That. 2000. "Self-Discharge of Carbon-Based Supercapacitors with Organic Electrolytes." Journal of Power Sources 89 (1): 64-69.

[66] - Wang, Guoping, Lei Zhang, and Jiujun Zhang. 2012. "A Review of Electrode Materials for Electrochemical Supercapacitors." Chemical Society Reviews 41 (2): 797-828.

[67] - Toupin, Mathieu, Thierry Brousse, and Daniel Bélanger. 2004. “Charge Storage Mechanism of $\mathrm{MnO} 2$ Electrode Used in Aqueous Electrochemical Capacitor." Chemistry of Materials 16 (16): 3184-90. 
[68] - Wang, Pengfei, Hui Liu, Yuxing Xu, Yunfa Chen, Jun Yang, and Qiangqiang Tan. 2016.

"Supported Ultrafine Ruthenium Oxides with Specific Capacitance up to 1099Fg-1 for a Supercapacitor." Electrochimica Acta 194 (March): 211-18.

[69] - Long, Jeffrey W., Karen E. Swider, Celia I. Merzbacher, and Debra R. Rolison. 1999. "Voltammetric Characterization of Ruthenium Oxide-Based Aerogels and Other RuO2 Solids: The Nature of Capacitance in Nanostructured Materials." Langmuir 15 (3): 780-85.

[70] - Harilal, Midhun, Syam G. Krishnan, Bincy Lathakumary Vijayan, M. Venkatashamy Reddy, Stefan Adams, Andrew R. Barron, Mashitah M. Yusoff, and Rajan Jose. 2017. "Continuous Nanobelts of Nickel Oxide-Cobalt Oxide Hybrid with Improved Capacitive Charge Storage Properties." Materials \& Design 122 (May): 376-84.

[71] - Cheng, Jie, Gao-Ping Cao, and Yu-Sheng Yang. 2006. “Characterization of Sol-Gel-Derived NiOx Xerogels as Supercapacitors." Journal of Power Sources, Special issue including selected papers from the 3rd International Conference on Materials for Advanced Technologies (ICMAT 2005, Singapore, Malaysia) and the Summer School on Synthesis of Nanostructured Materials for Polymer Batteries (Augustów, Poland) together with regular papers, 159 (1): 734-41. [72] - Yang, Jie, Jiao Guo, Xiaowei Guo, and Leishan Chen. 2019. “In-Situ Growth Carbon Nanotubes Deriving from a New Metal-Organic Framework for High-Performance All-Solid-State Supercapacitors." Materials Letters 236 (February): 739-42.

[73] - Frackowiak, Elzbieta, and François Béguin. 2001. “Carbon Materials for the Electrochemical Storage of Energy in Capacitors." Carbon 39 (6): 937-50.

[74] - Fan, L.-Z., Y.-S. Hu, J. Maier, P. Adelhelm, B. Smarsly, and M. Antonietti. 2007. “High Electroactivity of Polyaniline in Supercapacitors by Using a Hierarchically Porous Carbon Monolith as a Support." Advanced Functional Materials 17 (16): 3083-87.

[75] - Haladkar, Sushant, and Prashant Alegaonkar. 2018. "Preparation and Performance Evaluation of Carbon-Nano-Sphere for Electrode Double Layer Capacitor." Applied Surface Science, 4th International Conference on Nanoscience and Nanotechnology, 449 (August): 500506. 
[76] - Gong, Youning, Delong Li, Chengzhi Luo, Qiang Fu, and Chunxu Pan. 2017. "Highly Porous Graphitic Biomass Carbon as Advanced Electrode Materials for Supercapacitors." Green Chemistry 19 (17): 4132-40.

[77] - Chen, Li-Feng, Yan Lu, Le Yu, and Xiong Wen (David) Lou. 2017. “Designed Formation of Hollow Particle-Based Nitrogen-Doped Carbon Nanofibers for High-Performance Supercapacitors." Energy \& Environmental Science 10 (8): 1777-83.

[78] - Sill, Travis J., and Horst A. von Recum. 2008. "Electrospinning: Applications in Drug Delivery and Tissue Engineering." Biomaterials 29 (13): 1989-2006.

[79] - Chen, Long, Lina Chen, Qing Ai, Deping Li, Pengchao Si, Jinkui Feng, Lin Zhang, Yanhui Li, Jun Lou, and Lijie Ci. 2018. “Flexible All-Solid-State Supercapacitors Based on Freestanding, Binder-Free Carbon Nanofibers@polypyrrole@graphene Film." Chemical Engineering Journal 334 (February): 184-90.

[80] - Lu, Xiaofeng, Ce Wang, Frédéric Favier, and Nicola Pinna. 2017. “Electrospun Nanomaterials for Supercapacitor Electrodes: Designed Architectures and Electrochemical Performance." Advanced Energy Materials 7 (2): 1601301.

[81] - Wang, Tanyuan, Lu Liu, Zhiwei Zhu, Pagona Papakonstantinou, Jingbo Hu, Hongyun Liu, and Meixian Li. 2013. "Enhanced Electrocatalytic Activity for Hydrogen Evolution Reaction from Self-Assembled Monodispersed Molybdenum Sulfide Nanoparticles on an Au Electrode." Energy \& Environmental Science 6 (2): 625-33.

[82] - Xu, Yanfei, Guankui Long, Lu Huang, Yi Huang, Xiangjian Wan, Yanfeng Ma, and Yongsheng Chen. 2010. “Polymer Photovoltaic Devices with Transparent Graphene Electrodes Produced by Spin-Casting." Carbon 48 (11): 3308-11.

[83] - Song, Zeming, Teng Ma, Rui Tang, Qian Cheng, Xu Wang, Deepakshyam Krishnaraju, Rahul Panat, Candace K. Chan, Hongyu Yu, and Hanqing Jiang. 2014. “Origami Lithium-Ion Batteries." Nature Communications 5 (1). 
[84] - Font, Francesc, Bartosz Protas, Giles Richardson, and Jamie M. Foster. 2018. "Binder Migration during Drying of Lithium-Ion Battery Electrodes: Modelling and Comparison to Experiment." ArXiv:1801.01580 [Cond-Mat], January.

[85] - Stein, Malcolm, Aashutosh Mistry, and Partha P. Mukherjee. 2017. "Mechanistic Understanding of the Role of Evaporation in Electrode Processing." Journal of The Electrochemical Society 164 (7): A1616-27.

[86] - Amplianitis, Aris, Athanasios Masouras, Giorgos Gkikas, Zampia Kalogridi, Athanasios Baltopoulos, Antonios Vavouliotis, Stavros Tsantzalis, Vassilis Kostopoulos, and Ugo Lafont. 2017. "Graphene-Based Systems for Enhanced Energy Storage." Edited by A. Fernandez. E3S Web of Conferences 16: 09006.

[87] - Kadir, M. F. Z., and A. K. Arof. 2011. “Application of PVA-Chitosan Blend Polymer Electrolyte Membrane in Electrical Double Layer Capacitor." Materials Research Innovations 15 (sup2): s217-20.

[88] - Akgül, Ö., Ü. Alver, and A. Tanrıverdi. 2016. “Characterization of Graphene Oxide Produced by Hummers Method and Its Supercapacitor Applications." In , 280001. Istanbul, Turkey.

[89] - Abbas, Q., P. Ratajczak, P. Babuchowska, A. Le Comte, D. Bélanger, T. Brousse, and F. Béguin. 2015. "Strategies to Improve the Performance of Carbon/Carbon Capacitors in Salt Aqueous Electrolytes." Journal of The Electrochemical Society 162 (5): A5148-57.

[90] - Chmiola, J. 2006. “Anomalous Increase in Carbon Capacitance at Pore Sizes Less Than 1 Nanometer." Science 313 (5794): 1760-63.

[91] - Zaijun, Li, Chang Jie, Shan Haixia, and Pan Jiaomai. 2011. "Advance of Room Temperature Ionic Liquid as Solvent for Extraction and Separation." Reviews in Analytical Chemistry 26 (2): 109-153.

[92] - Galiński, Maciej, Andrzej Lewandowski, and Izabela Stępniak. 2006. “Ionic Liquids as Electrolytes." Electrochimica Acta 51 (26): 5567-80. 
[93] - Noda, Akihiro, Kikuko Hayamizu, and Masayoshi Watanabe. 2001. "Pulsed-Gradient Spin-Echo $1 \mathrm{H}$ and 19F NMR Ionic Diffusion Coefficient, Viscosity, and Ionic Conductivity of NonChloroaluminate Room-Temperature lonic Liquids." The Journal of Physical Chemistry B 105 (20): 4603-10.

[94] - Fuller, Joan, Amy C Breda, and Richard T Carlin. 1998. “Ionic Liquid-Polymer Gel Electrolytes from Hydrophilic and Hydrophobic Ionic Liquids1Presented at the Electrochemical Society Symposium: Processes in Polymers and Polymer|Metal Interfaces, Montreal, 4-9 May 1997.1." Journal of Electroanalytical Chemistry 459 (1): 29-34.

[95] - Ong, Shyue Ping, Oliviero Andreussi, Yabi Wu, Nicola Marzari, and Gerbrand Ceder. 2011. “Electrochemical Windows of Room-Temperature Ionic Liquids from Molecular Dynamics and Density Functional Theory Calculations." Chemistry of Materials 23 (11): 2979-86.

[96] - Hayyan, Maan, Farouq S. Mjalli, Mohd Ali Hashim, Inas M. AINashef, and Tan Xue Mei. 2013. "Investigating the Electrochemical Windows of Ionic Liquids." Journal of Industrial and Engineering Chemistry 19 (1): 106-12.

[97] - Ignat'ev, N. V., U. Welz-Biermann, A. Kucheryna, G. Bissky, and H. Willner. 2005. “New Ionic Liquids with Tris(Perfluoroalkyl)Trifluorophosphate (FAP) Anions." Journal of Fluorine Chemistry 126 (8): 1150-59.

[98] - Barisci, J. N, G. G Wallace, D. R MacFarlane, and R. H Baughman. 2004. "Investigation of Ionic Liquids as Electrolytes for Carbon Nanotube Electrodes." Electrochemistry Communications 6 (1): 22-27.

[99] - Portet, C., P. L. Taberna, P. Simon, and E. Flahaut. 2005. "Influence of Carbon Nanotubes Addition on Carbon-Carbon Supercapacitor Performances in Organic Electrolyte." Journal of Power Sources 139 (1): 371-78.

[100] - Kim, Myeongjin, Ilgeun Oh, and Jooheon Kim. 2015. "Effects of Different Electrolytes on the Electrochemical and Dynamic Behavior of Electric Double Layer Capacitors Based on a Porous Silicon Carbide Electrode." Physical Chemistry Chemical Physics 17 (25): 16367-74. 
[101] - Tanahashi, Ichiro, Akihiko Yoshida, and Atsushi Nishino. 1990. "Comparison of the Electrochemical Properties of Electric Double-Layer Capacitors with an Aqueous Electrolyte and with a Nonaqueous Electrolyte." Bulletin of the Chemical Society of Japan 63 (12): 3611-14.

[102] - El-Kady, Maher F., Melanie Ihns, Mengping Li, Jee Youn Hwang, Mir F. Mousavi, Lindsay Chaney, Andrew T. Lech, and Richard B. Kaner. 2015. “Engineering Three-Dimensional Hybrid Supercapacitors and Microsupercapacitors for High-Performance Integrated Energy Storage." Proceedings of the National Academy of Sciences 112 (14): 4233-38.

[103] - Stoller, Meryl D., Sungjin Park, Yanwu Zhu, Jinho An, and Rodney S. Ruoff. 2008. “Graphene-Based Ultracapacitors." Nano Letters 8 (10): 3498-3502.

[104] - Coury, Lou. 1999. "Conductance Measurements Part 1: Theory." Current Separations, 6. [105] - Xia, Mengyang, Jinhui Nie, Zailei Zhang, Xianmao Lu, and Zhong Lin Wang. 2018. "Suppressing Self-Discharge of Supercapacitors via Electrorheological Effect of Liquid Crystals." Nano Energy 47 (May): 43-50.

[106] - Wang, Y., X. Qiao, C. Zhang, and Xiangyang Zhou. 2018. "Self-Discharge of a Hybrid Supercapacitor with Incorporated Galvanic Cell Components." Energy 159 (September): 103545.

[107] - Wang, Jie, Bing Ding, Xiaodong Hao, Yunling Xu, Ya Wang, Laifa Shen, Hui Dou, and Xiaogang Zhang. 2016. “A Modified Molten-Salt Method to Prepare Graphene Electrode with High Capacitance and Low Self-Discharge Rate." Carbon 102 (June): 255-61.

[108] - Tevi, Tete, Houman Yaghoubi, Jing Wang, and Arash Takshi. 2013. "Application of Poly (p-Phenylene Oxide) as Blocking Layer to Reduce Self-Discharge in Supercapacitors." Journal of Power Sources 241 (November): 589-96.

[109] - "Abundances of the Elements 3.1.3." n.d. Accessed February 14, 2019.

[110] - Zhu, Jianbo, Youlong Xu, Jie Wang, Jun Lin, Xiaofei Sun, and Shengchun Mao. 2015. “The Effect of Various Electrolyte Cations on Electrochemical Performance of Polypyrrole/RGO Based Supercapacitors." Physical Chemistry Chemical Physics 17 (43): 28666-73. 
[111] - Eliad, Linoam, Gregory Salitra, Abraham Soffer, and Doron Aurbach. 2001. “Ion Sieving Effects in the Electrical Double Layer of Porous Carbon Electrodes: Estimating Effective Ion Size in Electrolytic Solutions." The Journal of Physical Chemistry B 105 (29): 6880-87.

[112] - Foster, M. D., I. Rivin, M. M. J. Treacy, and O. Delgado Friedrichs. 2006. “A Geometric Solution to the Largest-Free-Sphere Problem in Zeolite Frameworks." Microporous and Mesoporous Materials, Dedicated to the late Denise Barthomeuf, George Kokotailo and Sergey P. Zhdanov in appreciation of their outstanding contributions to zeolite science, 90 (1): 32-38. [113] - “Database of Zeolite Structures." n.d. Accessed February 14, 2019. [114] - "Product Name Molecular Sieves, 4 A | Sigma-Aldrich." n.d. Accessed February 21, 2019.

[115] - Mintova, Svetlana, Norman H. Olson, Valentin Valtchev, and Thomas Bein. 1999. "Mechanism of Zeolite A Nanocrystal Growth from Colloids at Room Temperature." Science 283 (5404): 958-60.

[116] - Valtchev, Valentin P., Lubomira Tosheva, and Krassimir N. Bozhilov. 2005. "Synthesis of Zeolite Nanocrystals at Room Temperature." Langmuir 21 (23): 10724-29.

[117] - Liu, Zhendong, Kotatsu Okabe, Chokkalingam Anand, Yasuo Yonezawa, Jie Zhu, Hiroki Yamada, Akira Endo, et al. 2016. "Continuous Flow Synthesis of ZSM-5 Zeolite on the Order of Seconds." Proceedings of the National Academy of Sciences 113 (50): 14267-71.

[118] - Severance, Michael, Yangong Zheng, Elizabeth Heck, and Prabir K. Dutta. 2013. "Influence of Crystallite Size on Cation Conductivity in Faujasitic Zeolites." The Journal of Physical Chemistry A 117 (50): 13704-11.

[119] - Stoller, Meryl D., and Rodney S. Ruoff. 2010. "Best Practice Methods for Determining an Electrode Material's Performance for Ultracapacitors." Energy \& Environmental Science 3 (9): 1294-1301. 
[120] - Allagui, Anis, Todd J. Freeborn, Ahmed S. Elwakil, and Brent J. Maundy. 2016.

"Reevaluation of Performance of Electric Double-Layer Capacitors from Constant-Current Charge/Discharge and Cyclic Voltammetry." Scientific Reports 6 (December): 38568.

[121] - Frenzel, Ninett, Jennifer Hartley, and Gero Frisch. 2017. “Voltammetric and Spectroscopic Study of Ferrocene and Hexacyanoferrate and the Suitability of Their Redox Couples as Internal Standards in Ionic Liquids." Physical Chemistry Chemical Physics 19 (42): 28841-52.

[122] - Khomenko, V., E. Frackowiak, and F. Béguin. 2005. “Determination of the Specific Capacitance of Conducting Polymer/Nanotubes Composite Electrodes Using Different Cell Configurations." Electrochimica Acta 50 (12): 2499-2506.

[123] - Vijayakumar, Manavalan, Duggirala Sri Rohita, Tata Narasinga Rao, and Mani Karthik.

2019. "Electrode Mass Ratio Impact on Electrochemical Capacitor Performance." Electrochimica Acta 298 (March): 347-59.

[124] - Zhu, Yanwu, Shanthi Murali, Meryl D. Stoller, K. J. Ganesh, Weiwei Cai, Paulo J. Ferreira, Adam Pirkle, et al. 2011. "Carbon-Based Supercapacitors Produced by Activation of Graphene." Science 332 (6037): 1537-41.

[125] - Taberna, P.L., C. Portet, and P. Simon. 2006. "Electrode Surface Treatment and Electrochemical Impedance Spectroscopy Study on Carbon/Carbon Supercapacitors." Applied Physics A 82 (4): 639-46.

[126] - Lehtimäki, Suvi, Anna Railanmaa, Jari Keskinen, Manu Kujala, Sampo Tuukkanen, and Donald Lupo. 2017. "Performance, Stability and Operation Voltage Optimization of ScreenPrinted Aqueous Supercapacitors." Scientific Reports 7 (April): 46001.

[127] - Sing, Kenneth. 2001. "The Use of Nitrogen Adsorption for the Characterisation of Porous Materials." Colloids and Surfaces A: Physicochemical and Engineering Aspects 187-188 (August): 3-9. 
[128] - Brunauer, Stephen, P. H. Emmett, and Edward Teller. 1938. “Adsorption of Gases in Multimolecular Layers." Journal of the American Chemical Society 60 (2): 309-19.

[129] - Zhang, Yan, Lu Liu, Peixin Zhang, Jun Wang, Mai Xu, Qiang Deng, Zheling Zeng, and Shuguang Deng. 2019. "Ultra-High Surface Area and Nitrogen-Rich Porous Carbons Prepared by a Low-Temperature Activation Method with Superior Gas Selective Adsorption and Outstanding Supercapacitance Performance." Chemical Engineering Journal 355 (January): 309-19.

[130] - Goldstein, Joseph I., Dale E. Newbury, Joseph R. Michael, Nicholas W. M. Ritchie, John Henry J. Scott, and David C. Joy. 2017. Scanning Electron Microscopy and X-Ray Microanalysis. Springer.

[131] - Annamalai, Perushini, Nicholas M. Musyoka, Jianwei Ren, Henrietta W. Langmi, Mkhulu Mathe, Dmitri Bessarabov, and Leslie F. Petrik. 2017. “Electrospun Zeolite-Templated Carbon Composite Fibres for Hydrogen Storage Applications." Research on Chemical Intermediates 43 (7): 4095-4102.

[132] - Ahlers, Caroline B., and Jan B. Talbot. 1999. "Fabrication of Zeolite-Modified Electrodes via Electrophoretic Deposition." Journal of The Electrochemical Society 146 (9): 3259-63.

[133] - Wang, Lu, Xiao Feng, Lantian Ren, Qiuhan Piao, Jieqiang Zhong, Yuanbo Wang, Haiwei Li, Yifa Chen, and Bo Wang. 2015. “Flexible Solid-State Supercapacitor Based on a Metal-Organic Framework Interwoven by Electrochemically-Deposited PANI." Journal of the American Chemical Society 137 (15): 4920-23.

[134] - Sakai, Kazuki, Shinichiroh Iwamura, Ryo Sumida, Isao Ogino, and Shin R. Mukai. 2018. "Carbon Paper with a High Surface Area Prepared from Carbon Nanofibers Obtained through the Liquid Pulse Injection Technique." ACS Omega 3 (1): 691-97.

[135] - Spahr, Michael E., Dietrich Goers, Antonio Leone, Salvatore Stallone, and Eusebiu Grivei. 2011. "Development of Carbon Conductive Additives for Advanced Lithium Ion Batteries." Journal of Power Sources 196 (7): 3404-13. 


\section{Appendix}

Appendix 1: Heating protocol for high-temperature heat treatment of carbon nanofibres.

"C\#" are temperature values, given in ${ }^{\circ} \mathrm{C}$, and " $\mathrm{T \#}$ " are time values, given in minutes.

\begin{tabular}{|c|c|}
\hline Heating Step & Value \\
\hline $\mathrm{C} 1$ & 0 \\
\hline $\mathrm{T} 1$ & 40 \\
\hline $\mathrm{C} 2$ & 200 \\
\hline $\mathrm{T} 2$ & 20 \\
\hline $\mathrm{C} 3$ & 200 \\
\hline $\mathrm{T} 3$ & 40 \\
\hline $\mathrm{C} 4$ & 600 \\
\hline $\mathrm{T} 4$ & 20 \\
\hline $\mathrm{C} 5$ & 600 \\
\hline $\mathrm{T} 5$ & 30 \\
\hline $\mathrm{C} 6$ & 750 \\
\hline $\mathrm{T} 6$ & 60 \\
\hline $\mathrm{C} 7$ & 750 \\
\hline $\mathrm{T} 7$ & 70 \\
\hline $\mathrm{C} 8$ & 1100 \\
\hline $\mathrm{T} 8$ & 60 \\
\hline $\mathrm{C} 9$ & 1100 \\
\hline $\mathrm{T} 9$ & 180 \\
\hline $\mathrm{C} 10$ & 200 \\
\hline $\mathrm{T} 10$ & -121 \\
\hline
\end{tabular}


Appendix 2: SEM images of zeolite-embedded carbon nanofibers (top), electrophoretically deposited zeolite on carbon nanofibers (middle), and zeolite-slurry coated carbon nanofibers (bottom) at a magnification of 500 times.
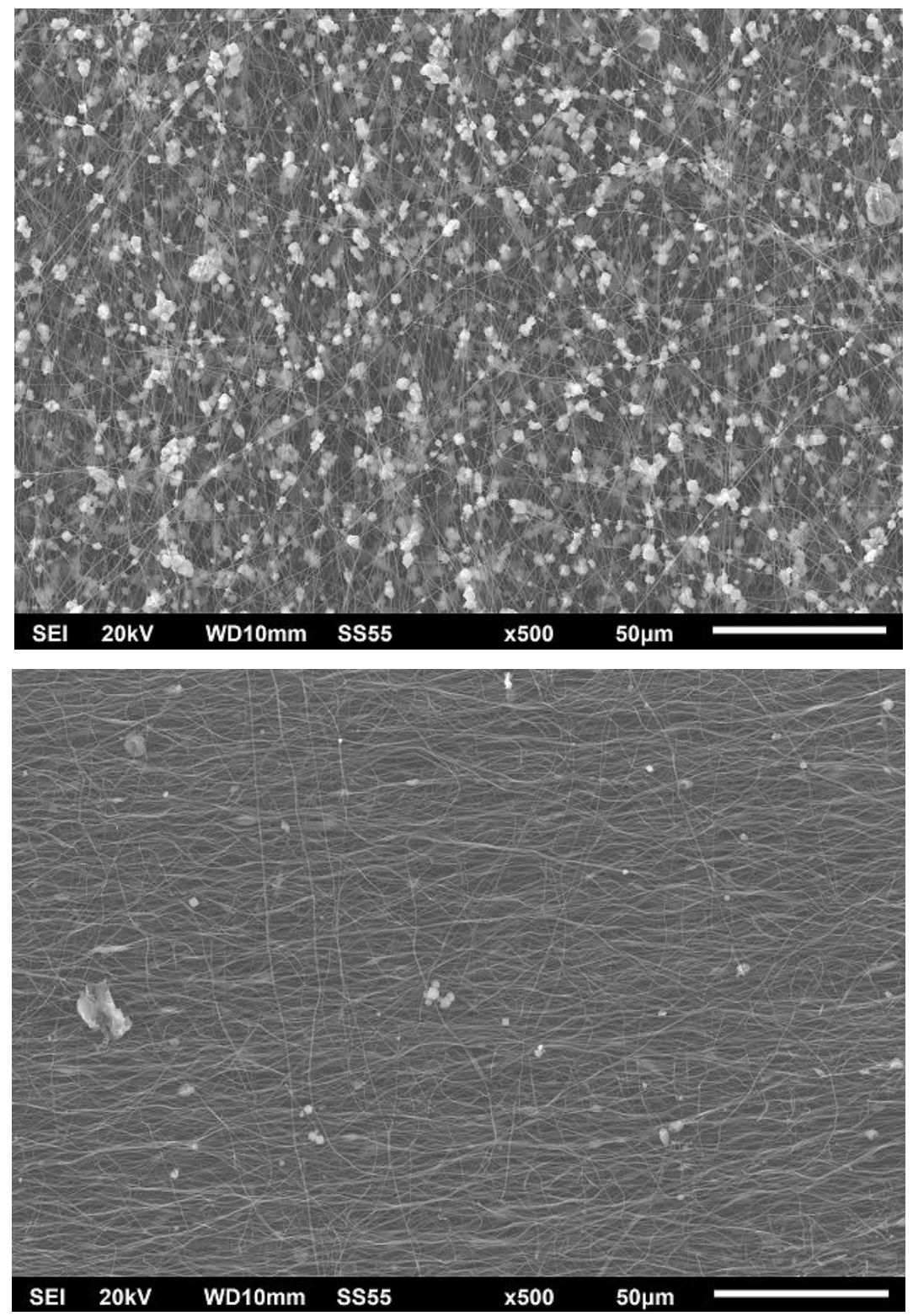


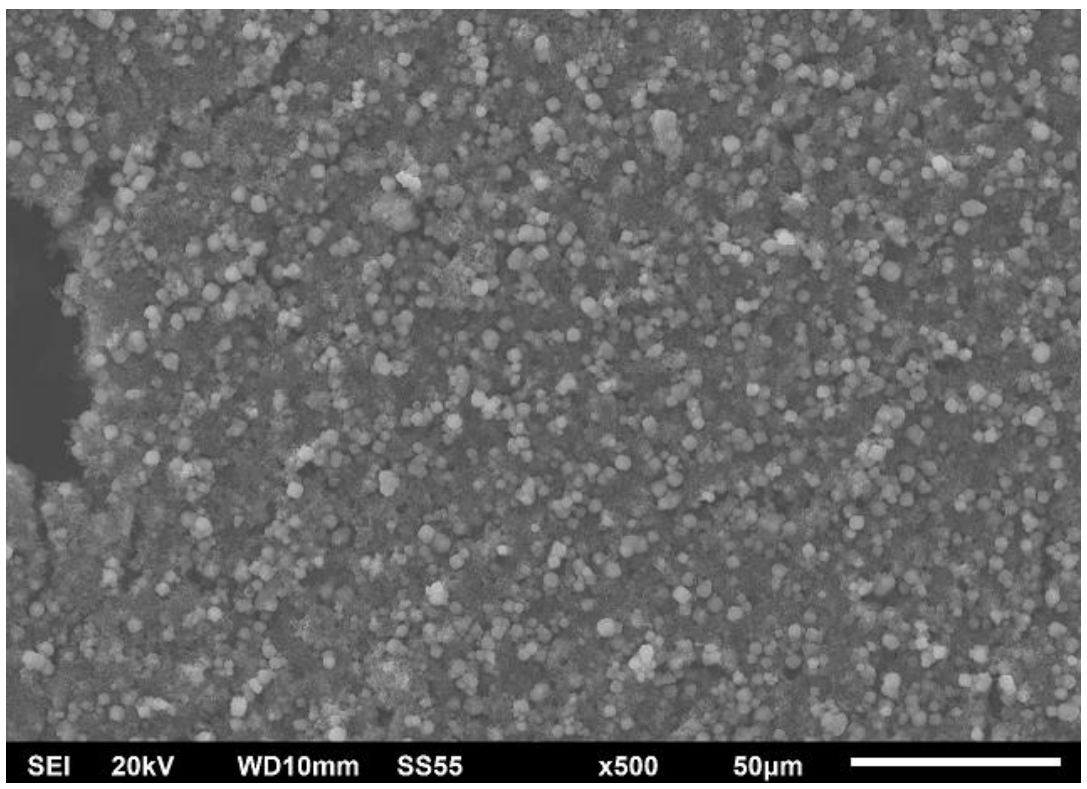

Appendix 3: Cyclic voltammograms at $50 \mathrm{mV} \mathrm{s}^{-1}$ for a) $60 \%$ slurry-coated, b) $70 \%$ slurrycoated, c) $80 \%$ slurry coated electrode, and d) uncoated carbon paper electrode
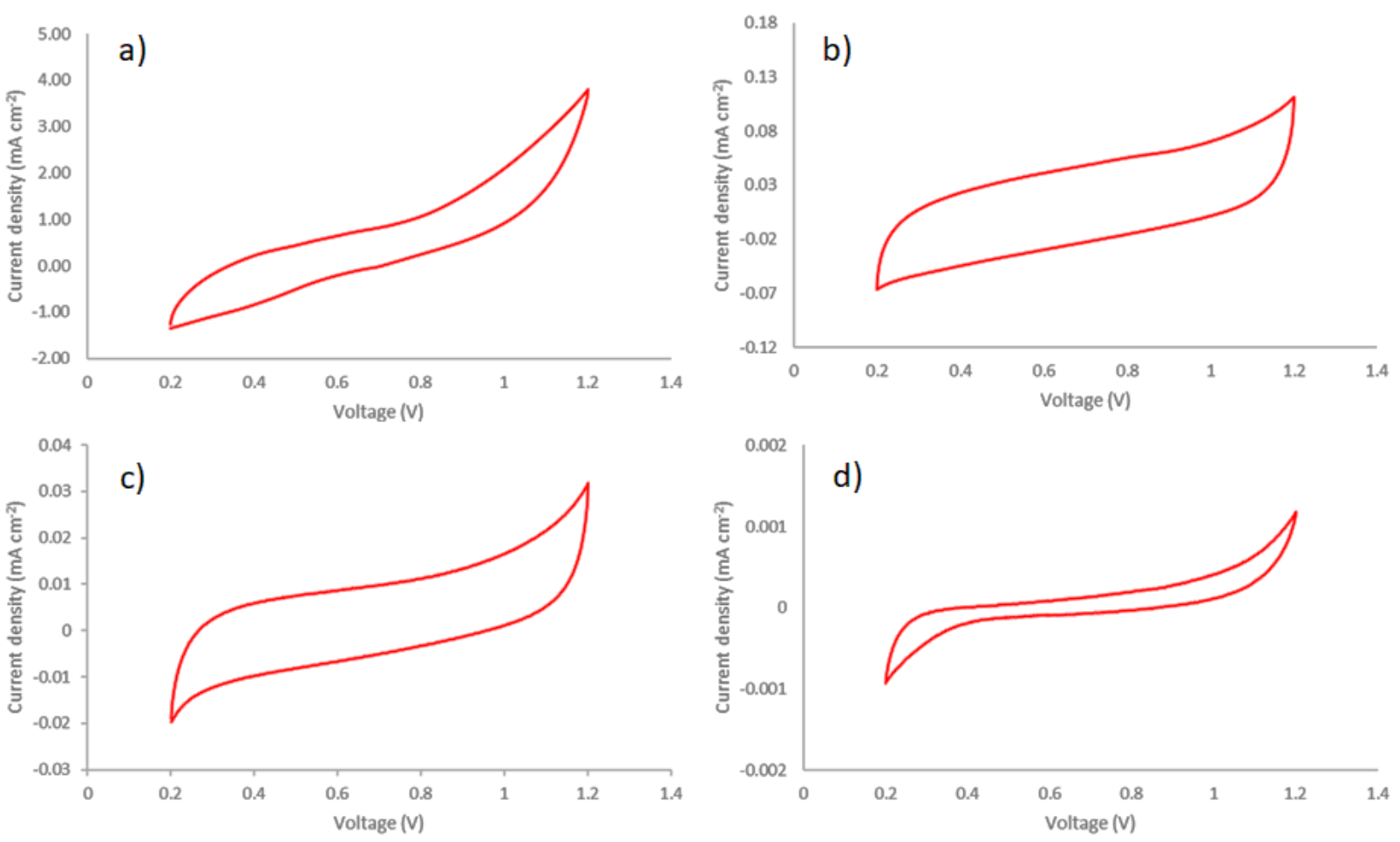
Appendix 4: Charge retention plot for 70 wt\% zeolite-slurry coated electrodes, initially charged to $1.5 \mathrm{~V}$ (red) and $1.2 \mathrm{~V}$ (black) to show how a higher voltage is maintained for a higher start voltage

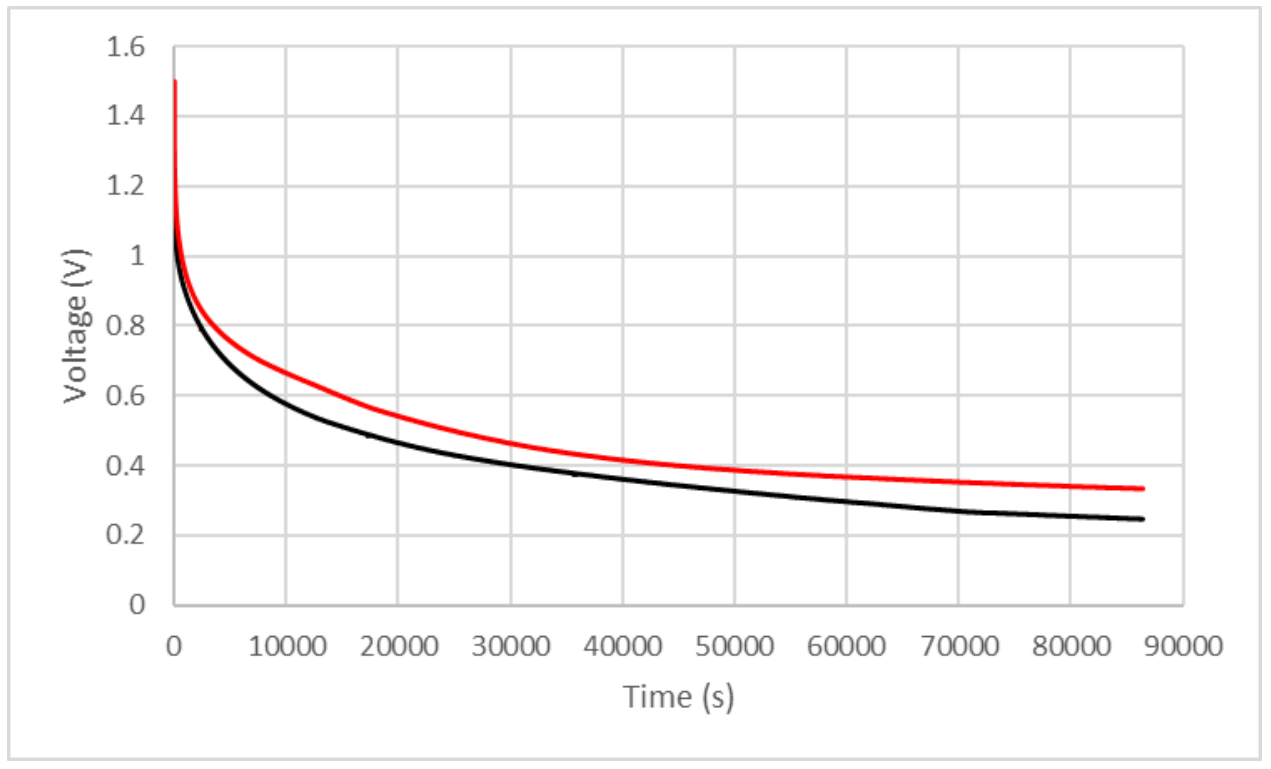

Appendix 5: Effect of constant current rate of carbon paper supercapacitor cell, with $0.1 \mathrm{~A} \mathrm{~g}^{-1}$ (red), $0.5 \mathrm{~A} \mathrm{~g}^{-1}$ (black), $1.0 \mathrm{~A} \mathrm{~g}^{-1}$ (blue), and $2 \mathrm{~A} \mathrm{~g}^{-1}$ (green)

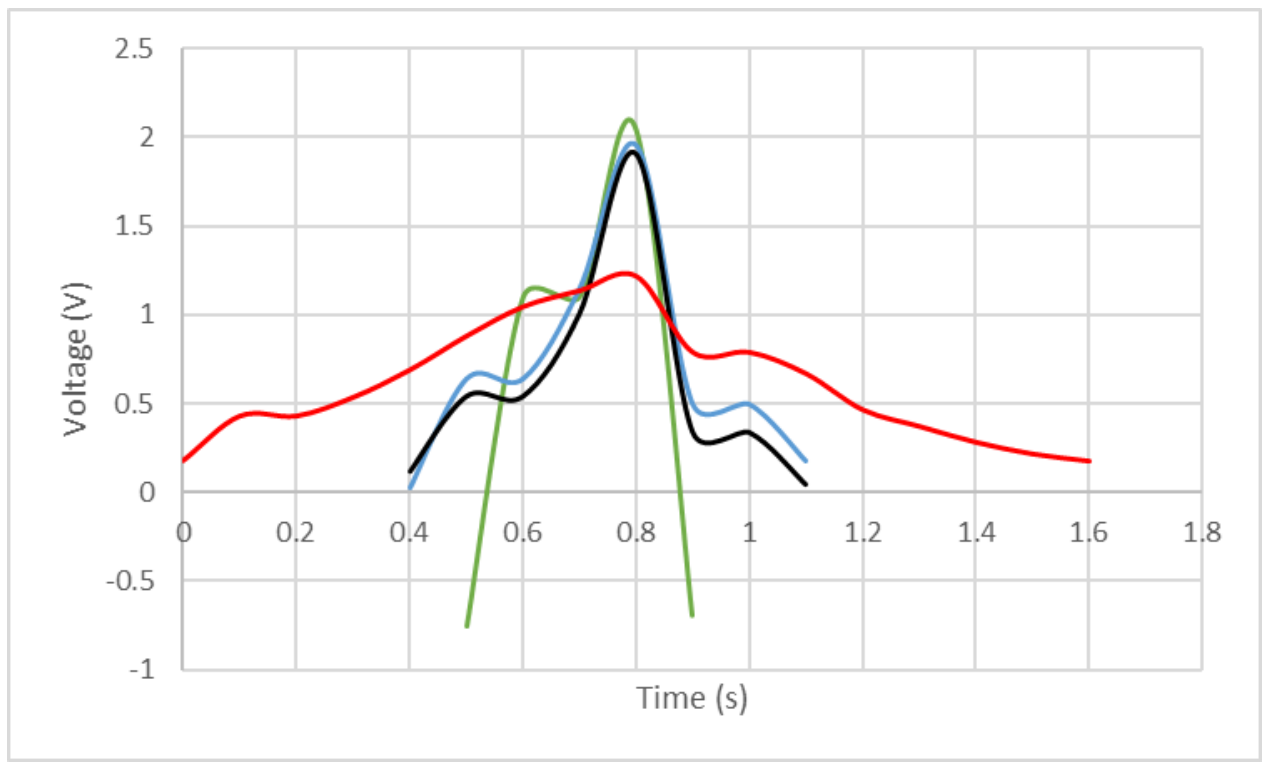


Appendix 6: Plot showing the pitchy nature of the uncoated carbon paper supercapacitor cell coulombic efficiency for a 10,000-cycle charge-discharge procedure at $0.1 \mathrm{~A} \mathrm{~g}^{-1}$.

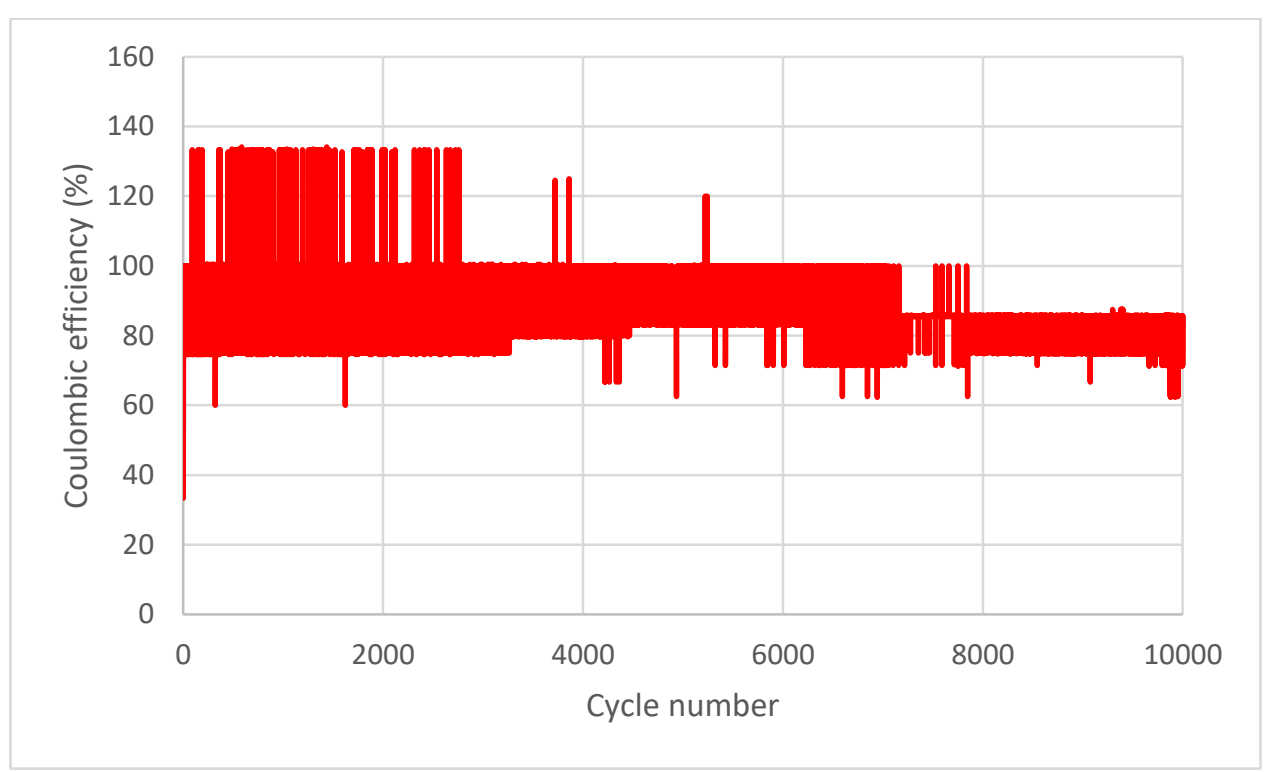


